\title{
Supplementary Data for
}

\section{Ferrocene linked thymine/uracil conjugates: Base pairing directed helical assembly and supramolecular packing}

\author{
Amit N. Patwa ${ }^{\text {a }}$ Susmita Gupta, ${ }^{\text {a }}$ Rajesh G. Gonnade, ${ }^{\mathrm{b}}$ Vaijayanti A. Kumar, ${ }^{\mathrm{a}}$ Mohan M. \\ Bhadbhade $^{\mathrm{b} *}$ and Krishna N. Ganesh ${ }^{\mathrm{a} *}$ \\ arganic Chemistry Division (Synthesis), National Chemical Laboratory, Dr. Homi Bhabha \\ Road, Pune-411008

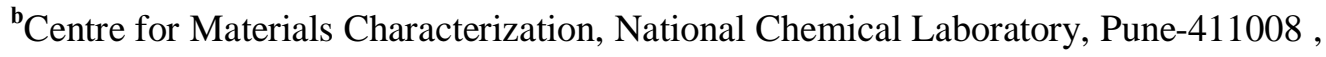 \\ kn.ganesh@iiserpune.ac.in
}




\section{Index}

Sr. No.

01 Abstract

02 General experimental methods Experimental section

$03 \quad{ }^{1} \mathrm{H},{ }^{13} \mathrm{C}$ and DEPT NMR photocopy of compound 4

$04{ }^{1} \mathrm{H},{ }^{13} \mathrm{C}$ and DEPT NMR photocopy of compound 5

$05 \quad{ }^{1} \mathrm{H},{ }^{13} \mathrm{C}$ and DEPT NMR photocopy of compound 6

$06{ }^{1} \mathrm{H},{ }^{13} \mathrm{C}$ and DEPT NMR photocopy of compound $\mathbf{7 a}, \mathbf{7 b}$ and $7 \mathbf{c}$

$07{ }^{1} \mathrm{H},{ }^{13} \mathrm{C}$ and DEPT NMR photocopy of compound $\mathbf{1 a}$

$08{ }^{1} \mathrm{H},{ }^{13} \mathrm{C}$ and DEPT NMR photocopy of compound $\mathbf{1 b}$

$09 \quad{ }^{1} \mathrm{H}$ NMR photocopy of compound 1c

$10 \quad{ }^{1} \mathrm{H}$ NMR photocopy of compound 8

$11 \quad{ }^{1} \mathrm{H},{ }^{13} \mathrm{C}$ and DEPT NMR photocopy of compound 9

$12{ }^{1} \mathrm{H},{ }^{13} \mathrm{C}$ and DEPT NMR photocopy of compound $\mathbf{1 0}$

$13{ }^{1} \mathrm{H},{ }^{13} \mathrm{C}$ and DEPT NMR photocopy of compound $\mathbf{1 1}$

$14{ }^{1} \mathrm{H},{ }^{13} \mathrm{C}$ and DEPT NMR photocopy of compound 12a

$15{ }^{1} \mathrm{H},{ }^{13} \mathrm{C}$ and DEPT NMR photocopy of compound $\mathbf{1 2 b}$

$16{ }^{1} \mathrm{H}$ NMR photocopy of compound $\mathbf{2 a}$

$17{ }^{1} \mathrm{H},{ }^{13} \mathrm{C}$ and DEPT NMR photocopy of compound $\mathbf{2 b}$

$18{ }^{1} \mathrm{H},{ }^{13} \mathrm{C}$ and DEPT NMR photocopy of compound $\mathbf{1 3}$

$19{ }^{1} \mathrm{H},{ }^{13} \mathrm{C}$ and DEPT NMR photocopy of compound $\mathbf{1 4}$

$20{ }^{1} \mathrm{H},{ }^{13} \mathrm{C}$ and DEPT NMR photocopy of compound $\mathbf{1 5}$

$21{ }^{1} \mathrm{H},{ }^{13} \mathrm{C}$ and DEPT NMR photocopy of compound 16

$22{ }^{1} \mathrm{H},{ }^{13} \mathrm{C}$ and DEPT NMR photocopy of compound $\mathbf{1 d}$

23 Crystallographic data for $\mathbf{1 a}, \mathbf{1 b}, \mathbf{1 c}, \mathbf{1 d}, \mathbf{2 a}$ and $\mathbf{2 b}$

24 Fig. 1 showing ORTEP view of 1a, 1b, 1d and structure refinement of $\mathbf{1 d}$

25 Fig. 2 showing other C-Hé O interactions in 1a

26 Fig. 3 showing other C-Hé O interactions in $\mathbf{1 b}$

27 Fig. 4 self base-pairing in 1c

28 Table for intermolecular C-Hé O interactions

29 Reference
Page No.

S3

S4-S5

S6-S7

S8-S9

S10-S11

S12-S17

S18-S19

S20-S21

S22

$\mathrm{S} 23$

S24-S25

S26-S27

S28-S29

S30-S31

S32-S33

S34

S35-S36

S37-S38

S39-S40

S41-S42

S443-S44

$\mathrm{S} 45-\mathrm{S} 46$

S47-S48

S49-S50

S51

S52

S53

S54

S54 


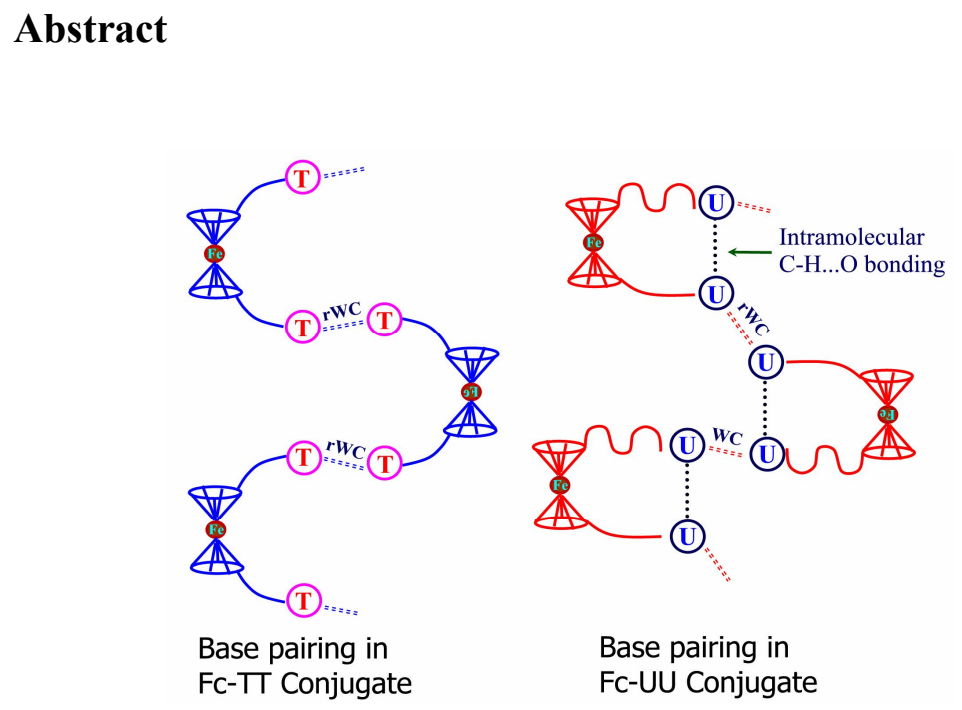

A variety of ferrocene linked nucleobase and chimeric mixed nucleobase conjugates are synthesized from mono and bis-hydroxybutylferrocene via Mitsunobu reaction as the key step. Further X-ray crystallographic studies of ferrocene bis-nucleobase conjugates reveal two dimensional supramolecular assemblies of helical backbones self assembled through Watson-Crick and reverse Watson-Crick type pairs. Such helical assemblies are not seen in mono substituted ferrocene nucleobase conjugates which form only planar sheets. 


\section{General experimental methods}

Melting points were measured on a melting point apparatus in Celsius degrees and were uncorrected. Infrared spectra (IR) were recorded on FTIR instrument. ${ }^{1} \mathrm{H}$ and ${ }^{13} \mathrm{C}$ NMR spectra were recorded on a spectrophotometer at 200.13 and $50.32 \mathrm{MHz}$, respectively. The chemical shifts are given in ppm relative to tetramethylsilane. Spin-spin coupling constants ( $\mathrm{J}$ value) recorded in Hz. Peak multiplicities were denoted by s (singlet); br s (broad singlet), d (doublet), dd (double doublet), t (triplet), m (multiplate). Mass spectra were recorded on LC-MS/MS-TOF spectrometer. Elemental analyses were performed by elemental analyzer. All reactions were monitored by analytical thin-layer chromatography (TLC) on aluminium precoated plates of silica gel 60 F254 with detection by either viewing under UV light or treating with an ethanolic solution of phosphomolybdic acid. Column chromatography was performed on silica gel column, packed with pet ether / triethylamine (98:2). All reagents and solvent were general reagent grade unless otherwise stated. THF was freshly distilled from $\mathrm{Na} /$ benzophenone under nitrogen. Dichloromethane was freshly distilled from $\mathrm{P}_{2} \mathrm{O}_{5}$ under nitrogen. Thymine, uracil and 5-bromouracil were purchased from Aldrich. N-3 benzoylation of thymine /uracil /5-bromouracil were performed by literature procedure. ${ }^{1}$

\section{Experimental Section}

1-(3-carboxypropionyl)ferrocene (8): Experimental procedure and set up is same as 4 (A). The quantities of reagents used are as follow. Anhydrous aluminium chloride (48 g, $0.36 \mathrm{~mol})$. Succinic anhydride (18 g, $0.18 \mathrm{~mol})$. Ferrocene 3 (16.65 g, $0.09 \mathrm{~mol})$. 
General procedure for the preparation of 12a-b via Mitsunobu reaction: Experimental procedure and set up is same as Mitsunobu reaction. The quantities of reagents used are as follow. N-3-benzoylthymine / N3-benzoyluracil (4.03 mmol), triphenylphosphine (1.22 g, $4.65 \mathrm{mmol})$, alcohol 11 (0.80 g, $3.10 \mathrm{mmol})$, DIAD (0.92 $\mathrm{mL}, 4.65 \mathrm{mmol})$. The resulting solid was purified by flash column using pet ether / ethyl acetate (4:1) to give ferrocene linked N3-benzoylprotected nucleobase 12a-b.

\section{1-(4-(N3-benzoylthyminyl)butyl)-1'-(4-(tert-butyldimethylsilyloxy)butyl)ferrocene}

(14). Experimental procedure and set up is same as Mitsunobu reaction. The quantities of reagents used are as follow. N3-benzoylthymine $(0.70 \mathrm{~g}, 3.03 \mathrm{mmol})$, triphenylphosphine (0.92 g, $3.50 \mathrm{mmol})$, alcohol 13 (1.03 g, $2.33 \mathrm{mmol})$, DIAD (0.69 mL, $3.50 \mathrm{mmol})$. The resulting solid was purified by flash chromatography on silica gel, eluted with ethyl acetate / pet ether (1:4) to give ferrocene linked benzoyl protected nucleobase 14 (1.05 g, $69 \%)$ as brown oil.

\section{1-(4-(N3-benzoylthyminyl)butyl)-1'-(4-(N3-benzoyluracyl)butyl)ferrocene}

(16).

Experimental procedure and set up is same as Mitsunobu reaction. The quantities of reagents used are as follow. N3-benzoyluracil $(0.17 \mathrm{~g}, 0.78 \mathrm{mmol})$, triphenylphosphine (0.24 g, $0.90 \mathrm{mmol})$, alcohol 15 (0.32 g, $0.60 \mathrm{mmol})$, DIAD (0.18 mL, $0.90 \mathrm{mmol})$. The resulting solid was purified by flash chromatography on silica gel, eluted with pet ether / ethyl acetate (7:3) to give ferrocene linked N3-benzoylprotected nucleobase $\mathbf{1 6}$. 


\section{Spectra}

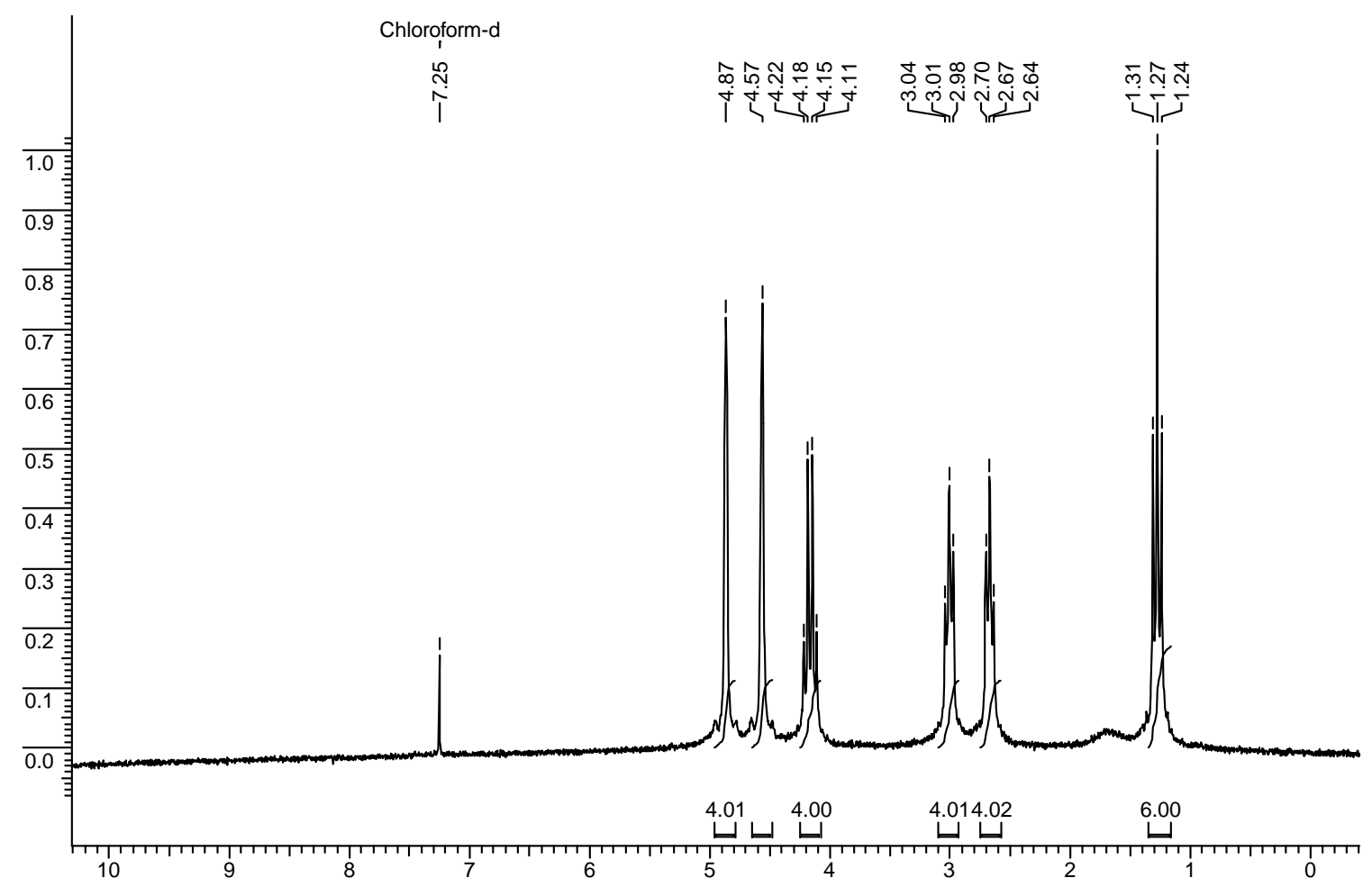

${ }^{1}$ H NMR of 1, 1'-Bis-(3-carbethoxypropionyl)ferrocene (4)

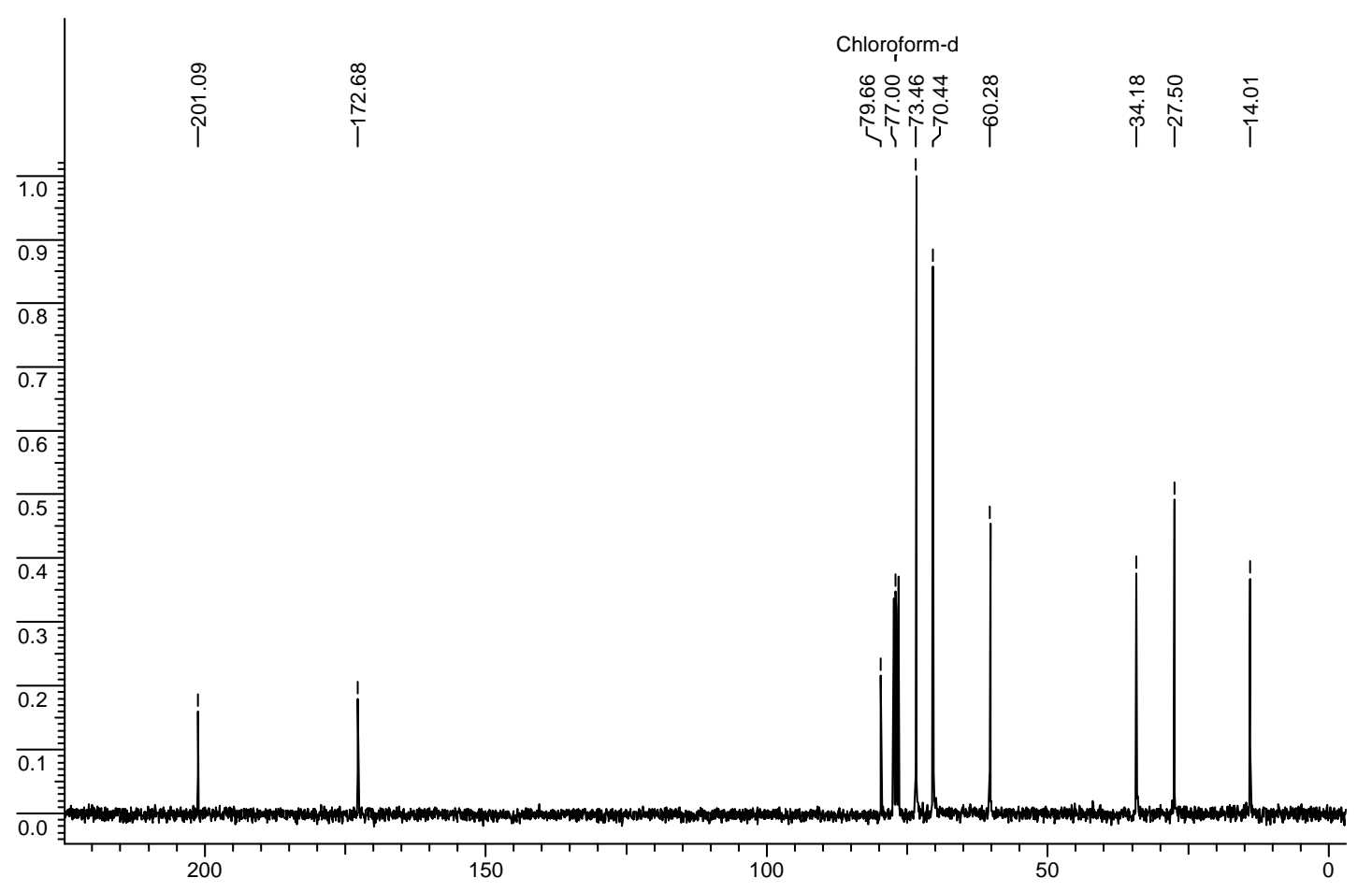

${ }^{13}$ C NMR of 1, 1'-Bis-(3-carbethoxypropionyl)ferrocene (4) 


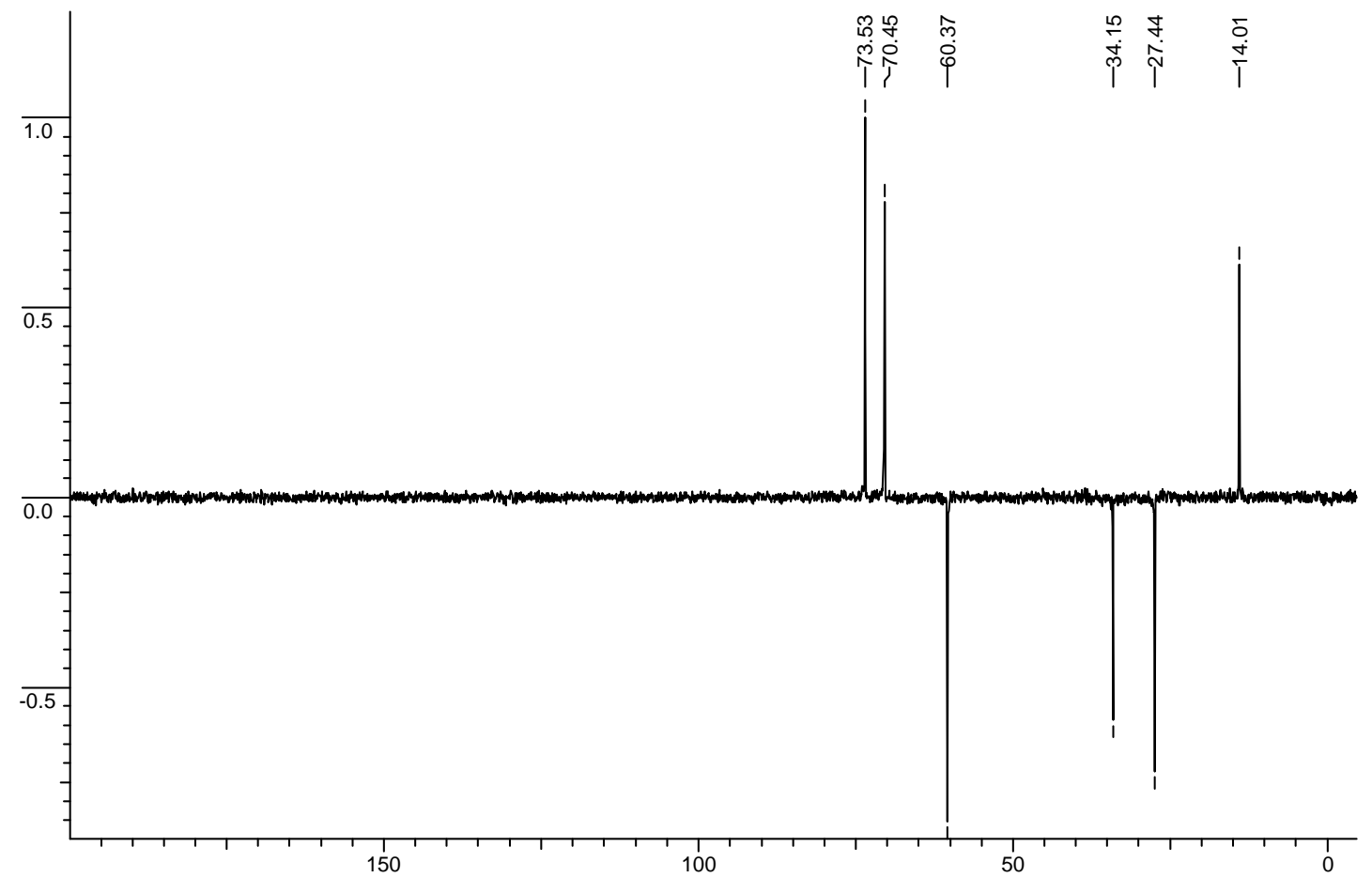

DEPT of 1, 1'-Bis-(3-carbethoxypropionyl)ferrocene (4) 


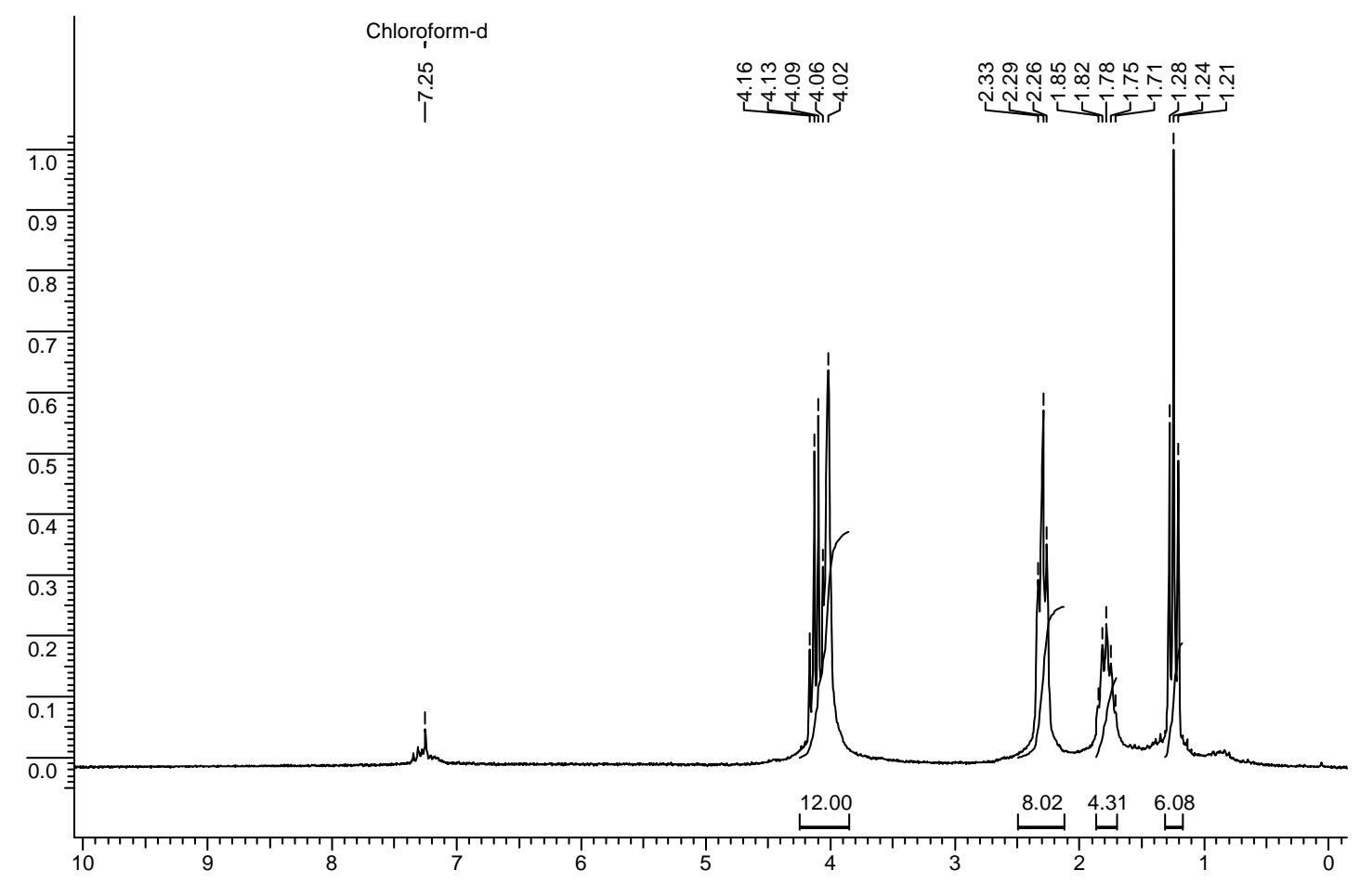

${ }^{1}$ H NMR of 1, 1'-Bis-(3-carbethoxypropyl)ferrocene (5)

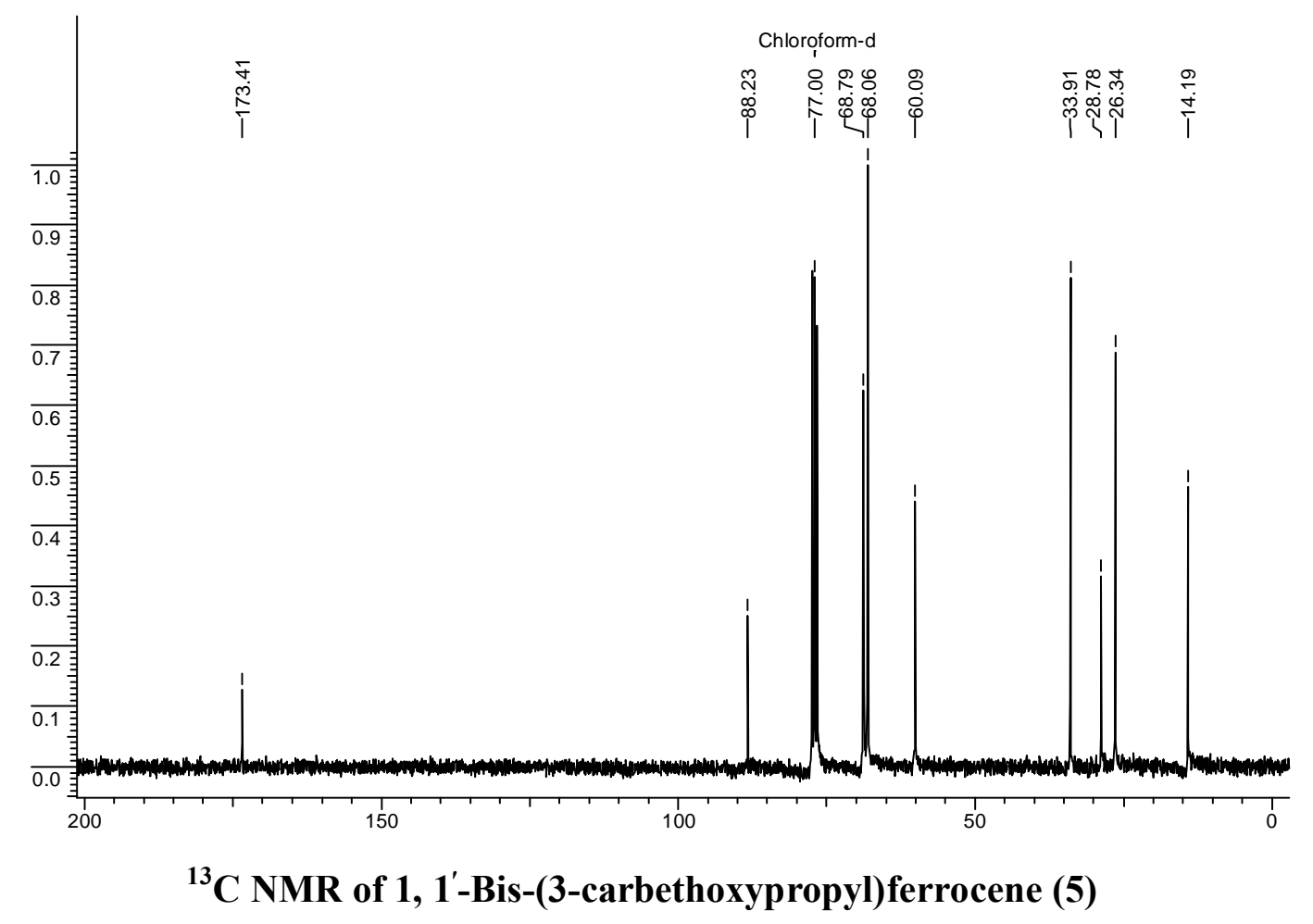




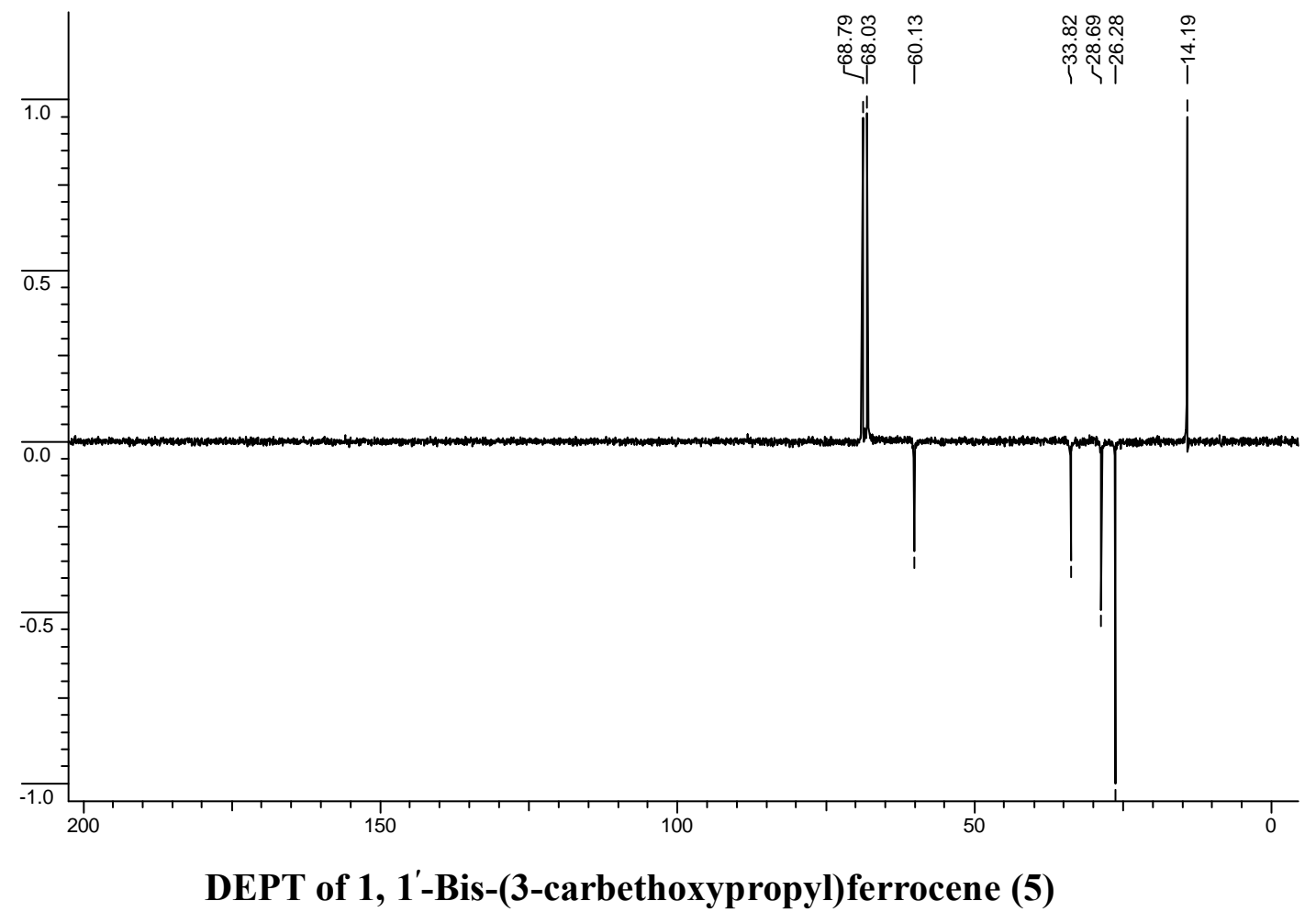




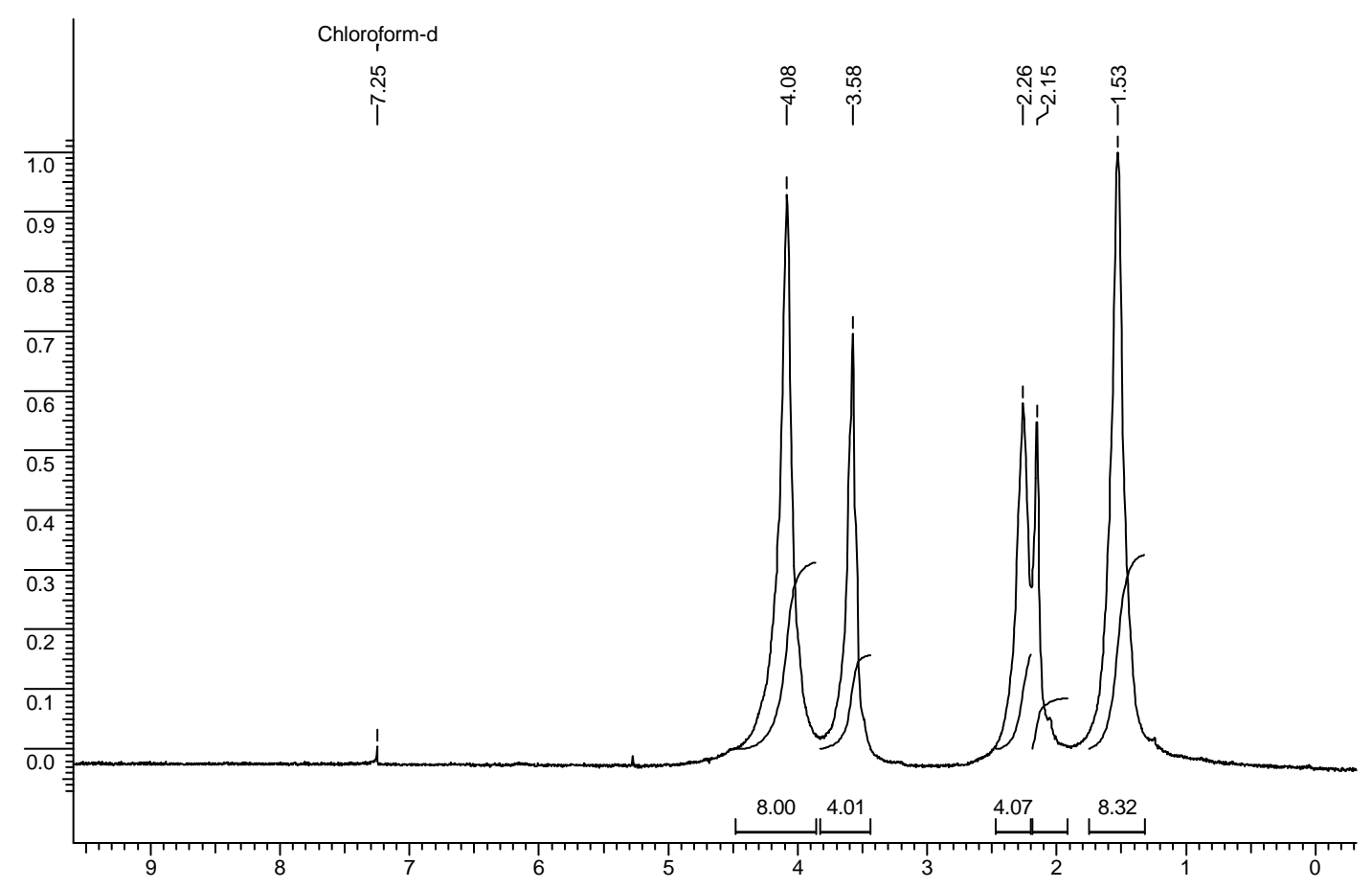

${ }^{1}$ H NMR of 1, 1'-Bis-(4-hydroxybutyl)ferrocene (6)

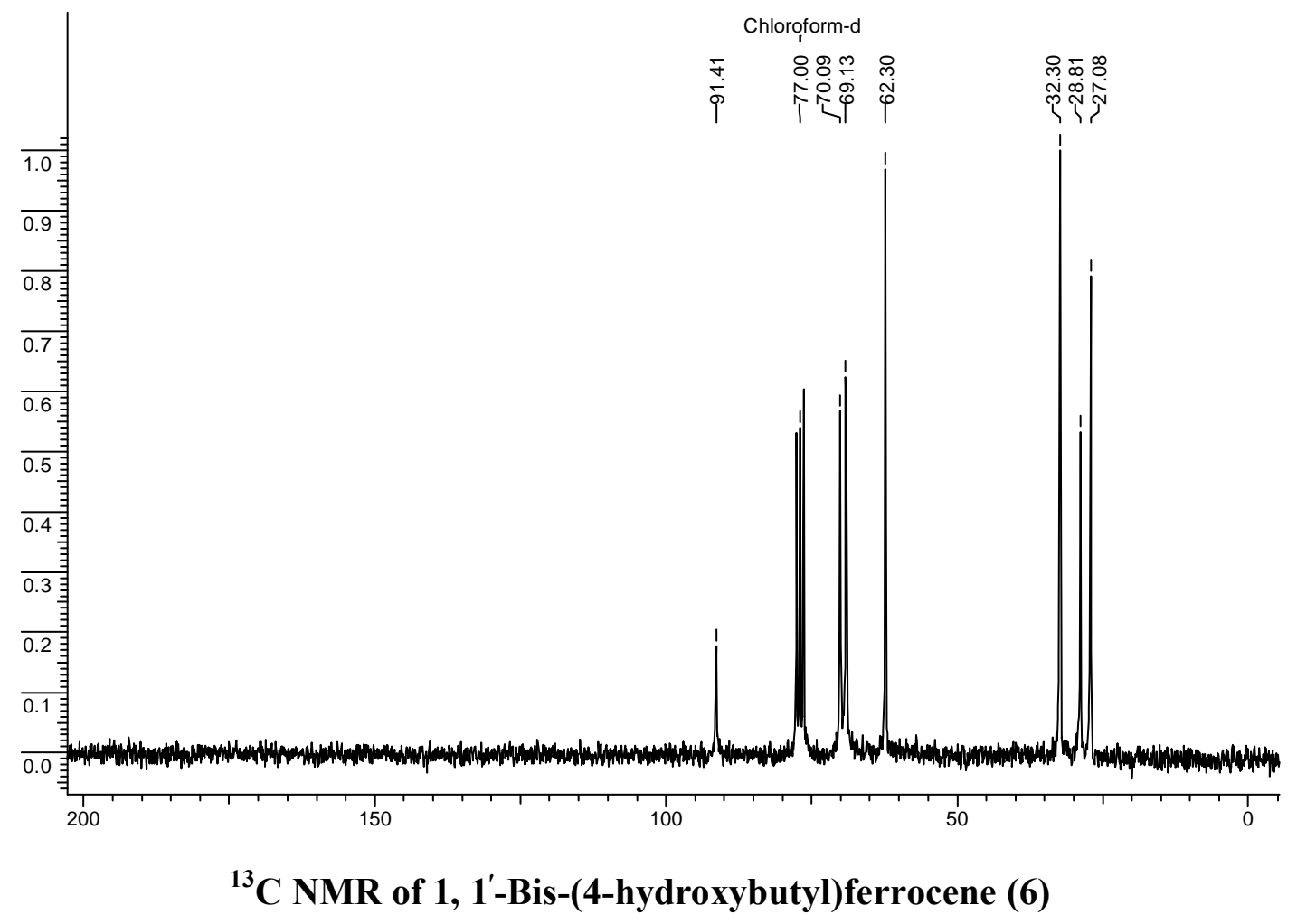




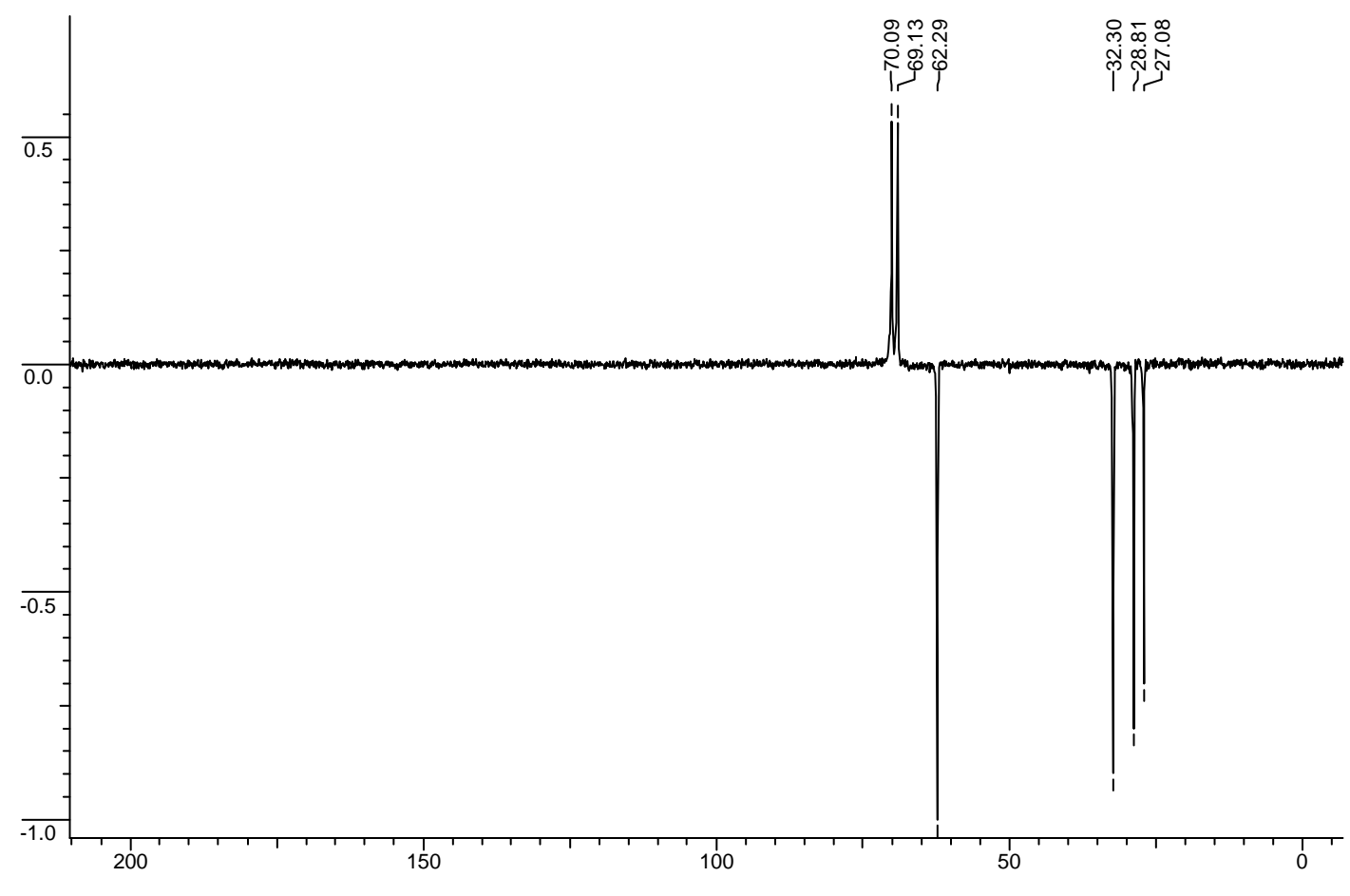

DEPT of 1, 1'-Bis-(4-hydroxybutyl)ferrocene (6) 


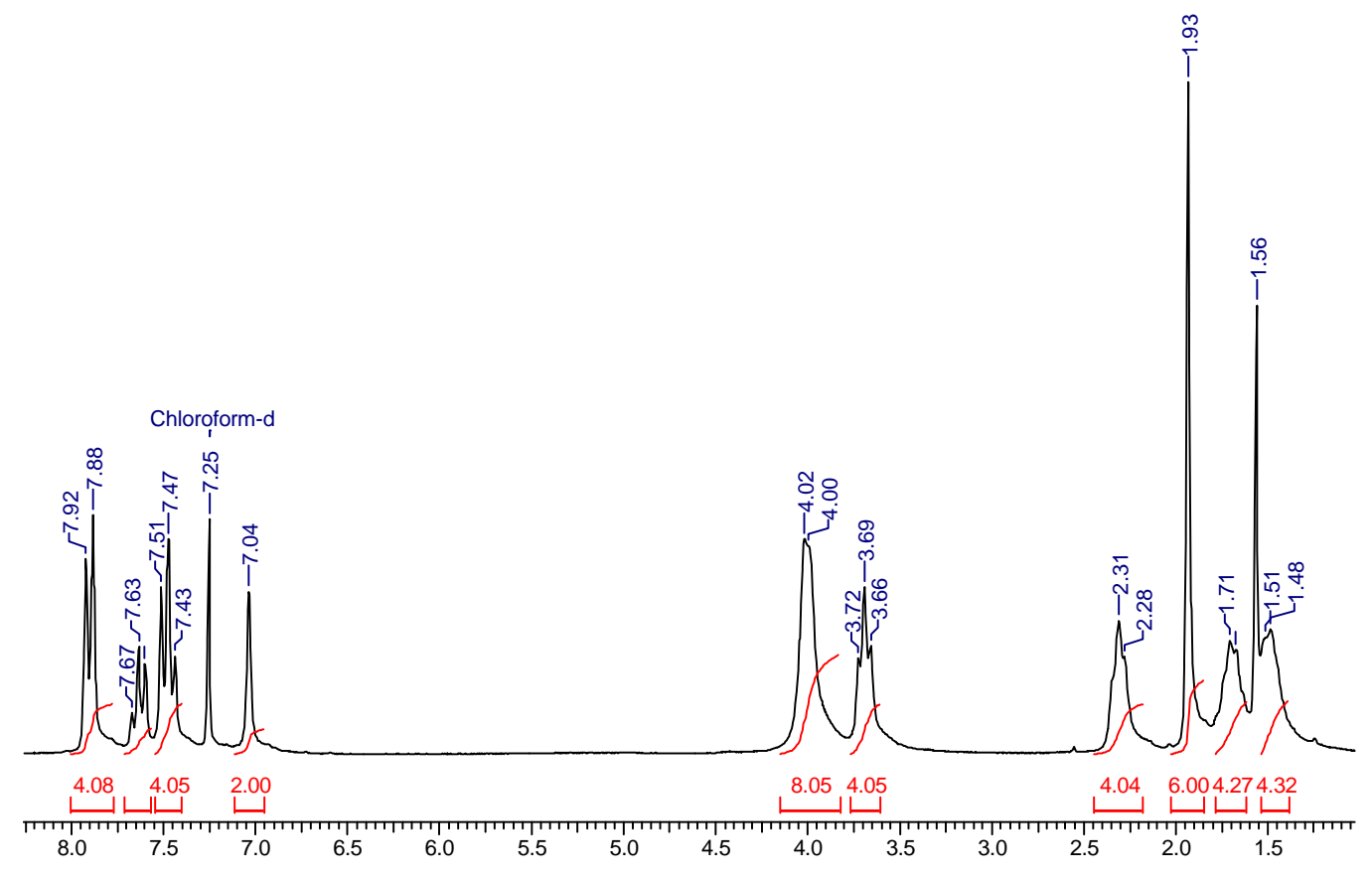

${ }^{1}$ H NMR of 1, 1'-Bis-(4-(N3-benzoylthyminyl)butyl)ferrocene (7a)

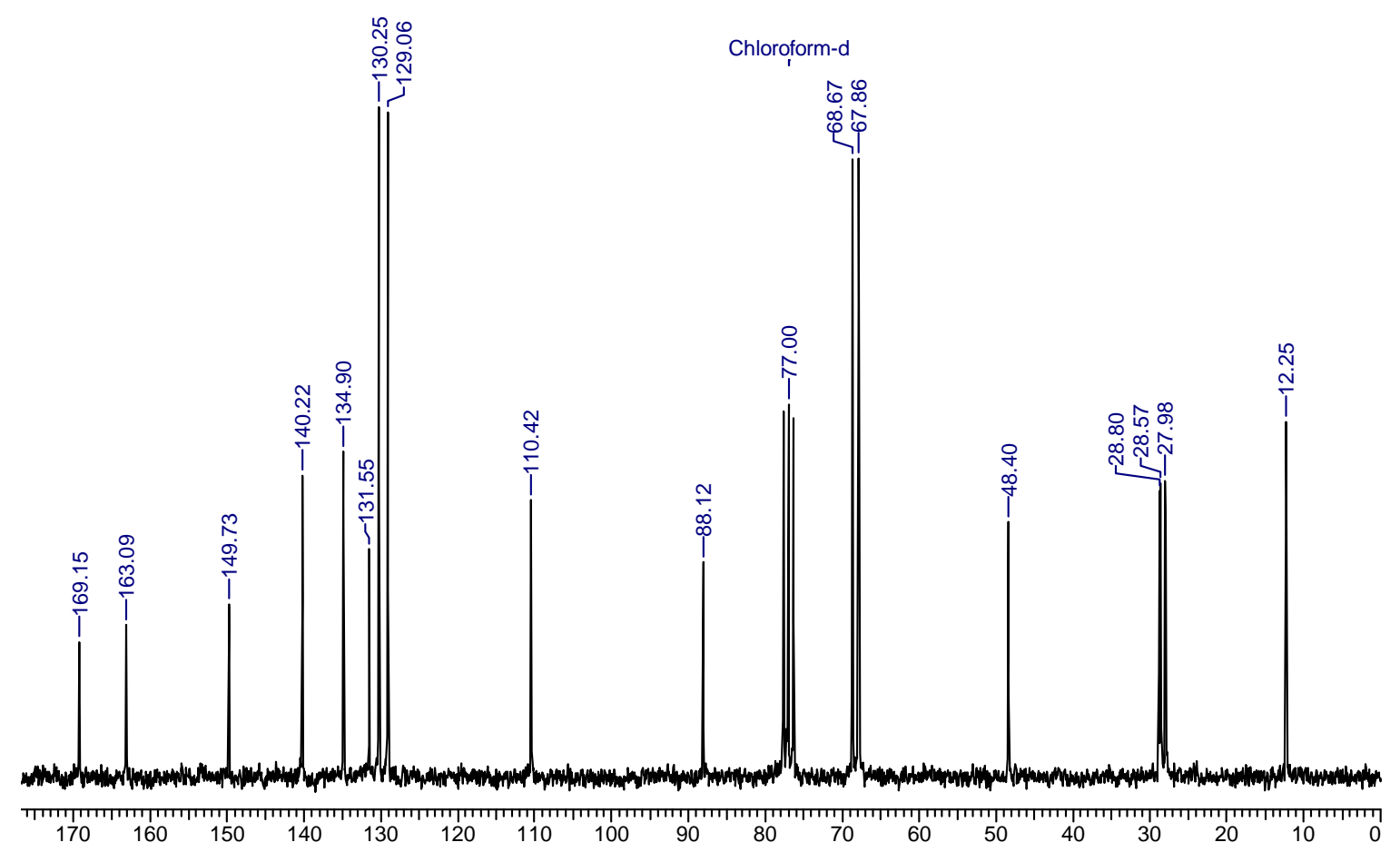

${ }^{13}$ C NMR of 1, 1'-Bis-(4-(N3-benzoylthyminyl)butyl)ferrocene (7a) 


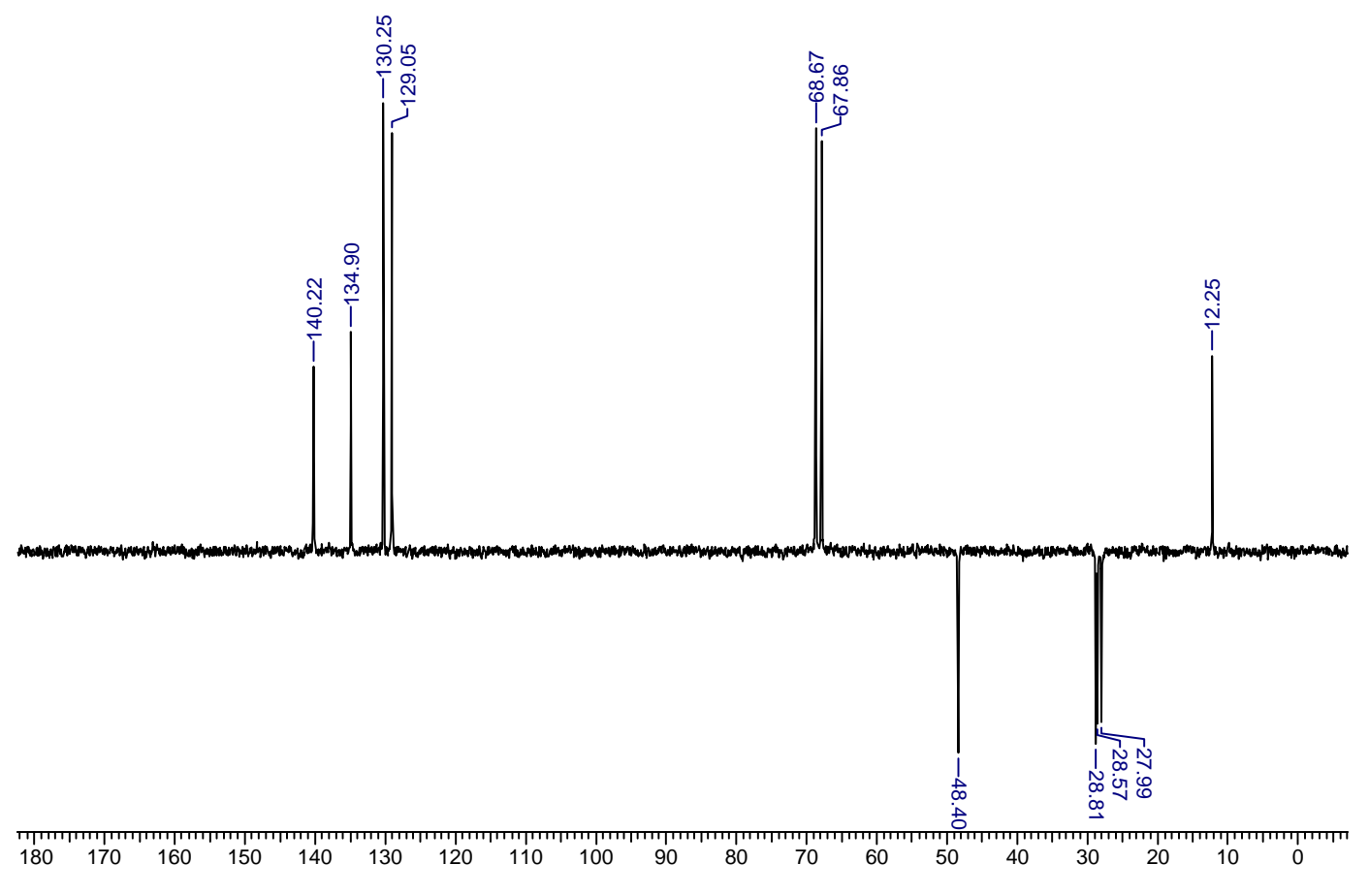

DEPT of 1, 1'-Bis-(4-(N3-benzoylthyminyl)butyl)ferrocene (7a) 


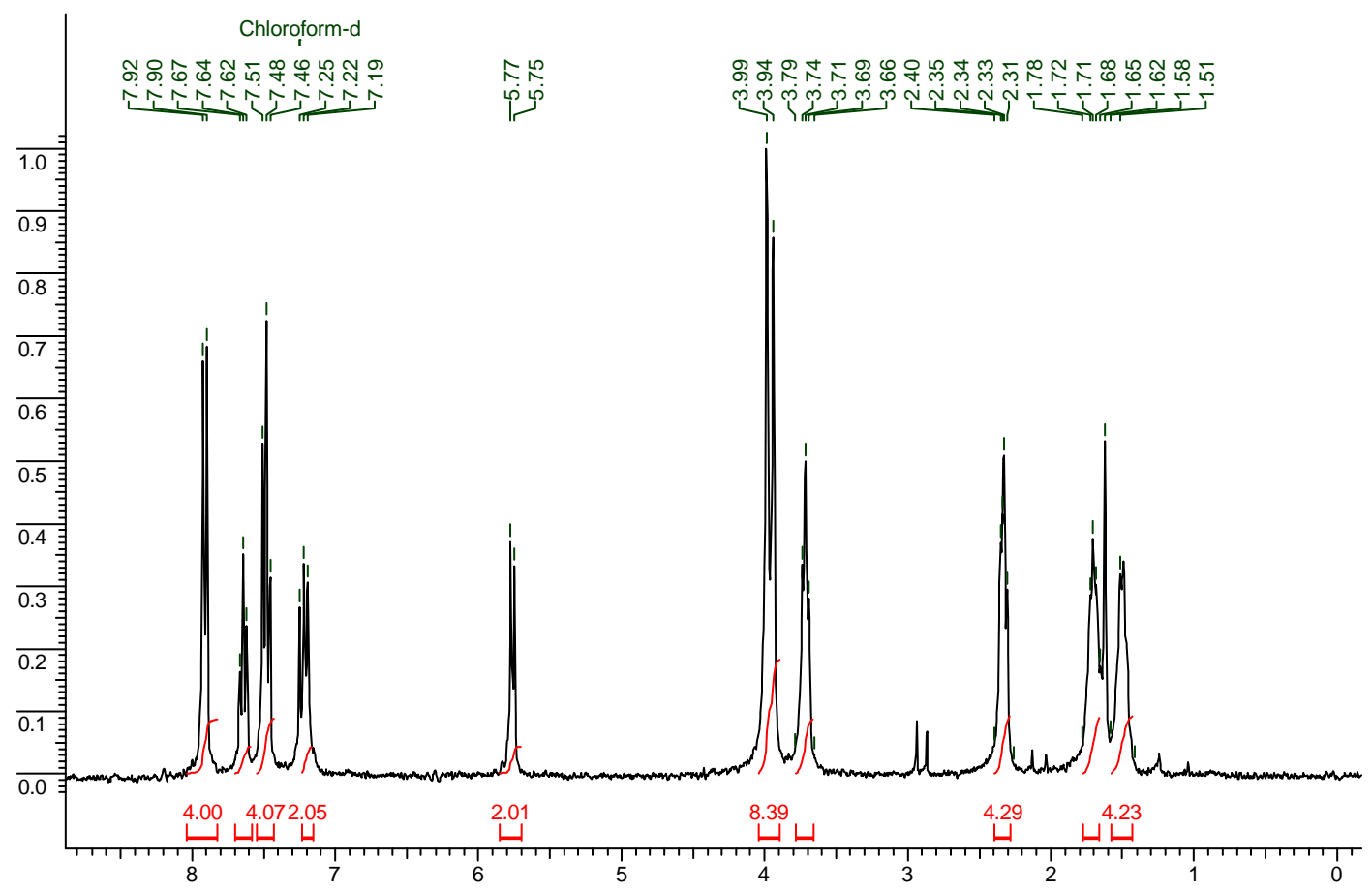

${ }^{1}$ H NMR of 1, 1'-Bis-(4-(N3-benzoyluracyl)butyl)ferrocene (7b)

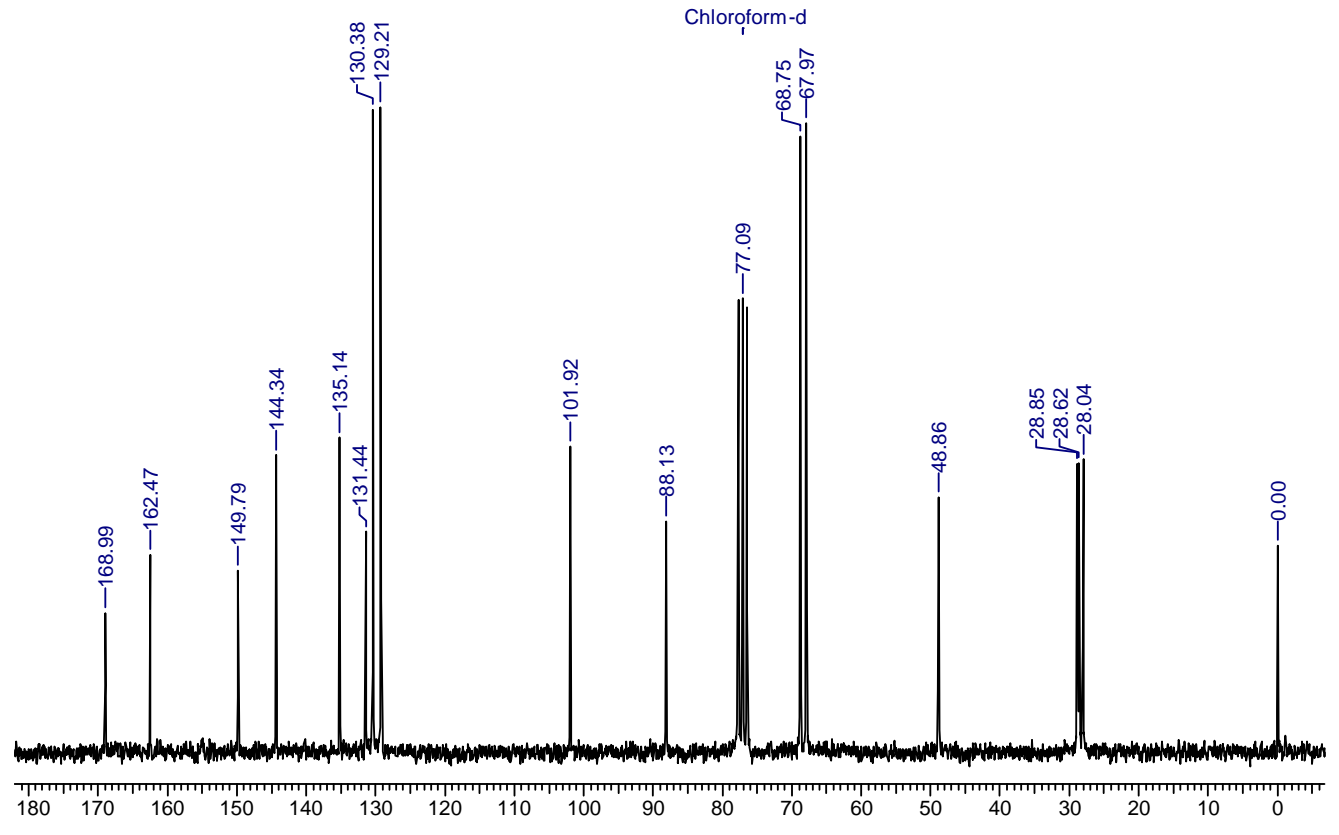

${ }^{13}$ C NMR of 1, 1'-Bis-(4-(N3-benzoyluracyl)butyl)ferrocene (7b) 


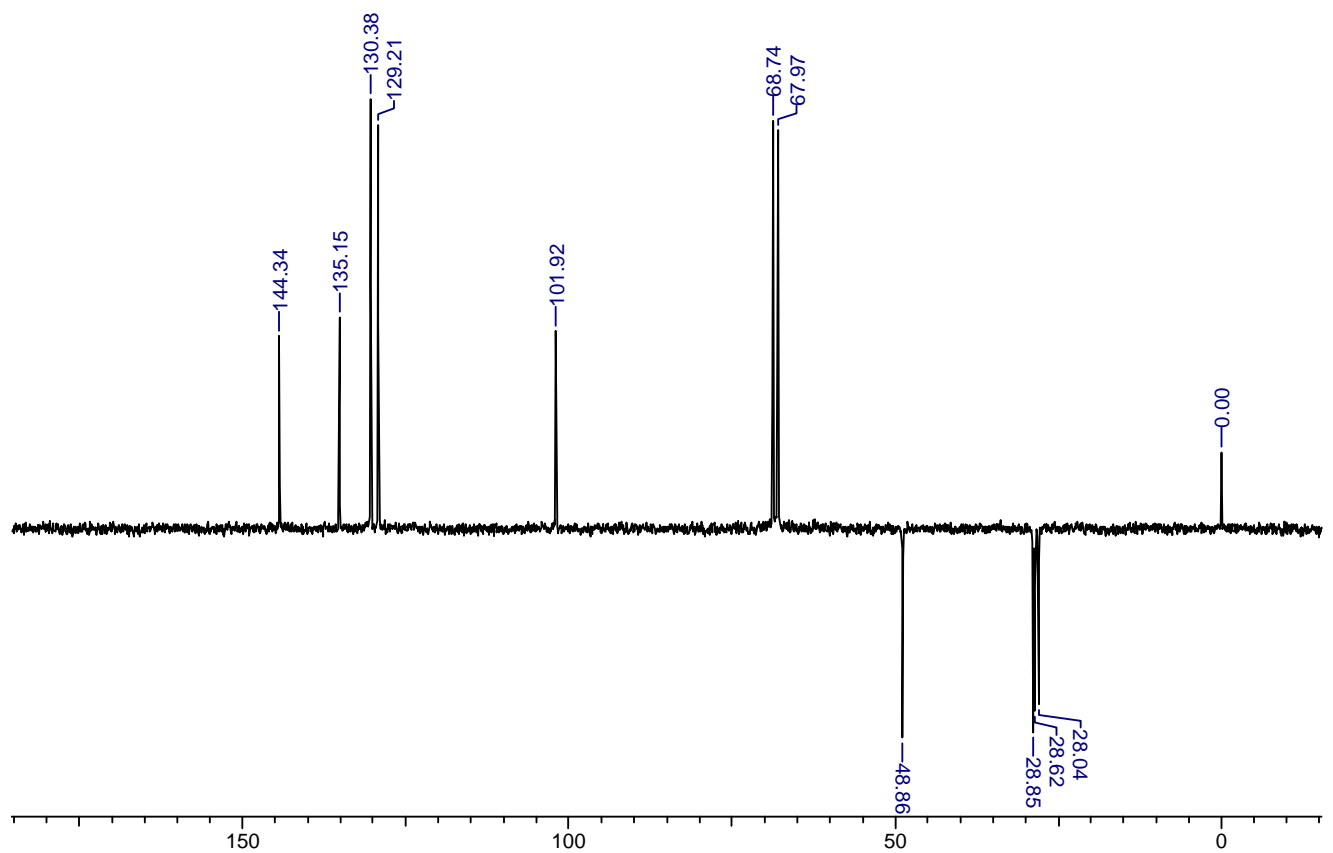

DEPT of 1, 1'-Bis-(4-(N3-benzoylu racyl)butyl)ferrocene (7b) 


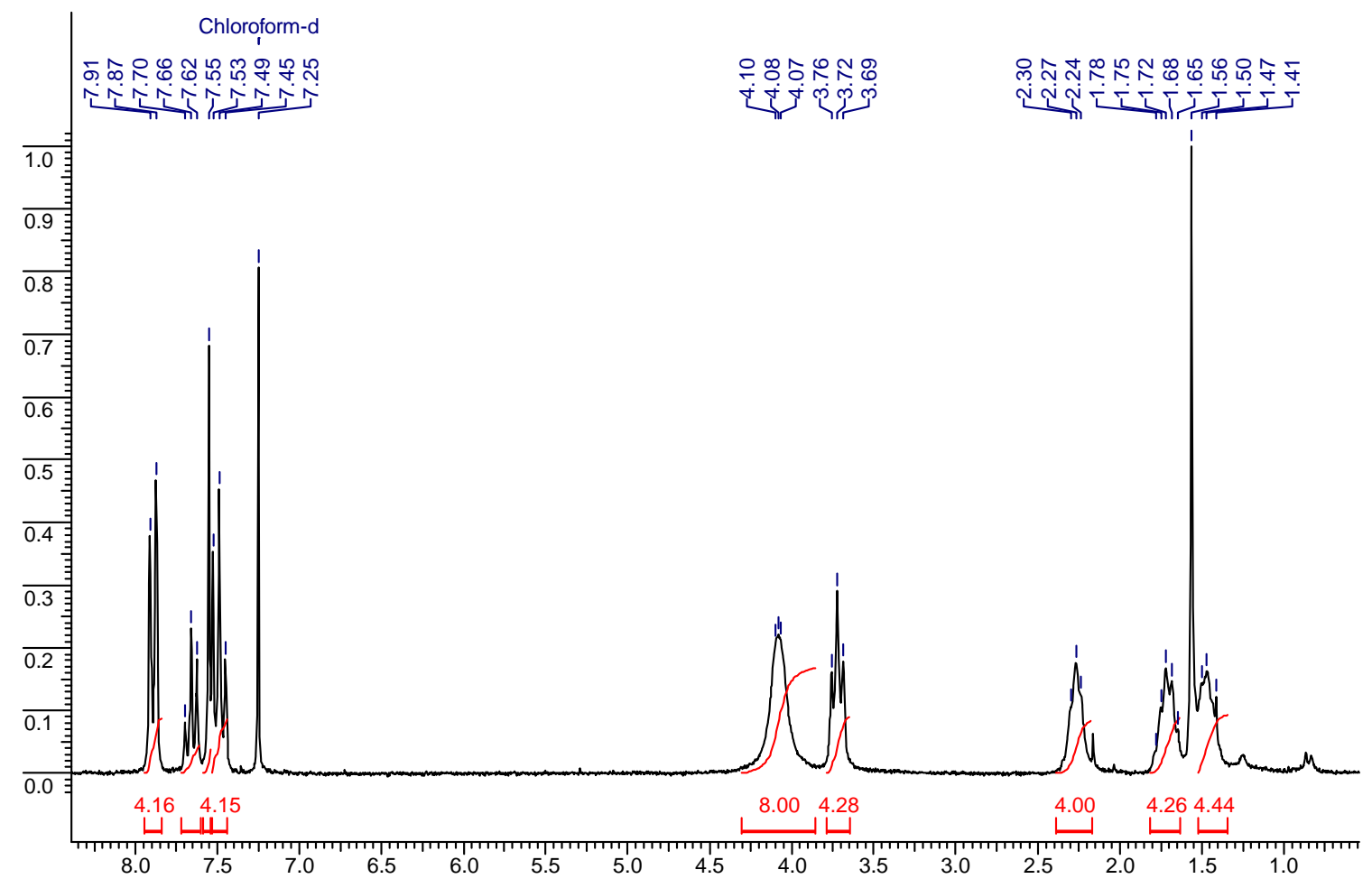

${ }^{1}$ H NMR of 1, 1'-Bis-[(4-(N3-benzoyl)-5-bromouracyl)n-butyl]ferrocene (7c)

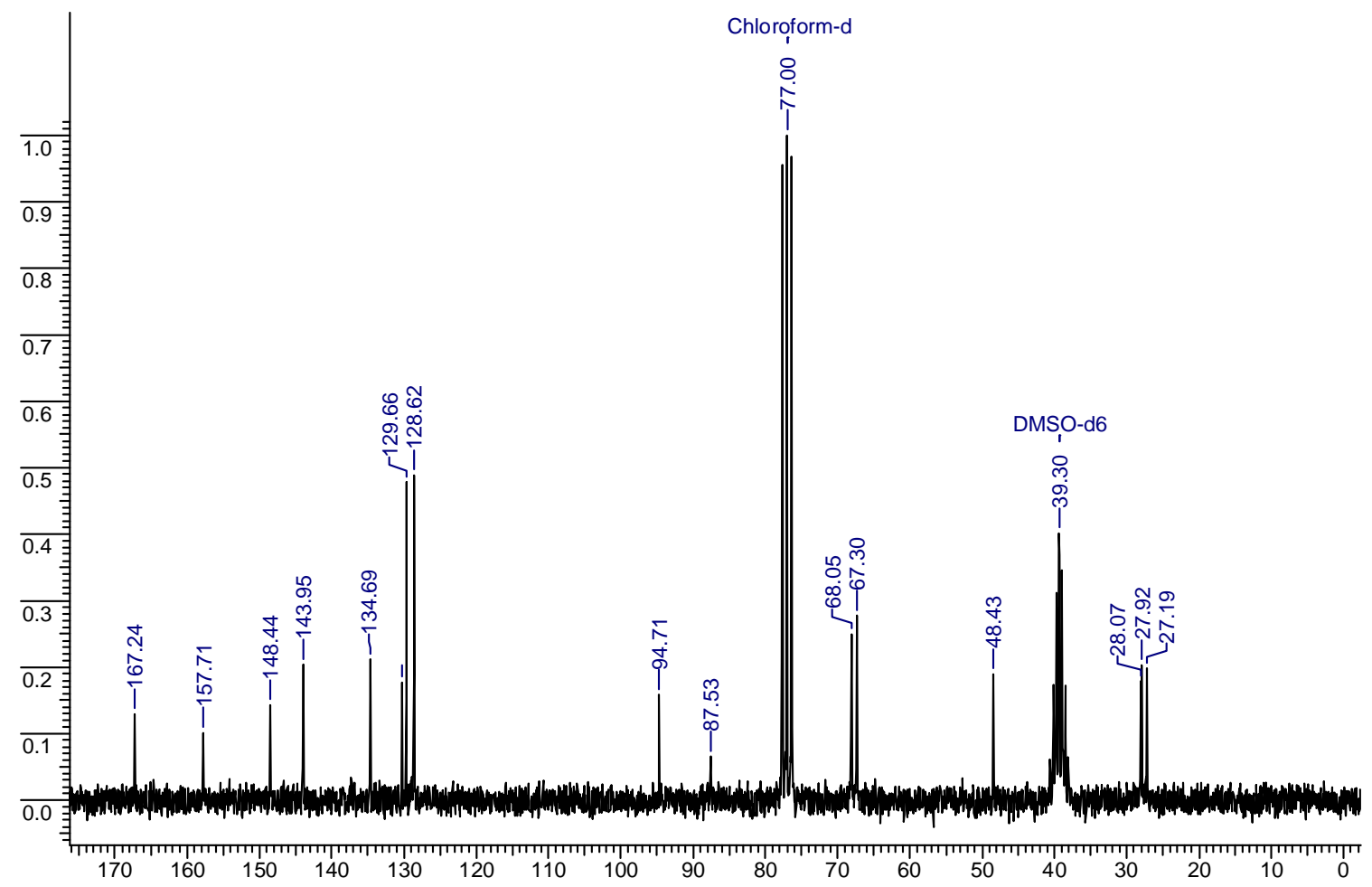

${ }^{13}$ C NMR of 1, 1'-Bis-[(4-(N3-benzoyl)-5-bromouracyl)butyl]ferrocene (7e) 


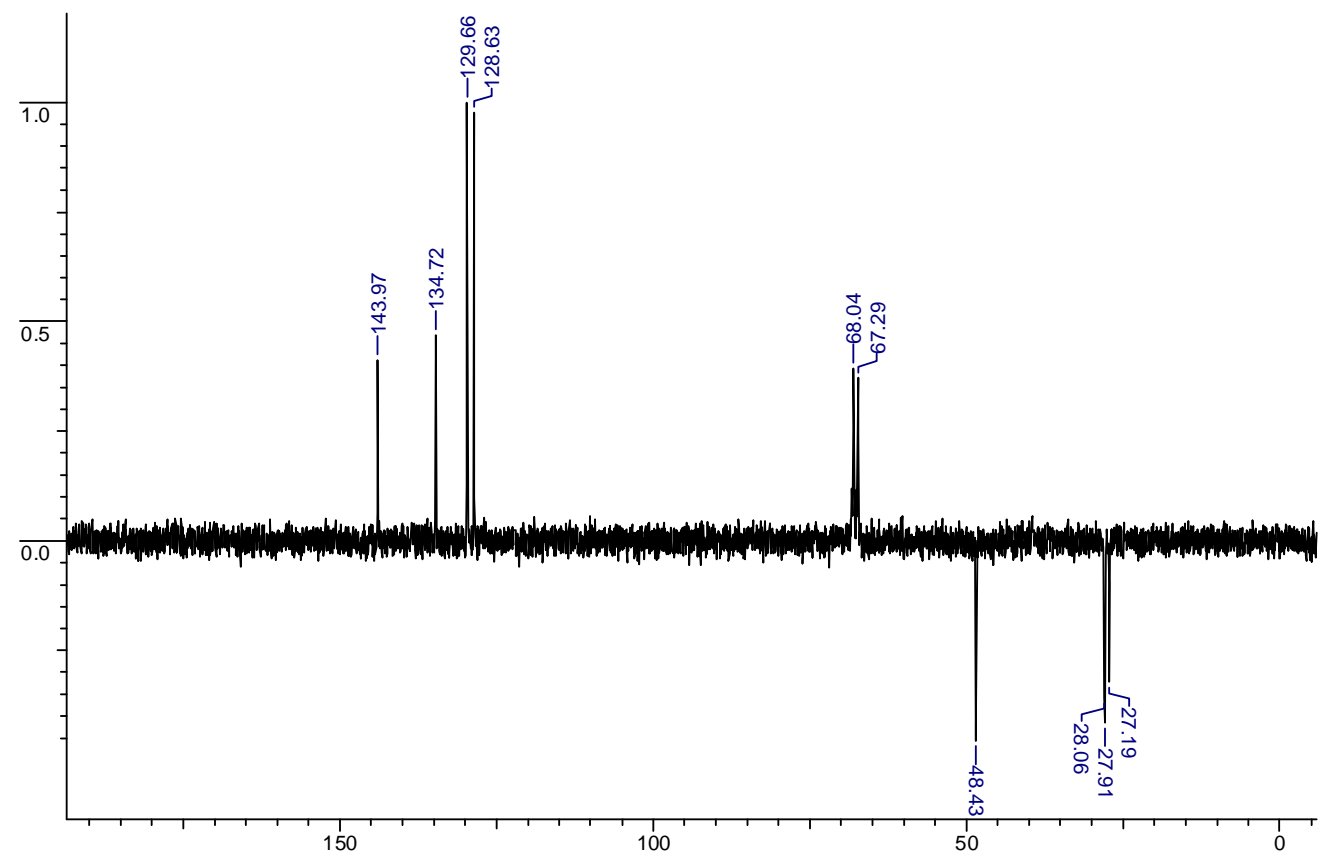

DEPT of 1, 1'-Bis-[(4-(N3-benzoyl)-5-bromouracyl)butyl]ferrocene (7c) 


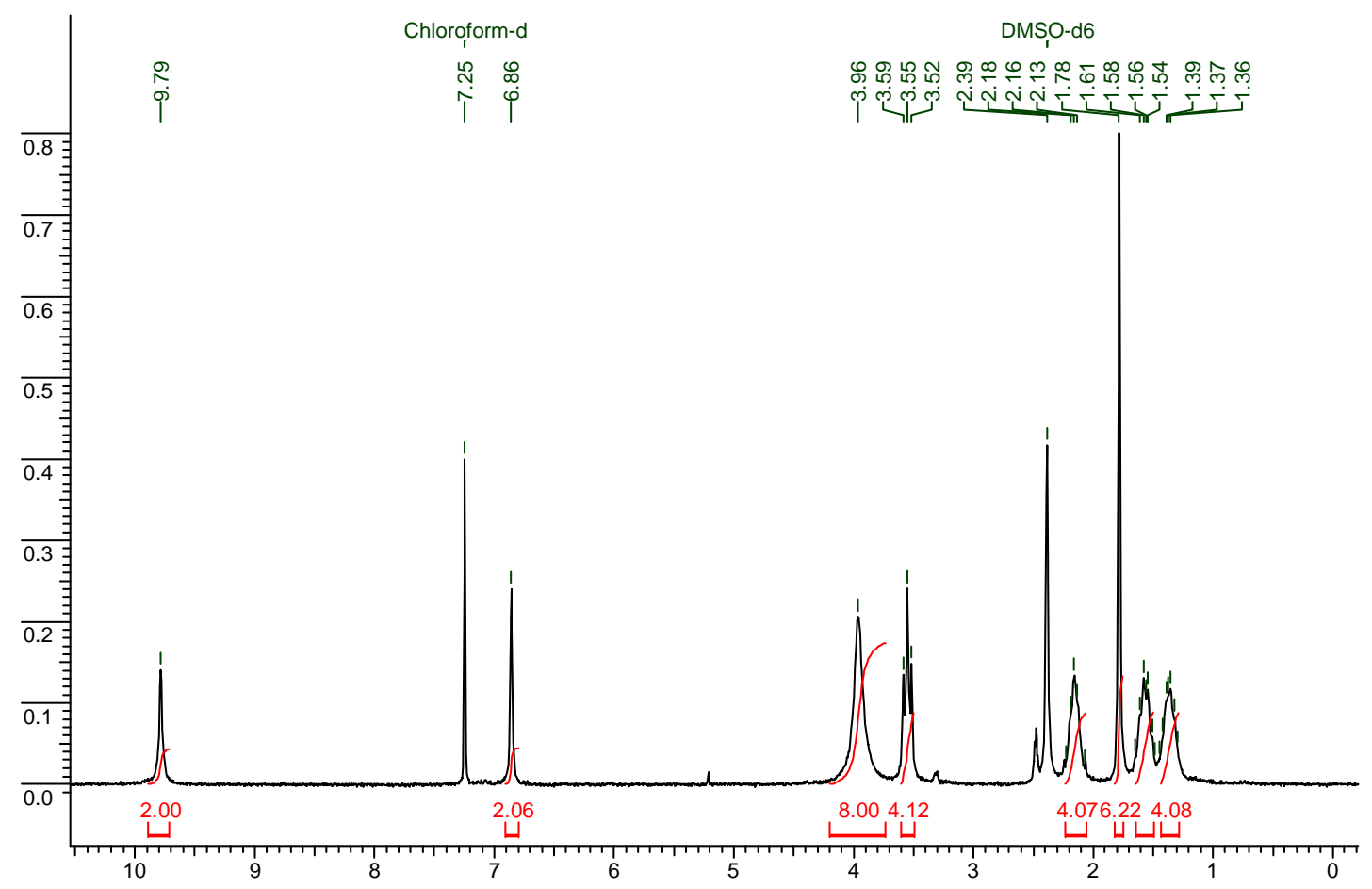

${ }^{1}$ H NMR of 1, 1'-Bis-(4-(thyminyl)butyl)ferrocene (1a)

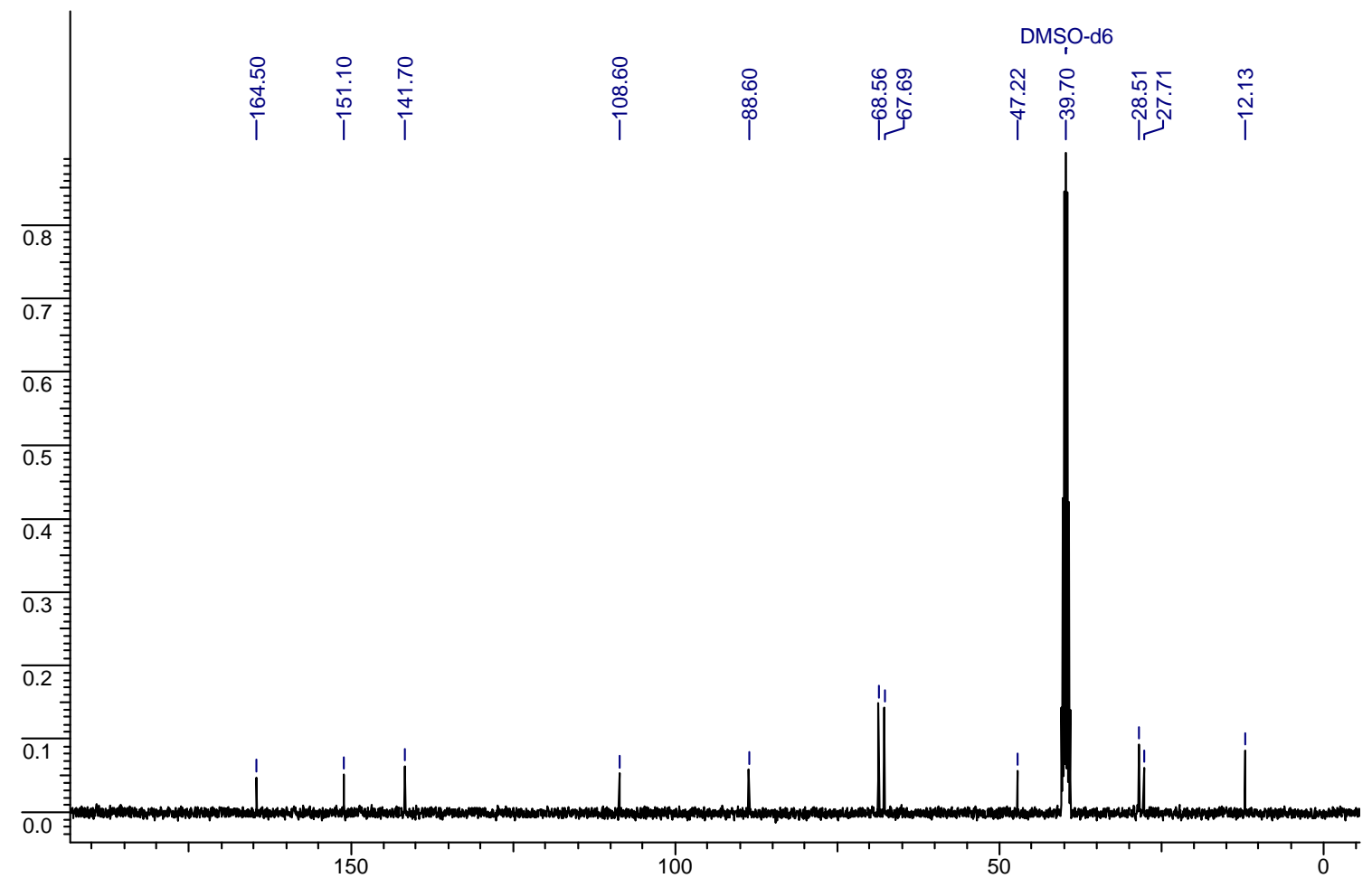

${ }^{13}$ C NMR of 1, 1'-Bis-(4-(thyminyl)butyl)ferrocene (1a) 


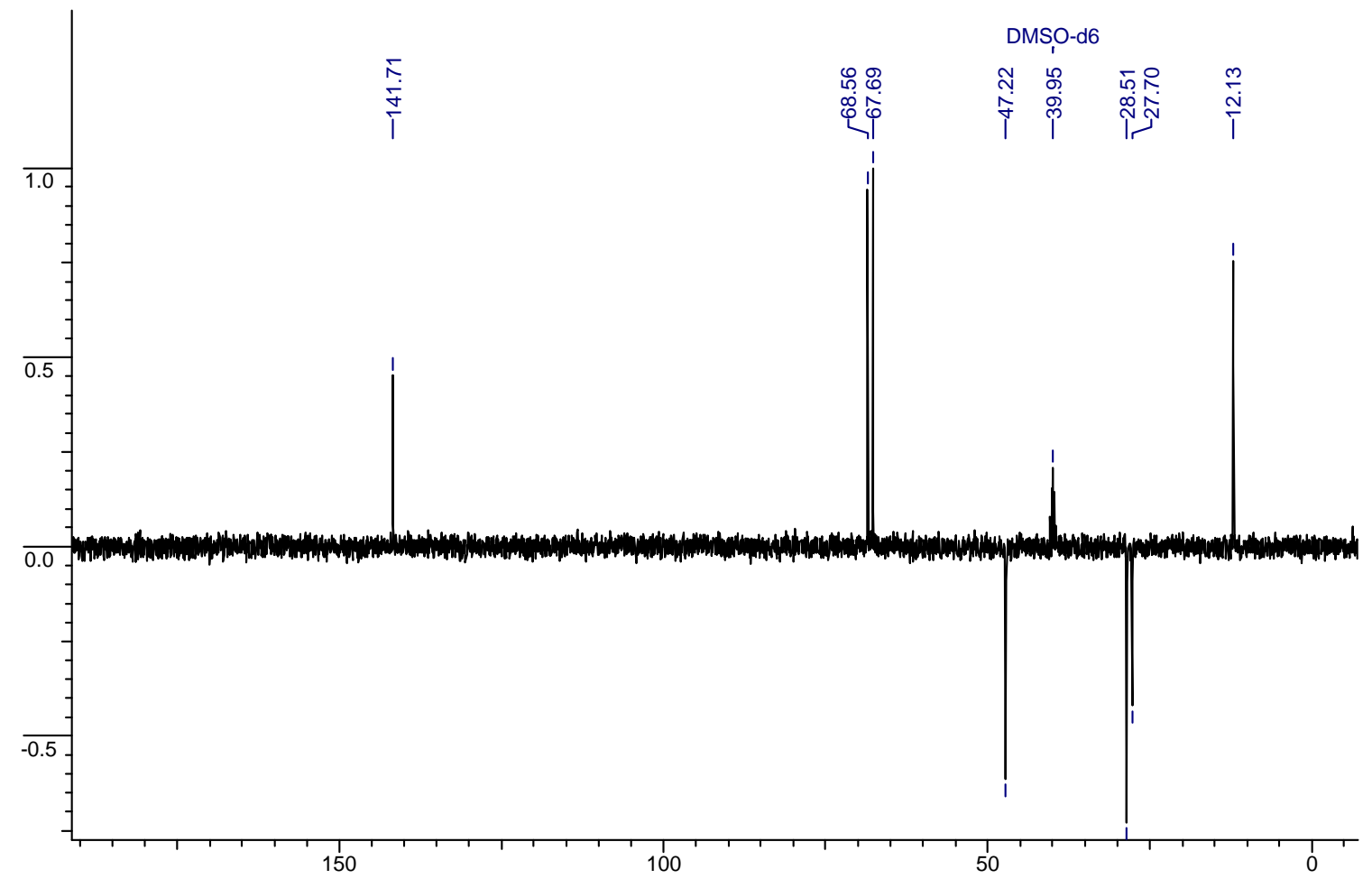

DEPT of 1, 1'-Bis-(4-(thyminyl)butyl)ferrocene (1a) 


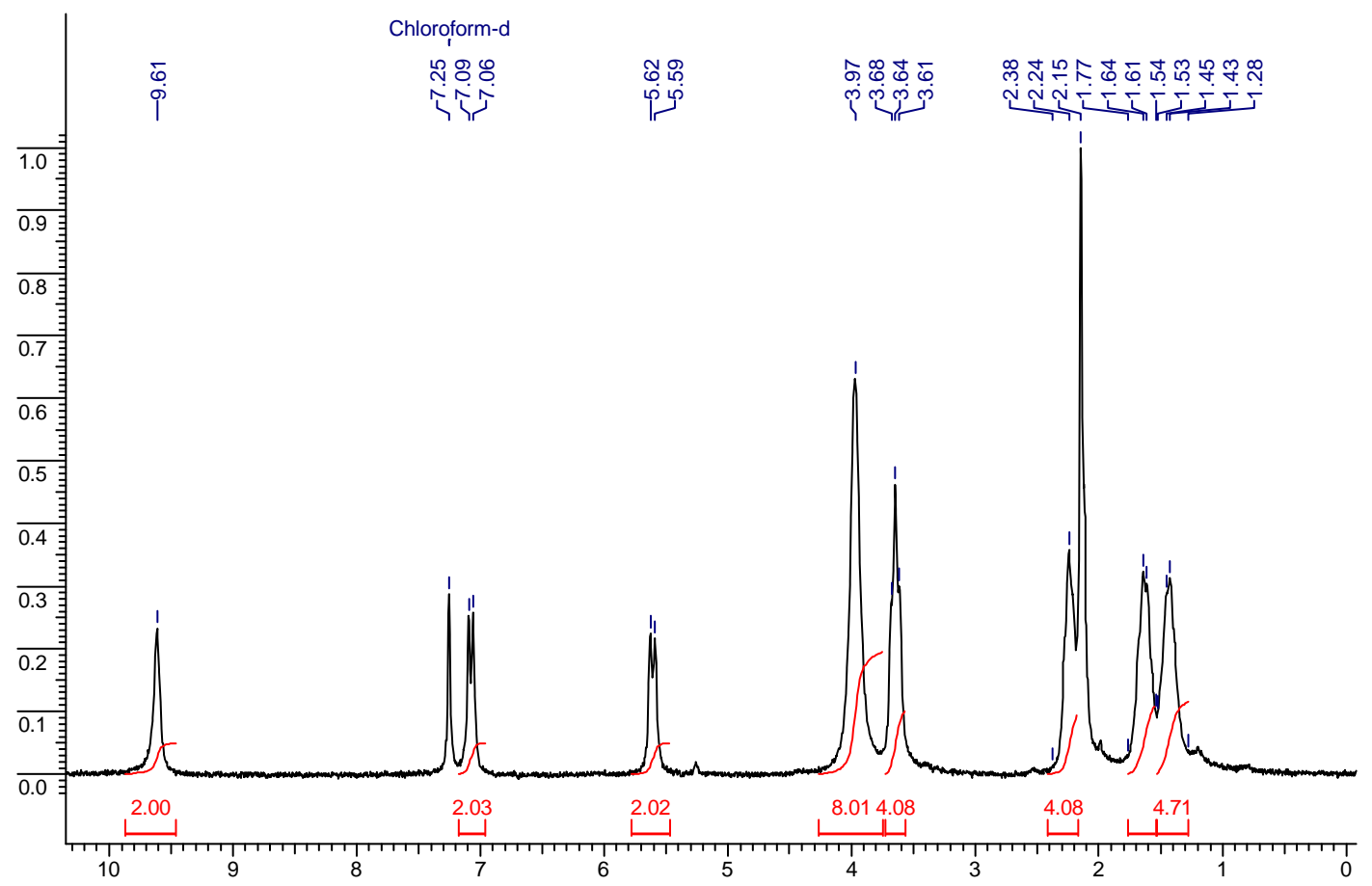

${ }^{1}$ H NMR of 1,1'-Bis-(4-(uracyl)butyl)ferrocene (1b)

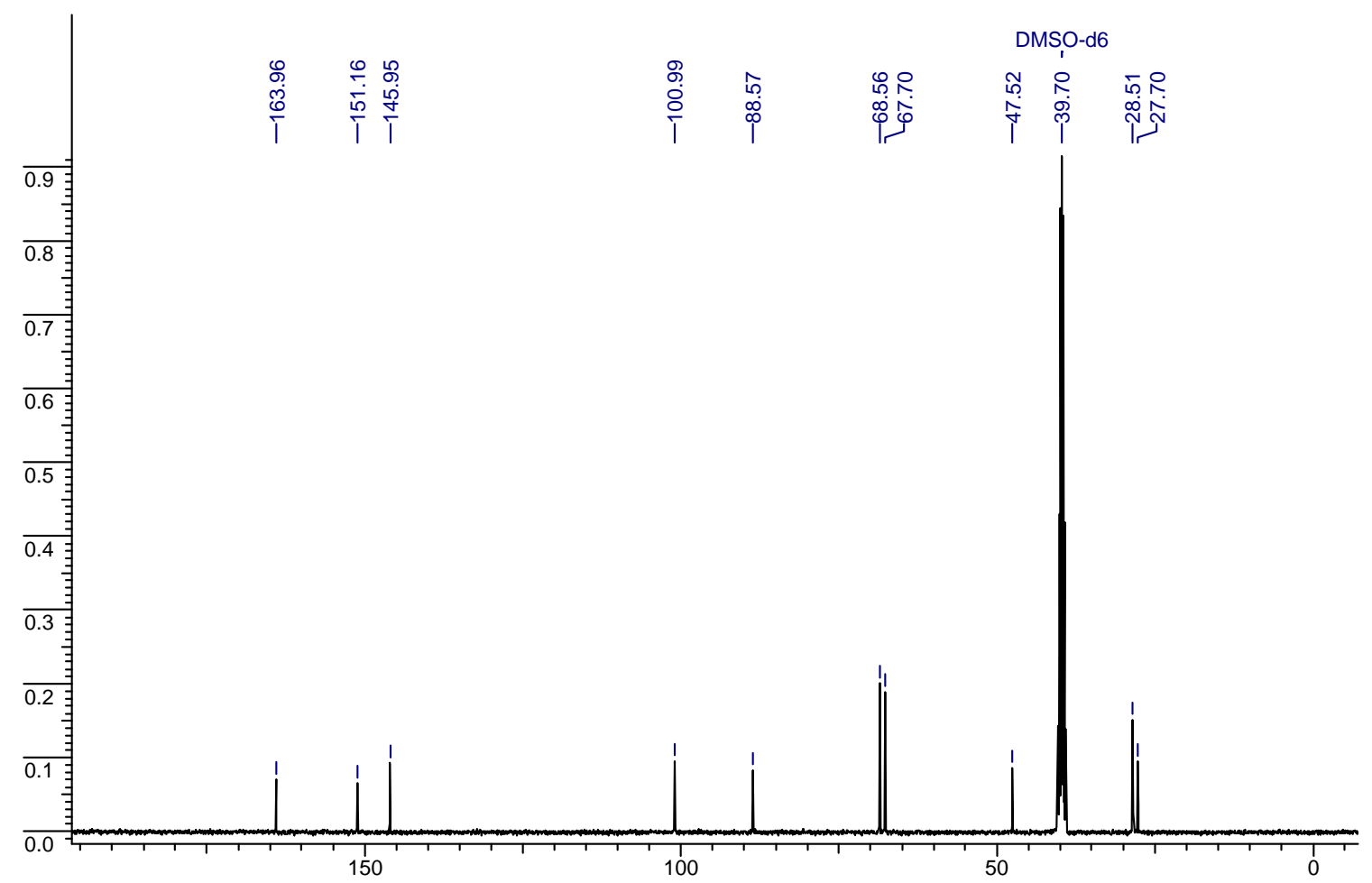

${ }^{13}$ C NMR of 1,1'-Bis-(4-(uracyl)butyl)ferrocene (1b) 


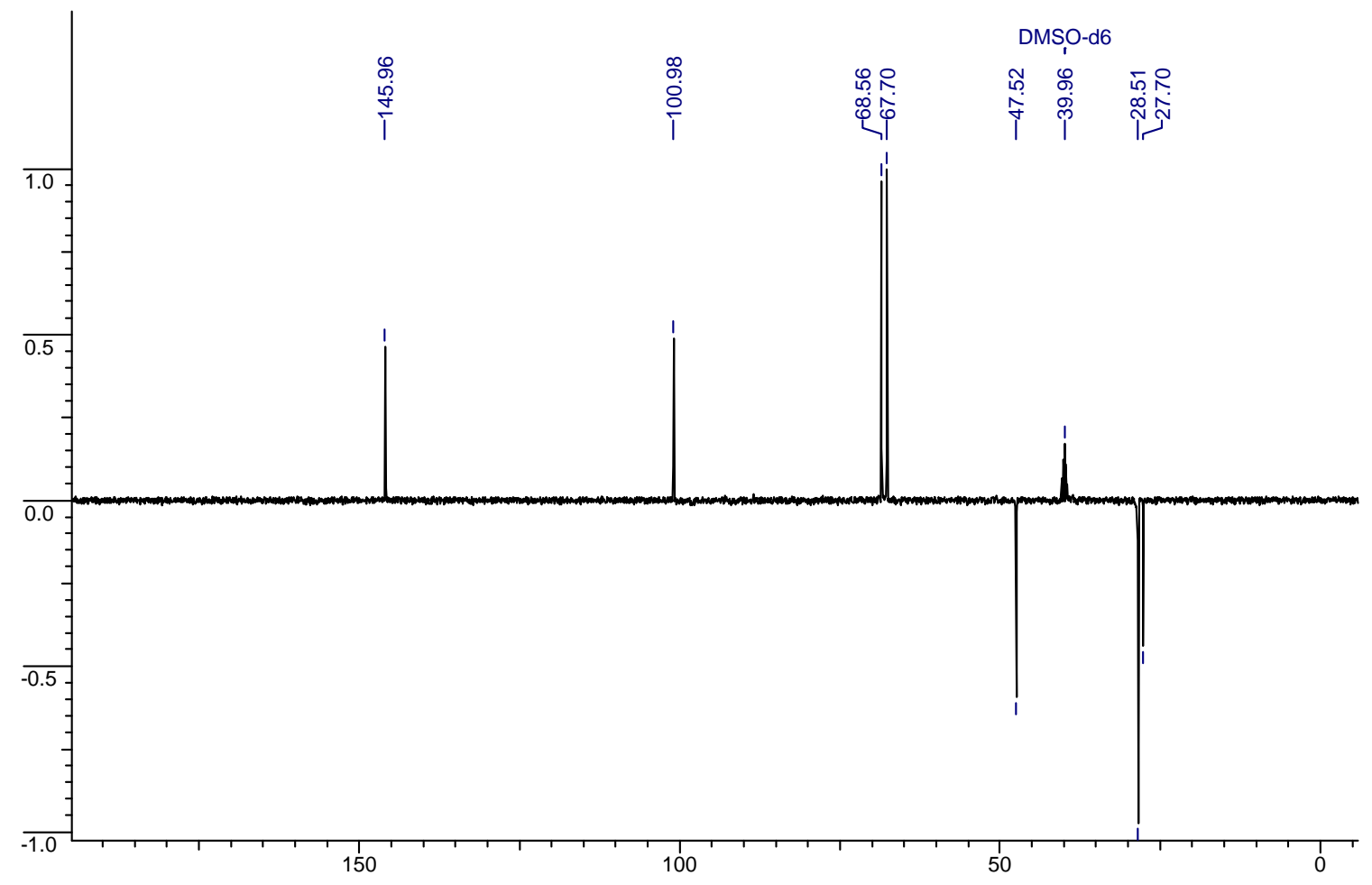

DEPT of 1,1'-Bis-(4-(uracyl)butyl)ferrocene (1b) 


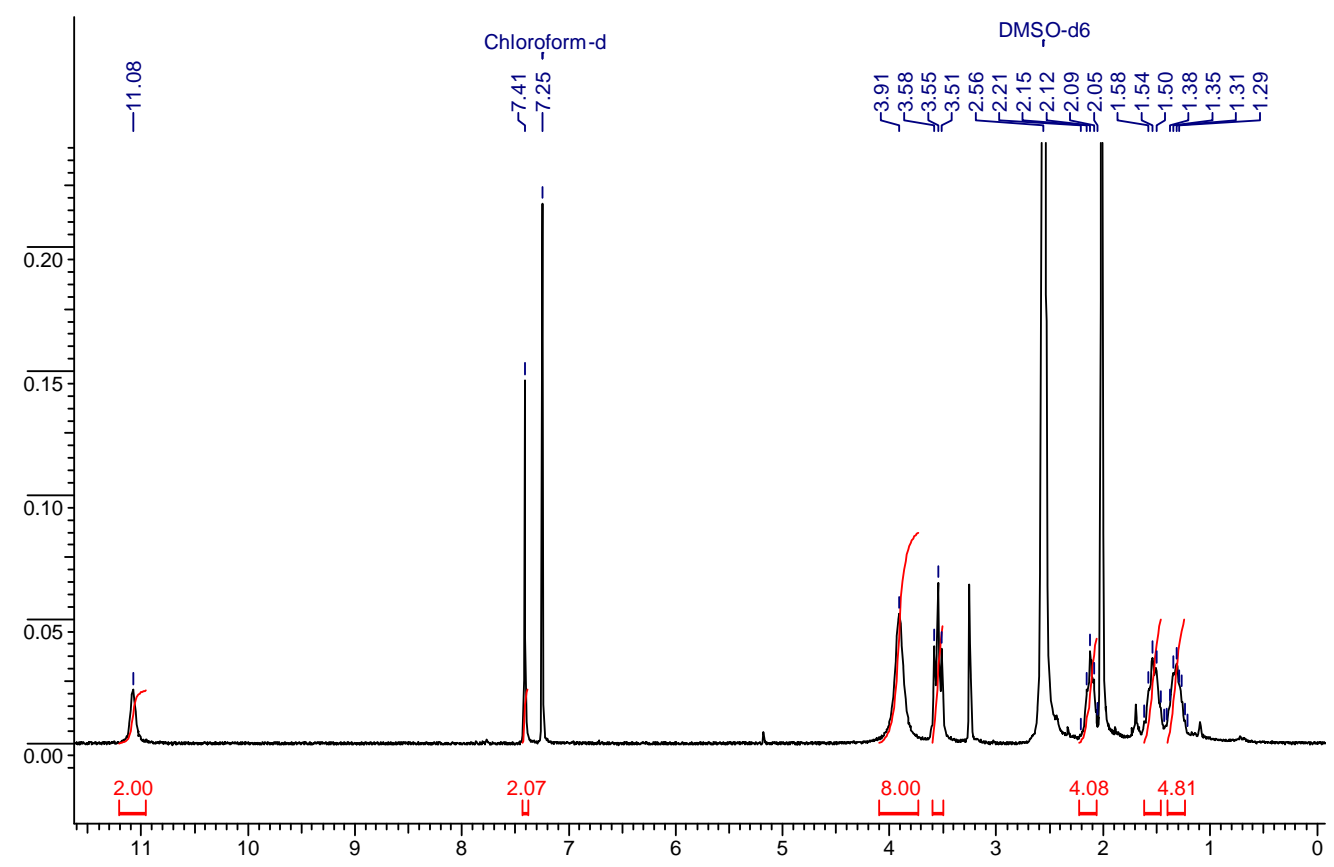

${ }^{1}$ H NMR of 1, 1'-Bis-[4-(5-bromouracyl)butyl]ferrocene (1c) 


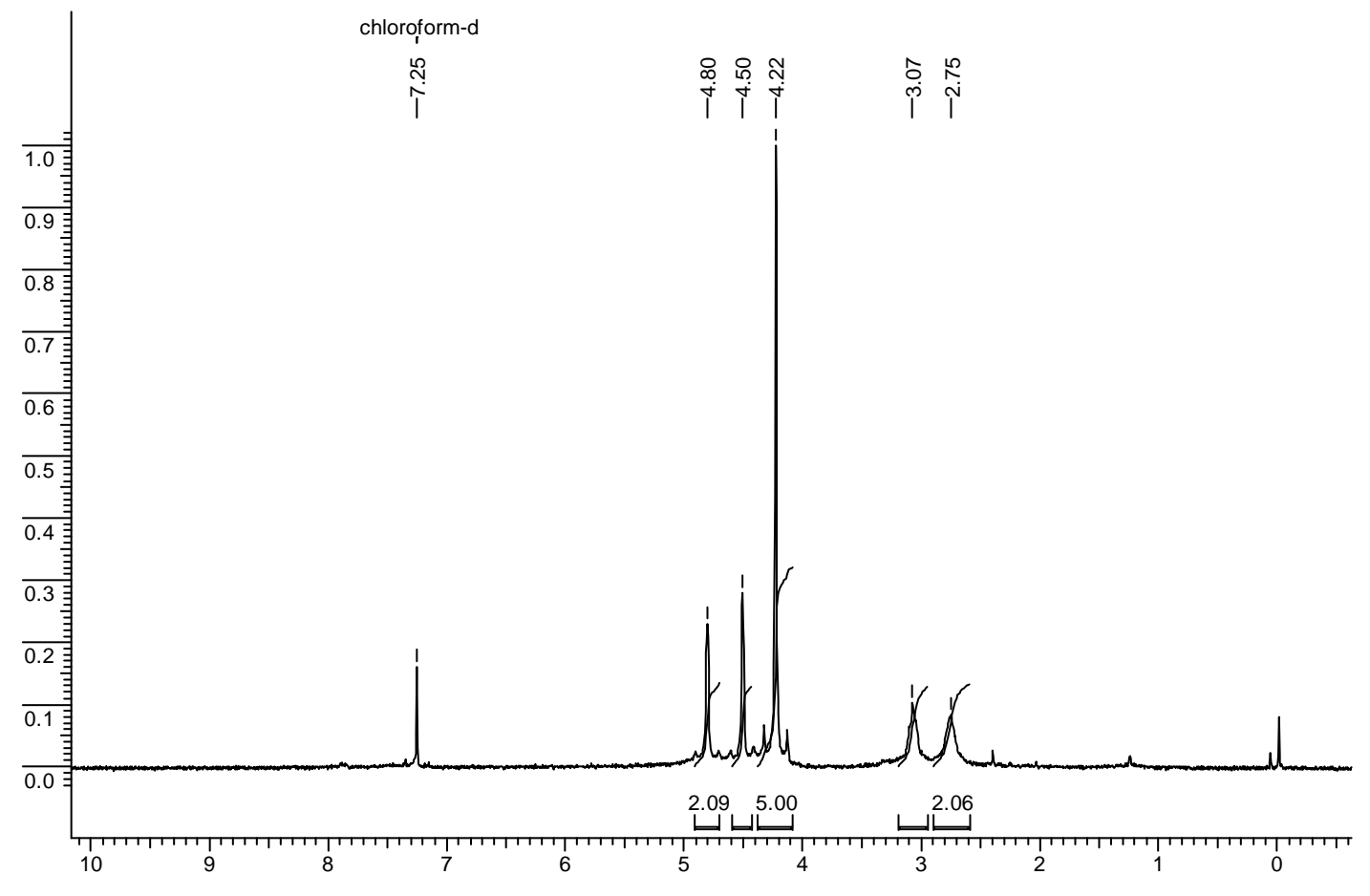

${ }^{1}$ H NMR of 1-(3-carboxypropionyl)ferrocene (8) 

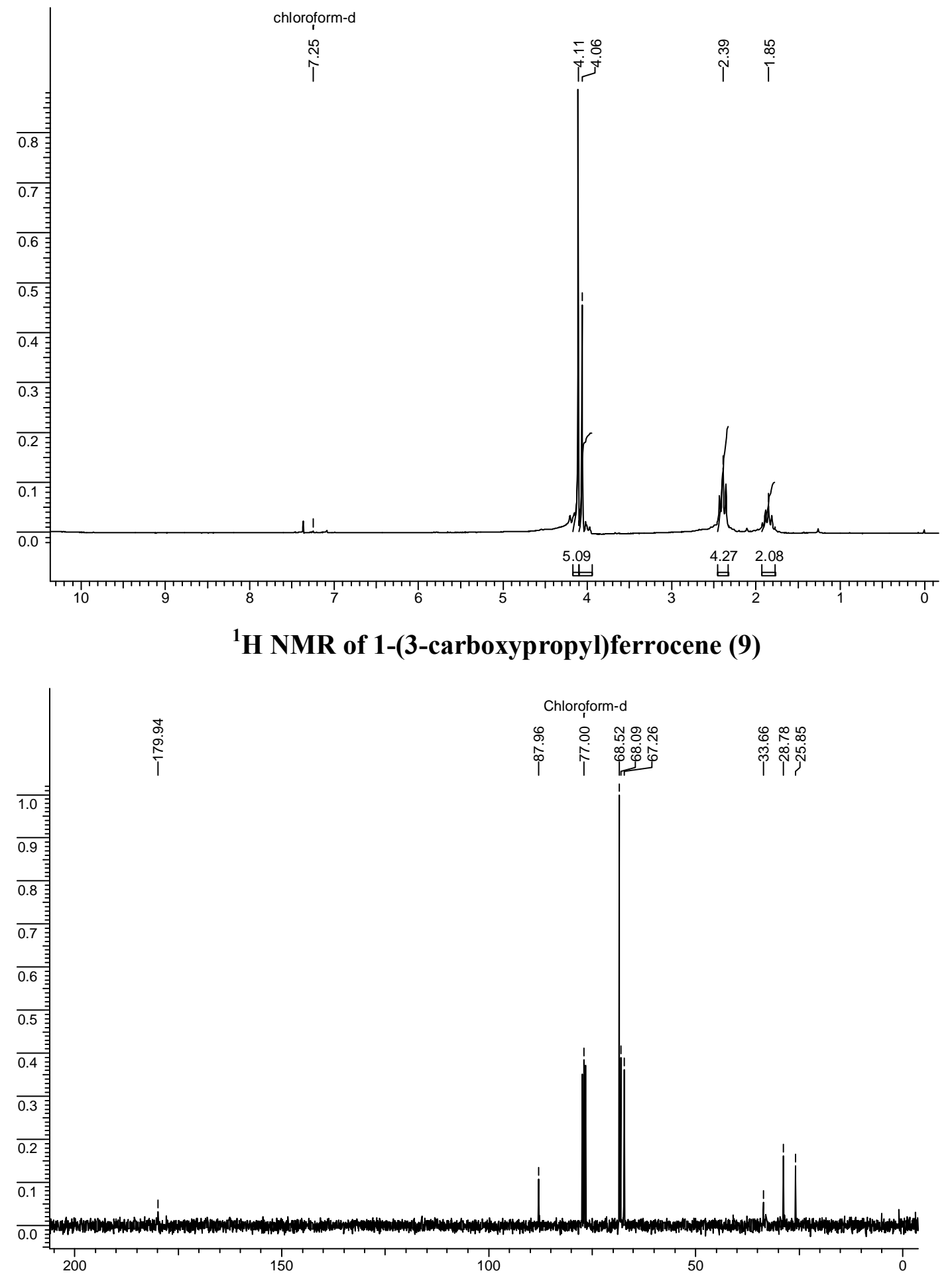

${ }^{13}$ C NMR of 1-(3-carboxypropyl)ferrocene (9) 


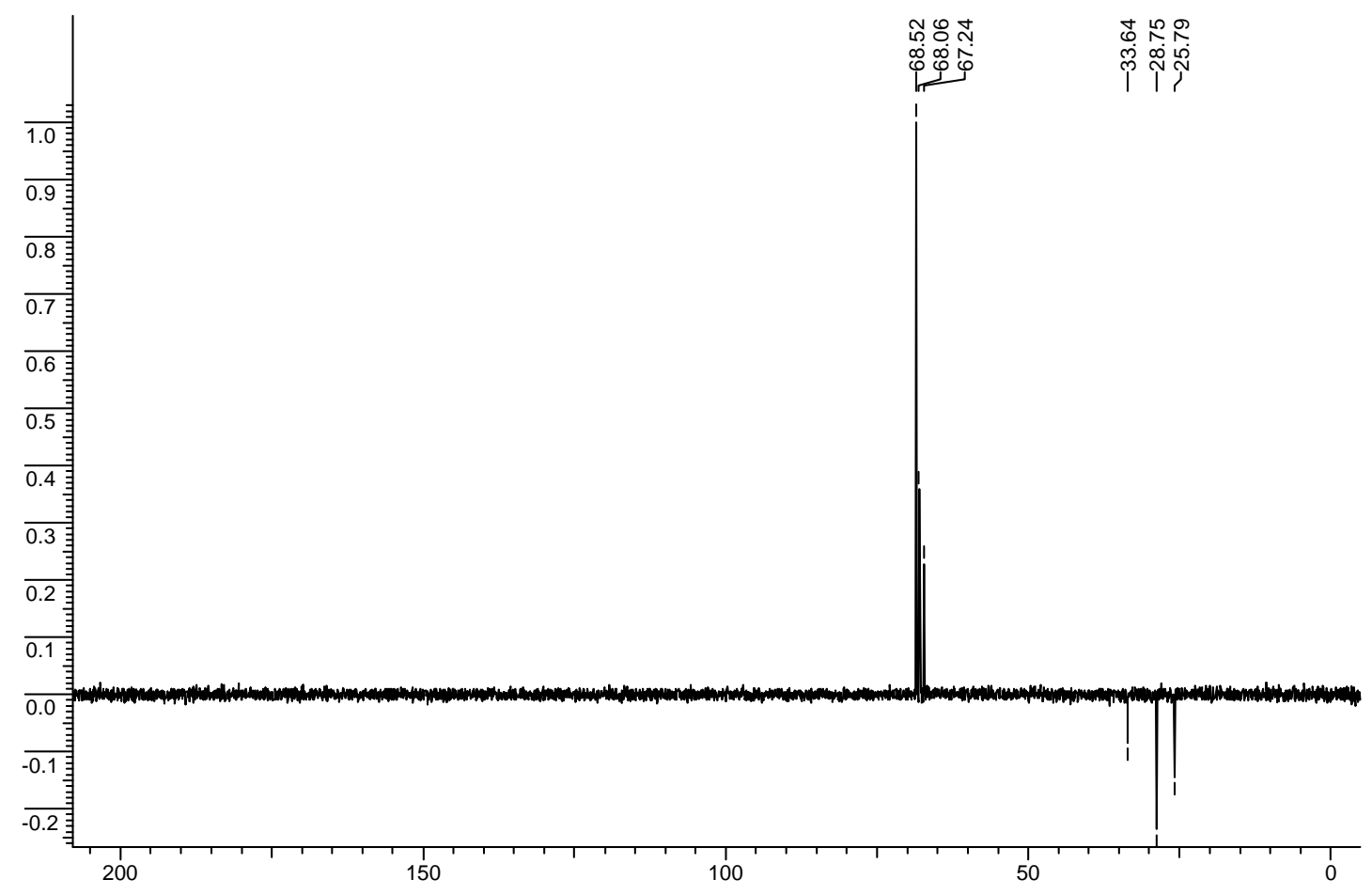

DEPT of 1-(3-carboxypropyl)ferrocene (9) 

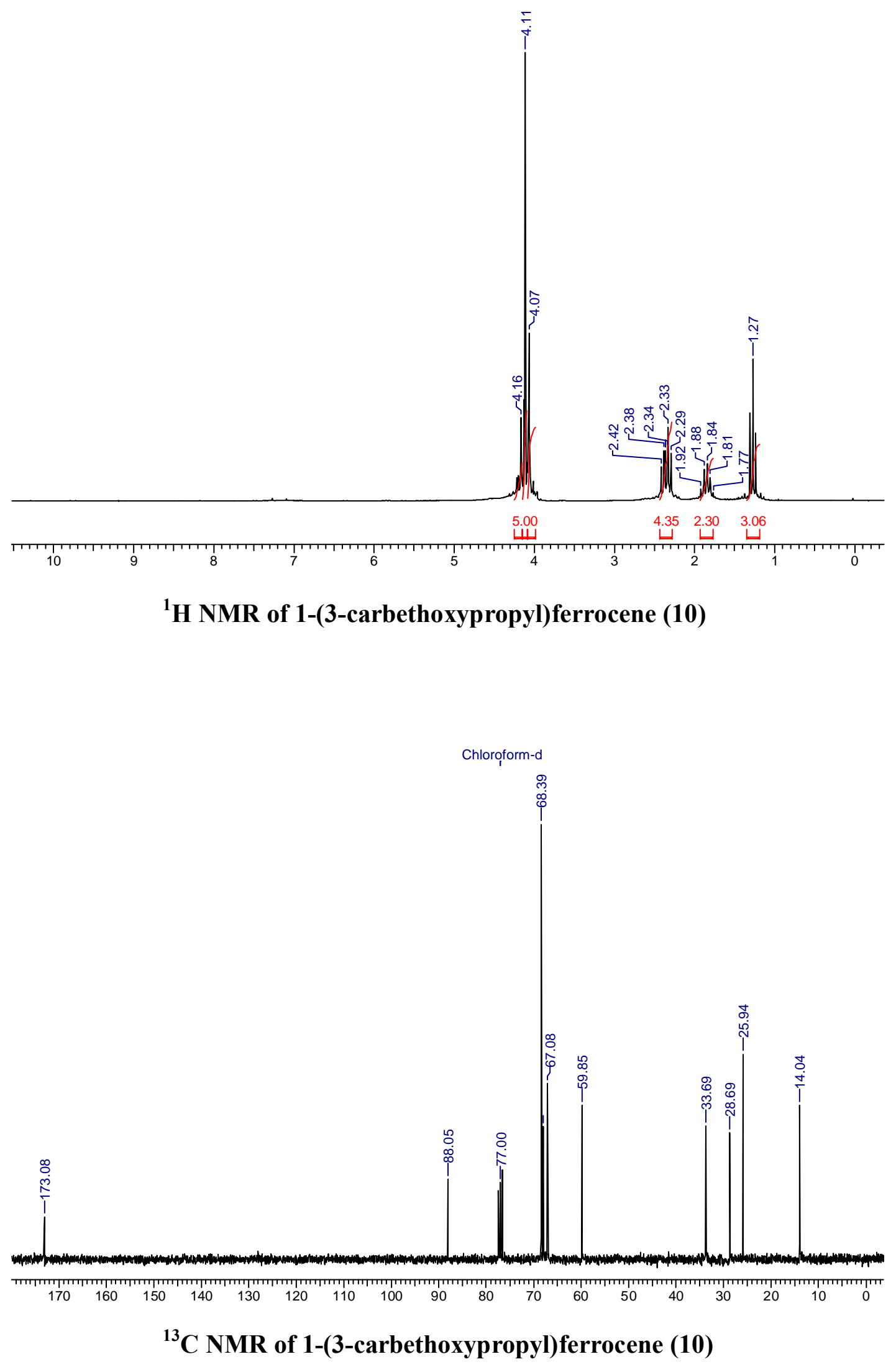


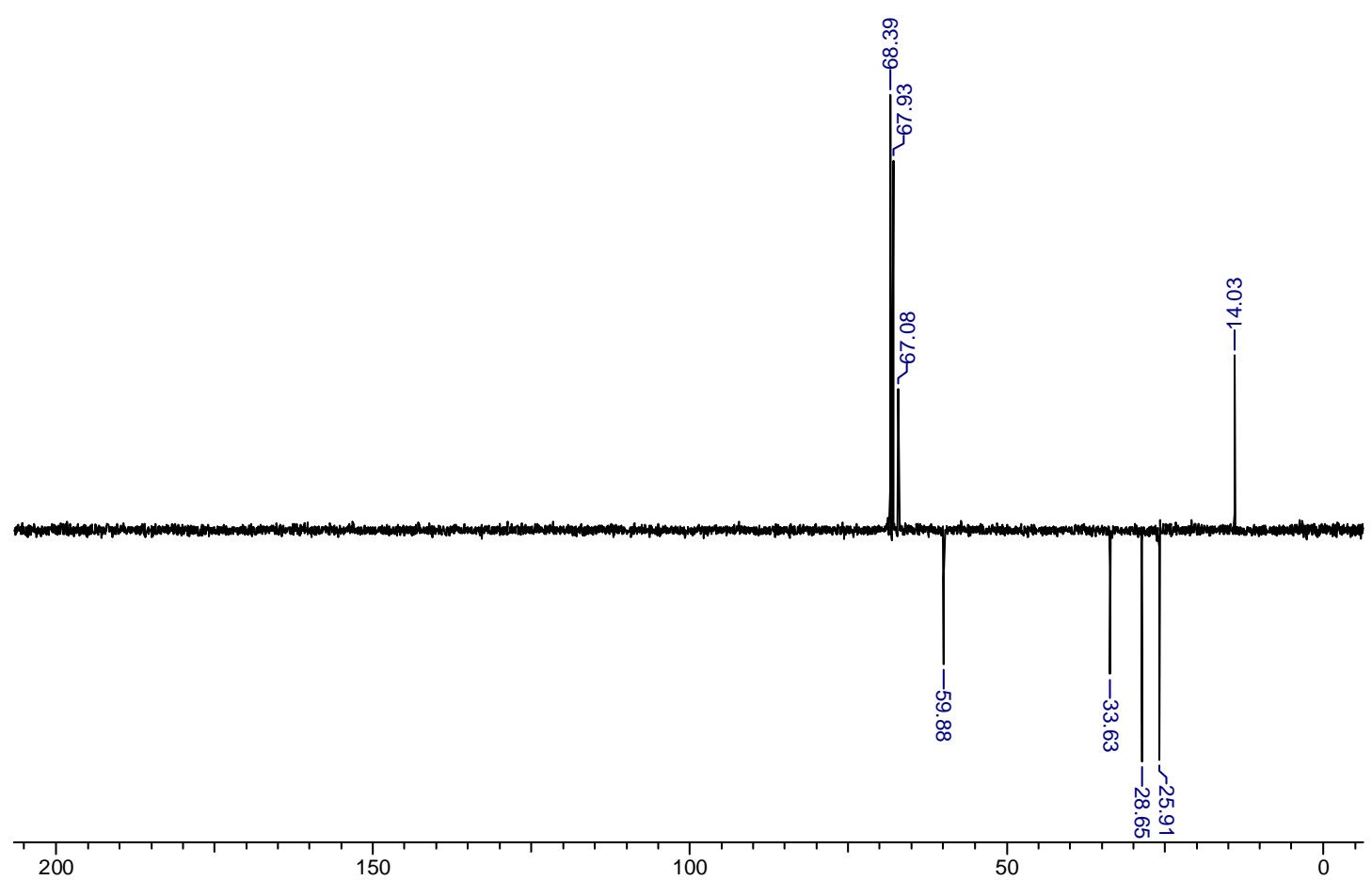

DEPT of 1-(3-carbethoxypropyl)ferrocene (10) 

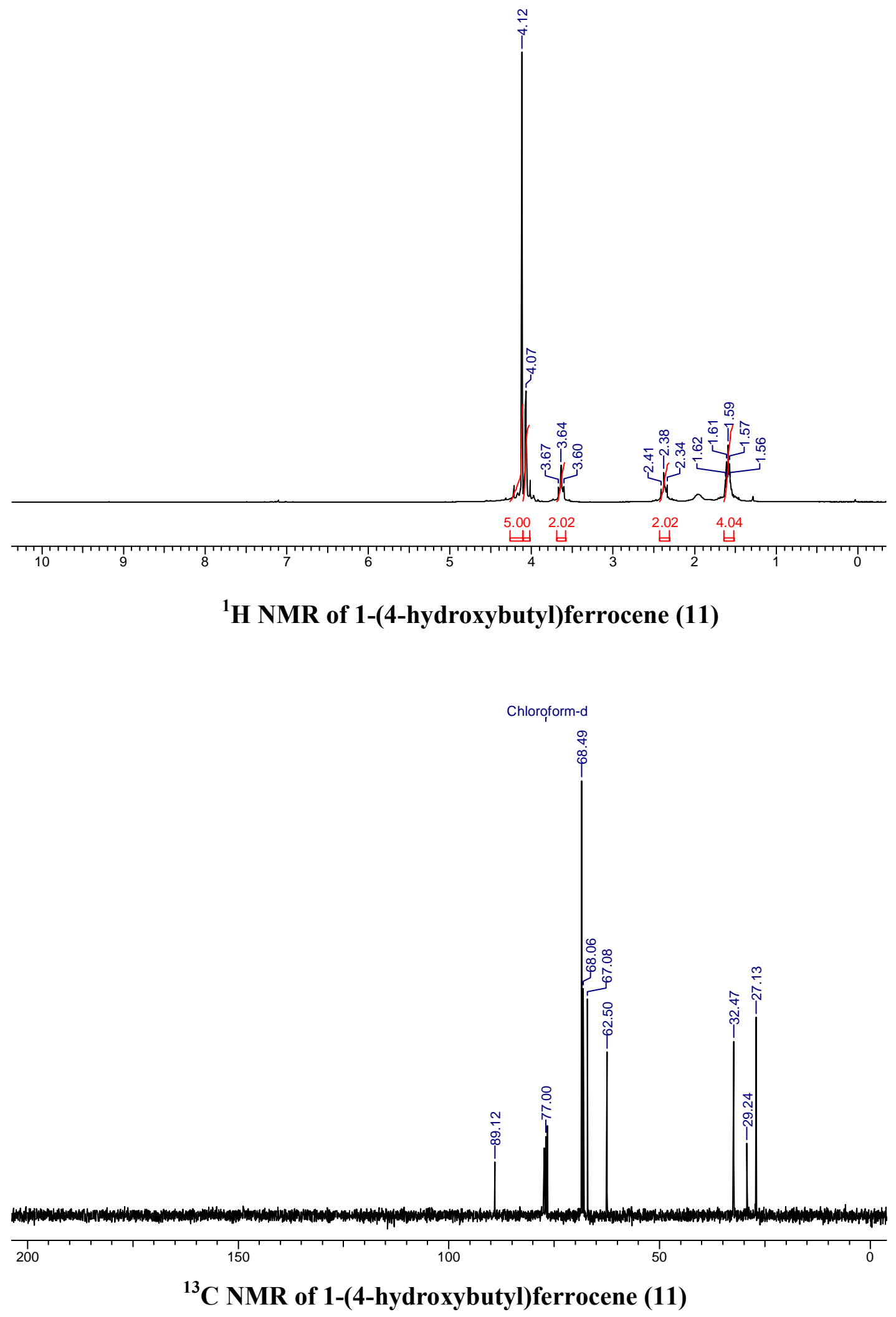


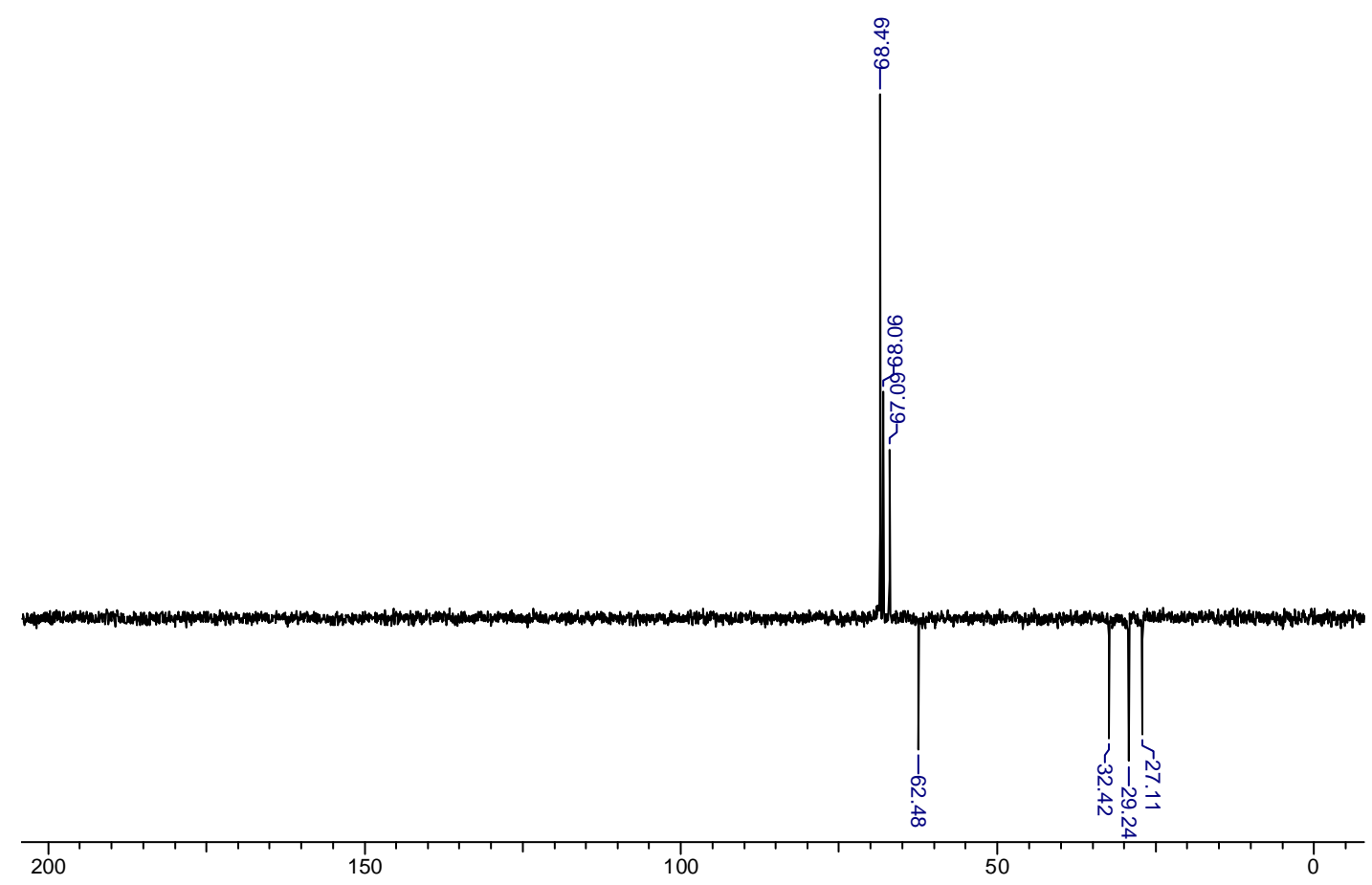

DEPT of 1-(4-hydroxybutyl)ferrocene (11) 

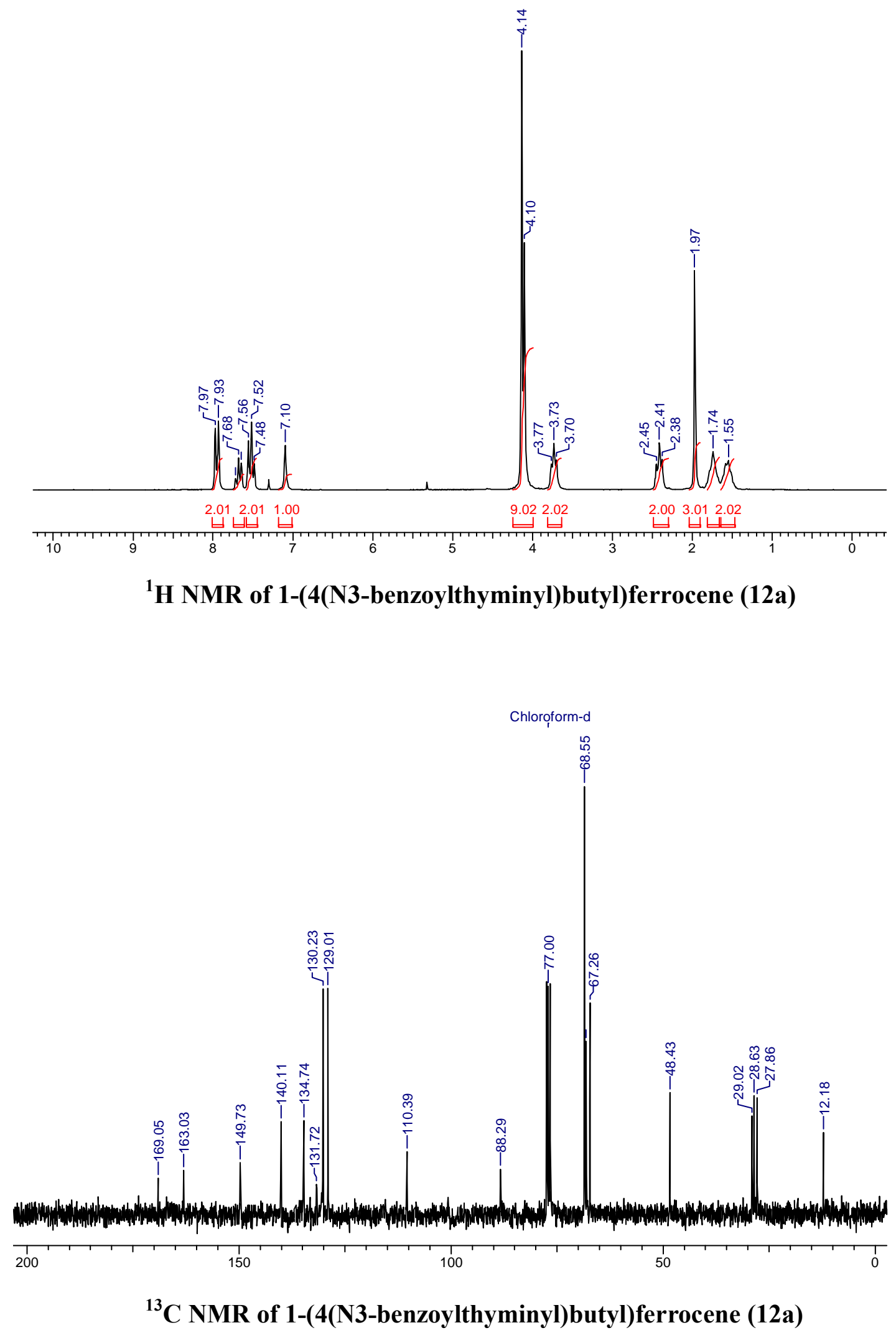


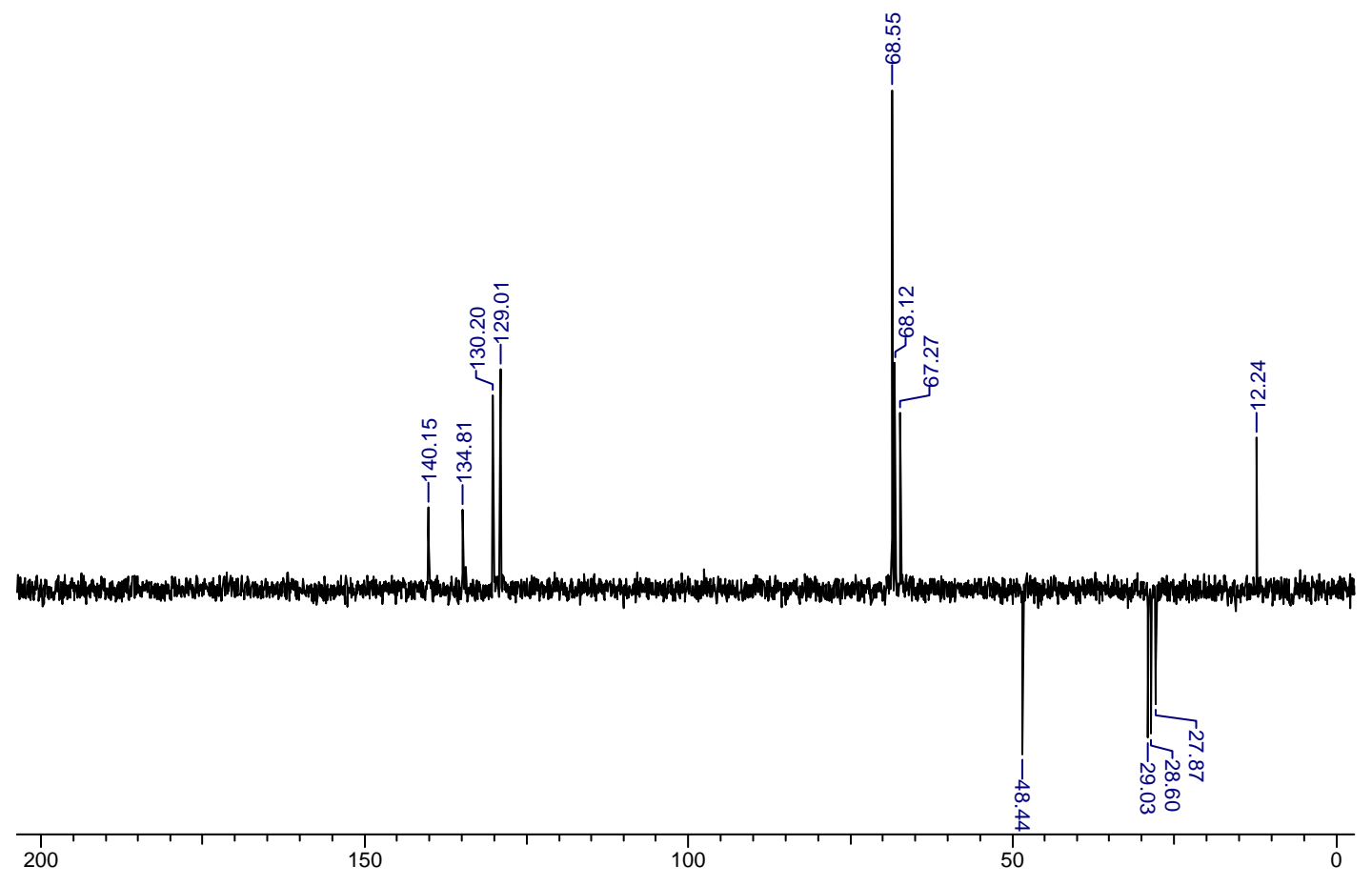

DEPT of 1-(4(N3-benzoylthyminyl)butyl)ferrocene (12a) 

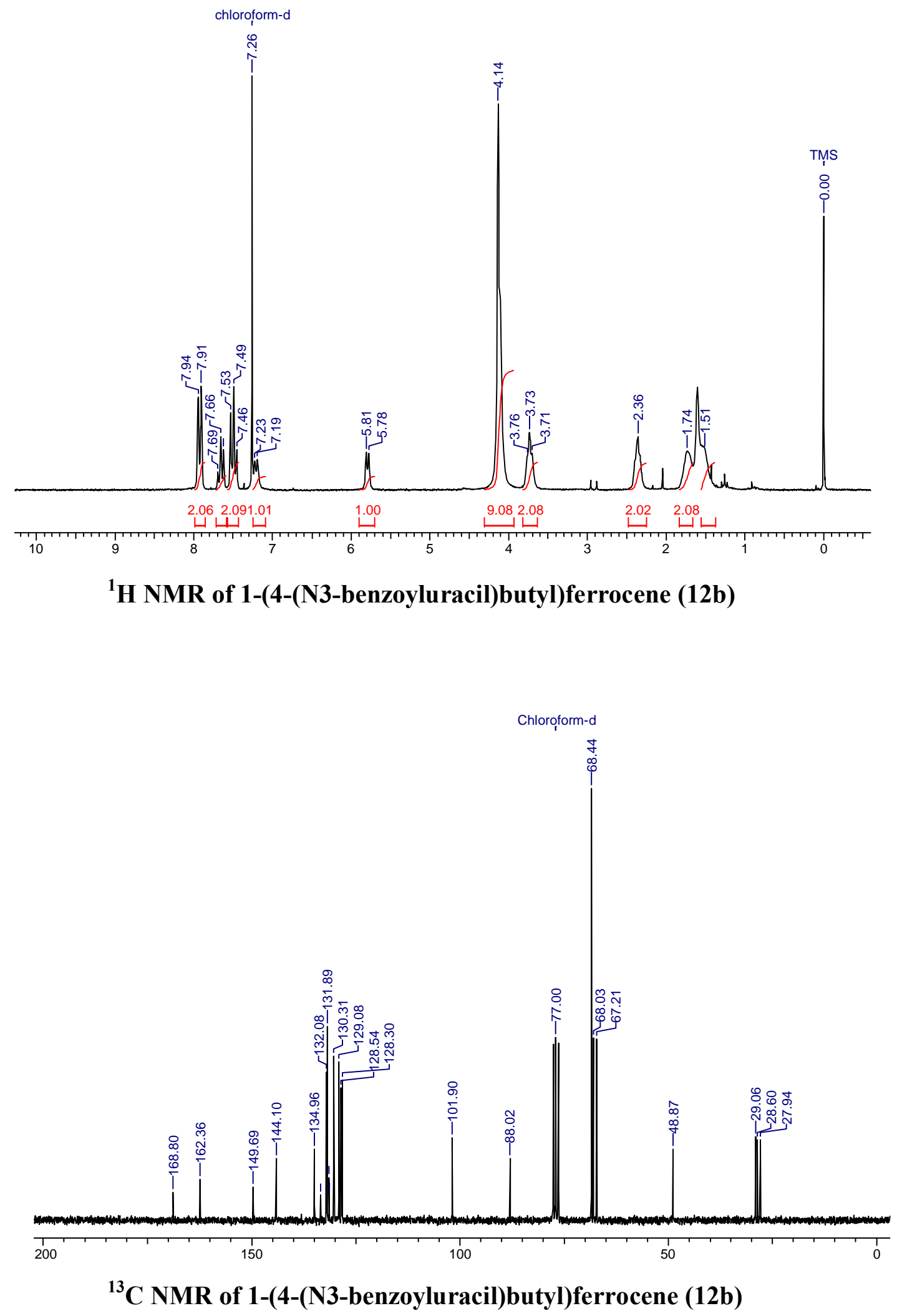


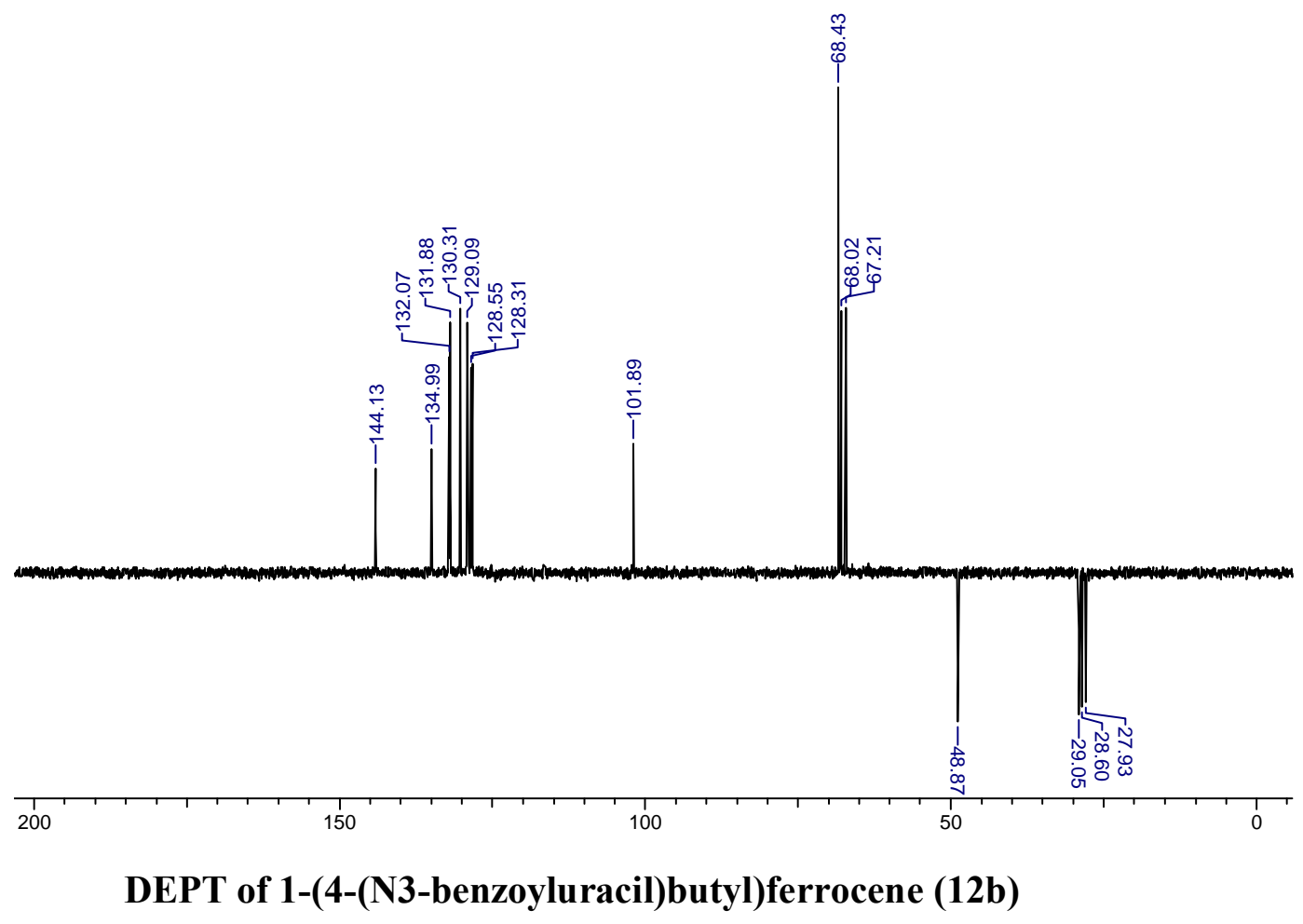




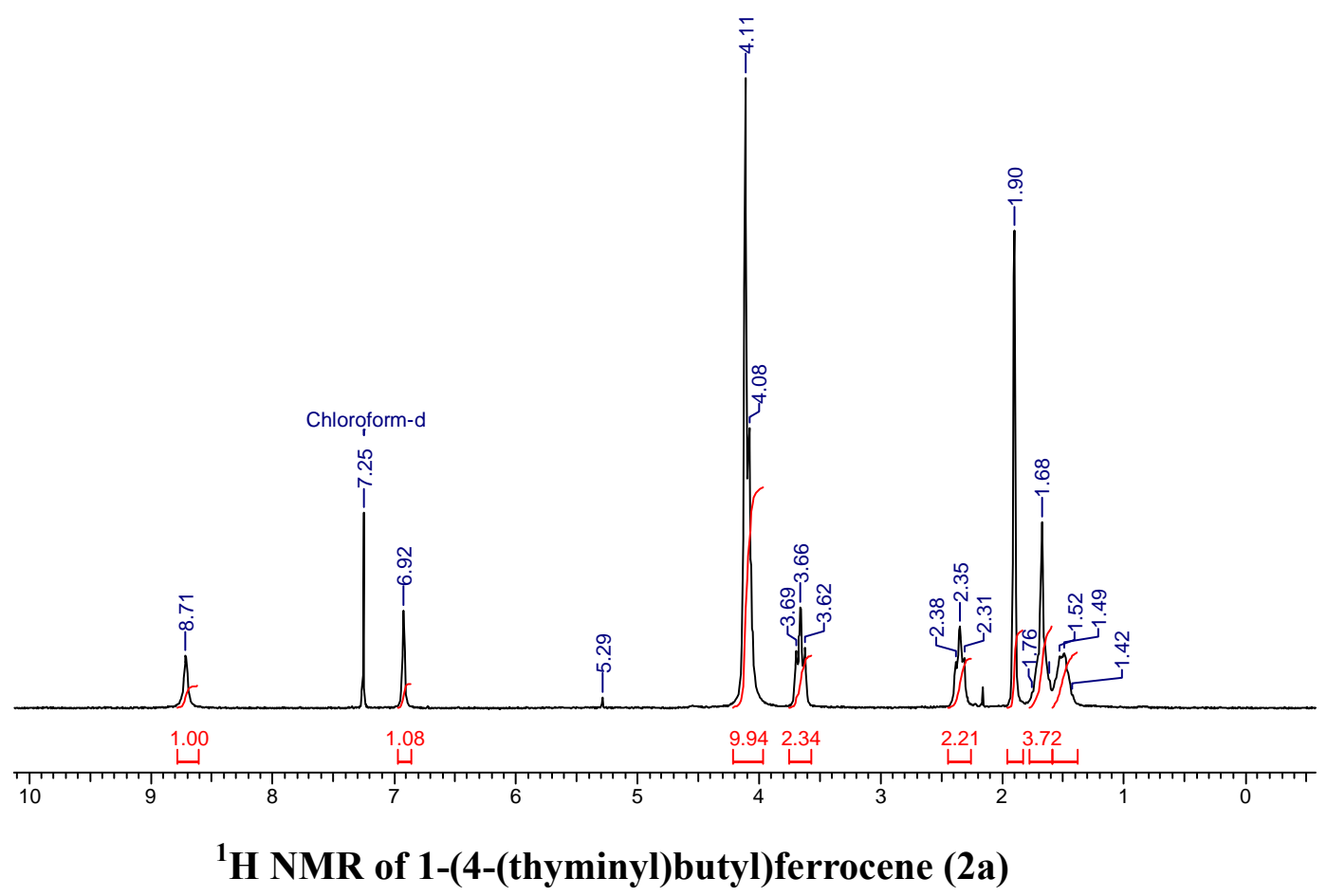



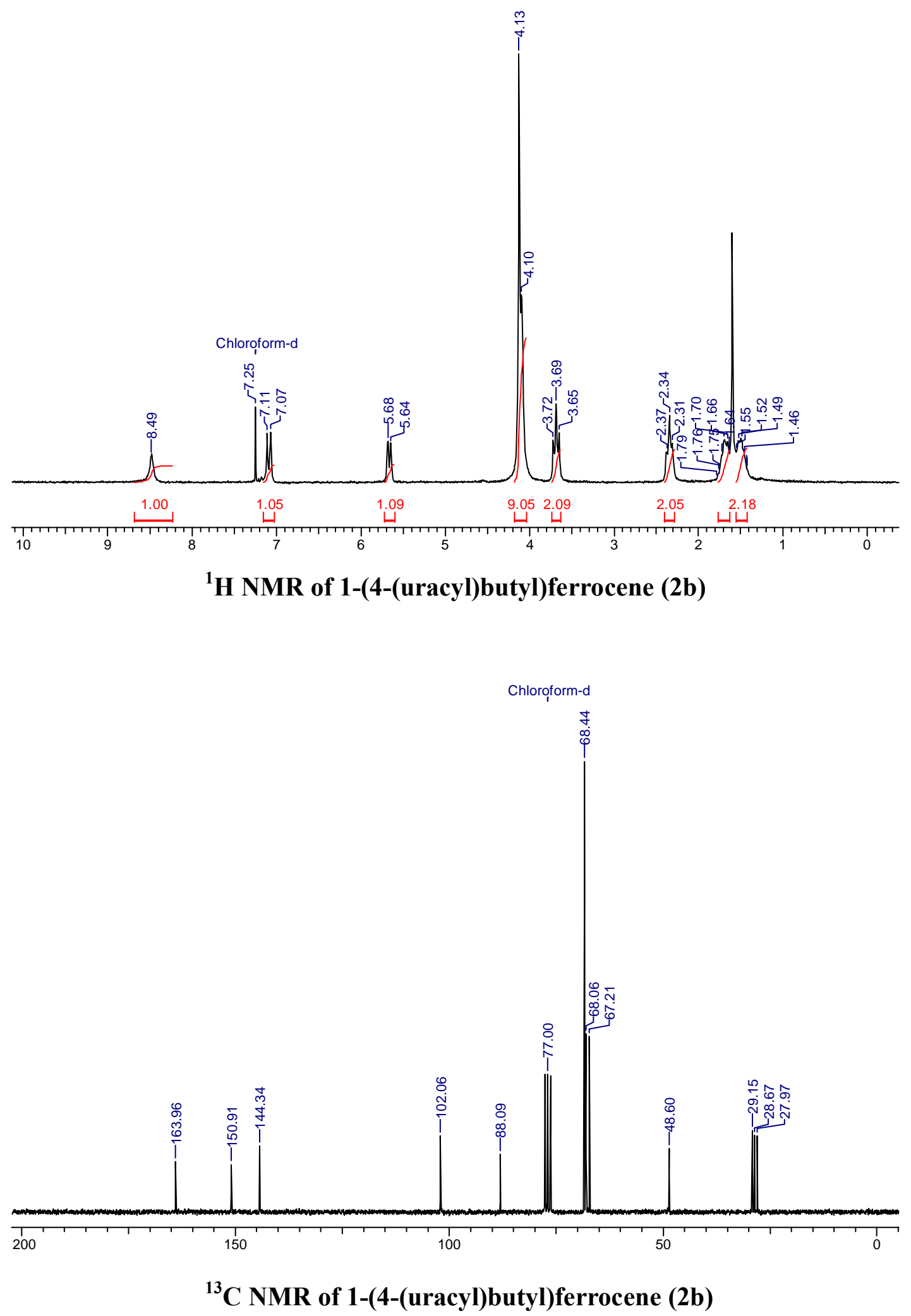


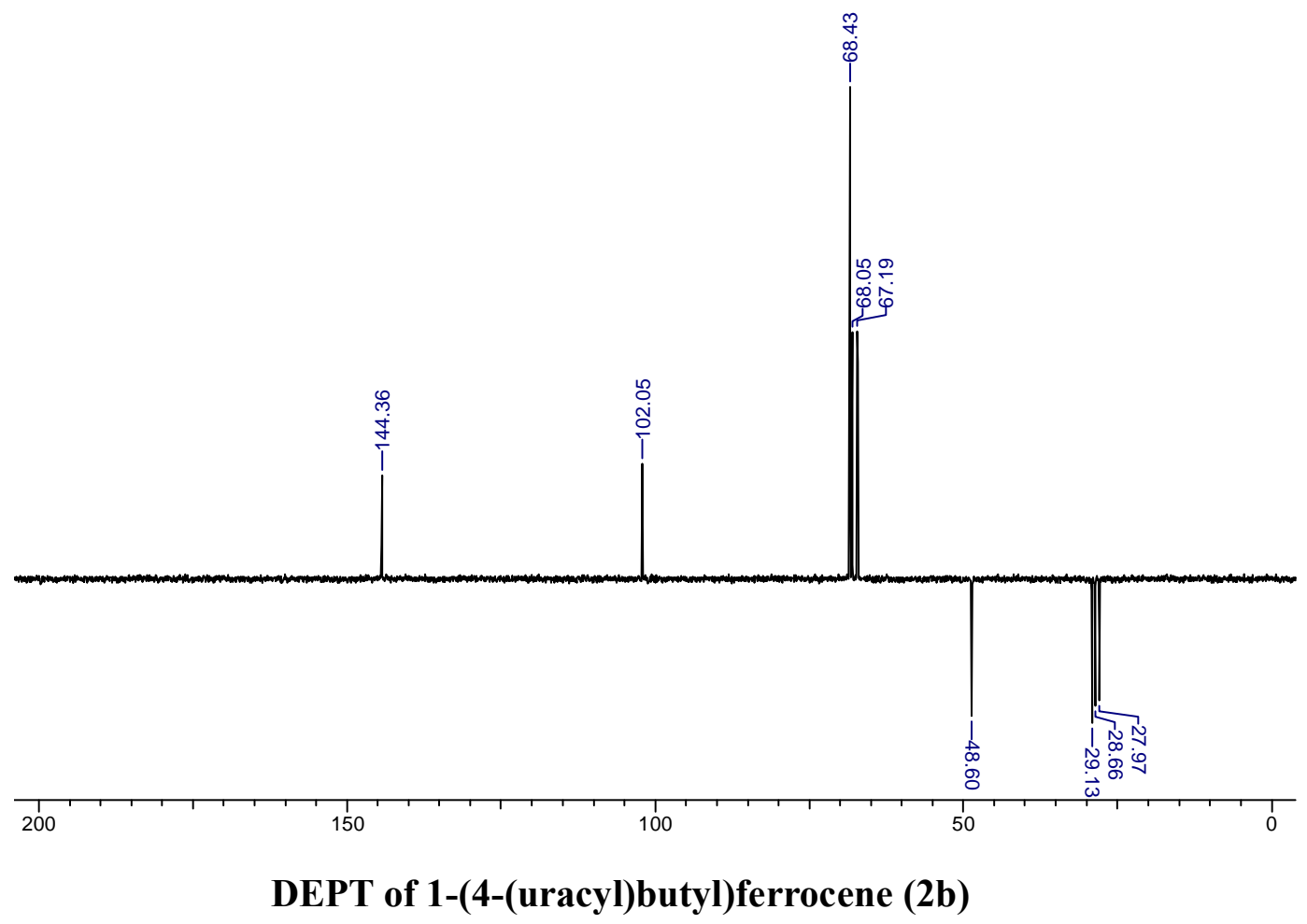




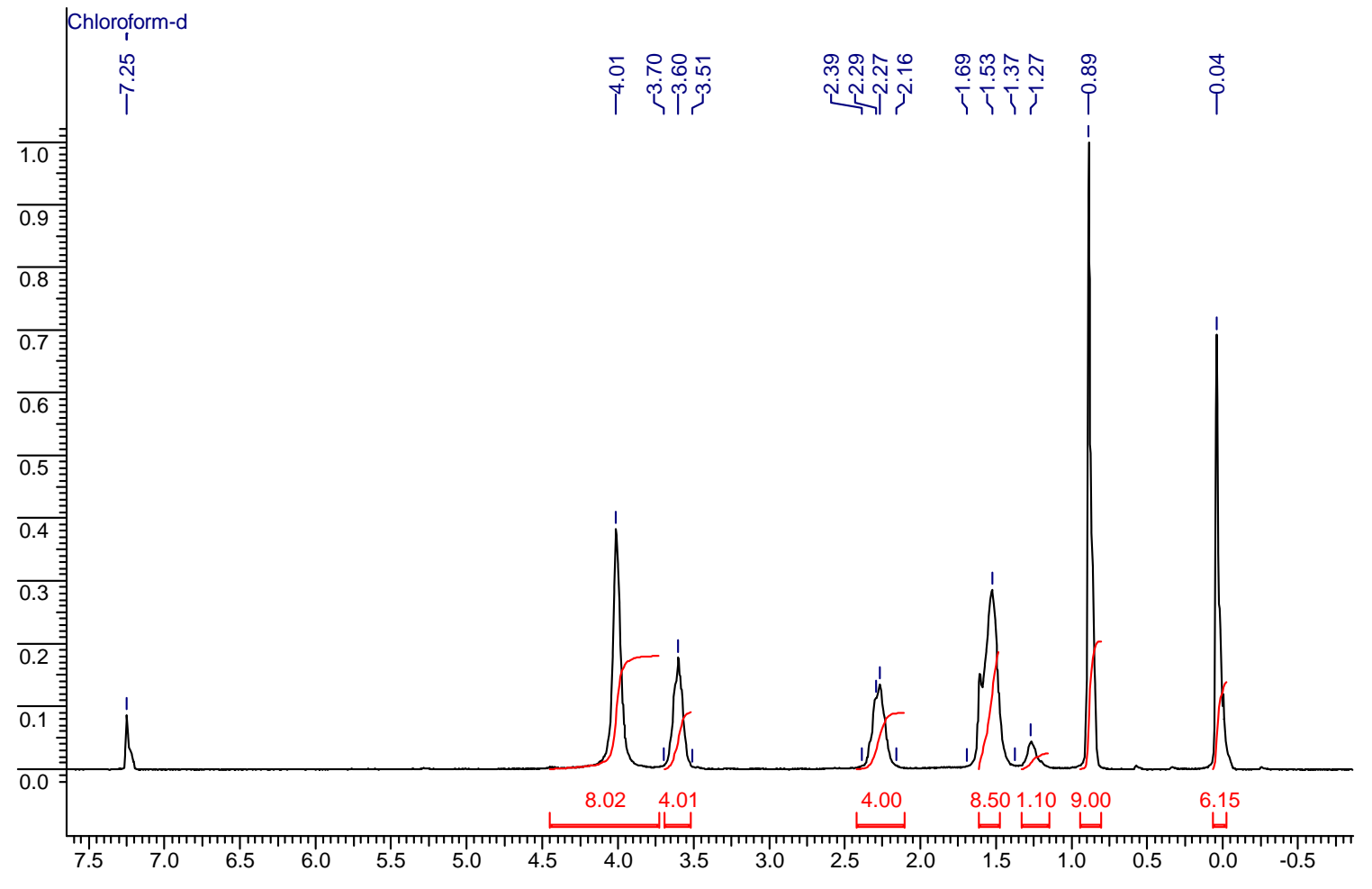

${ }^{1}$ H NMR of 1-(4-Hydroxybutyl)-1'-(4-(tert-butyldimethylsilyloxy)butyl)ferrocene (13)

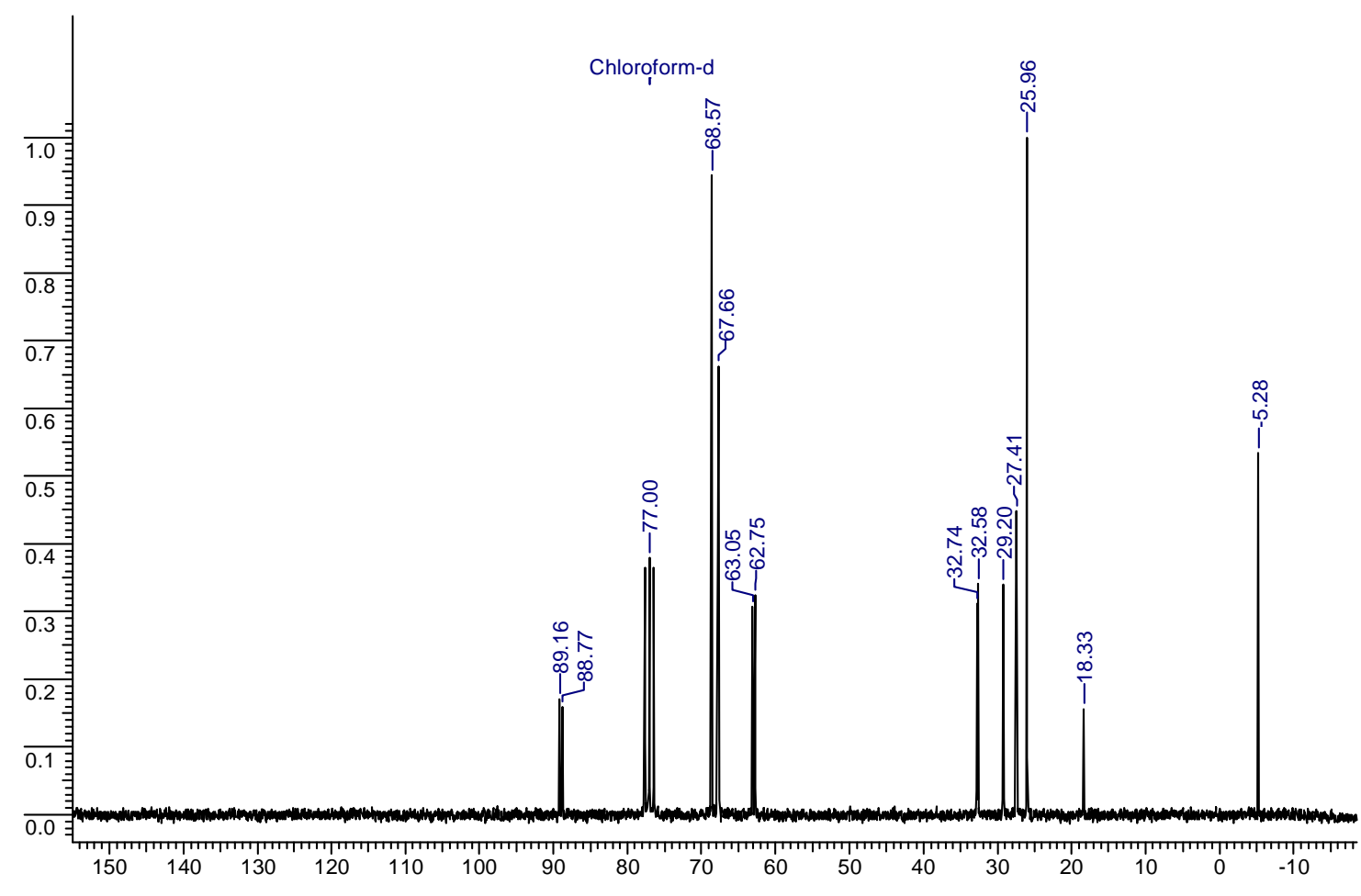

${ }^{13}$ C NMR of 1-(4-Hydroxybutyl)-1'-(4-(tert-butyldimethylsilyloxy)butyl)ferrocene (13) 


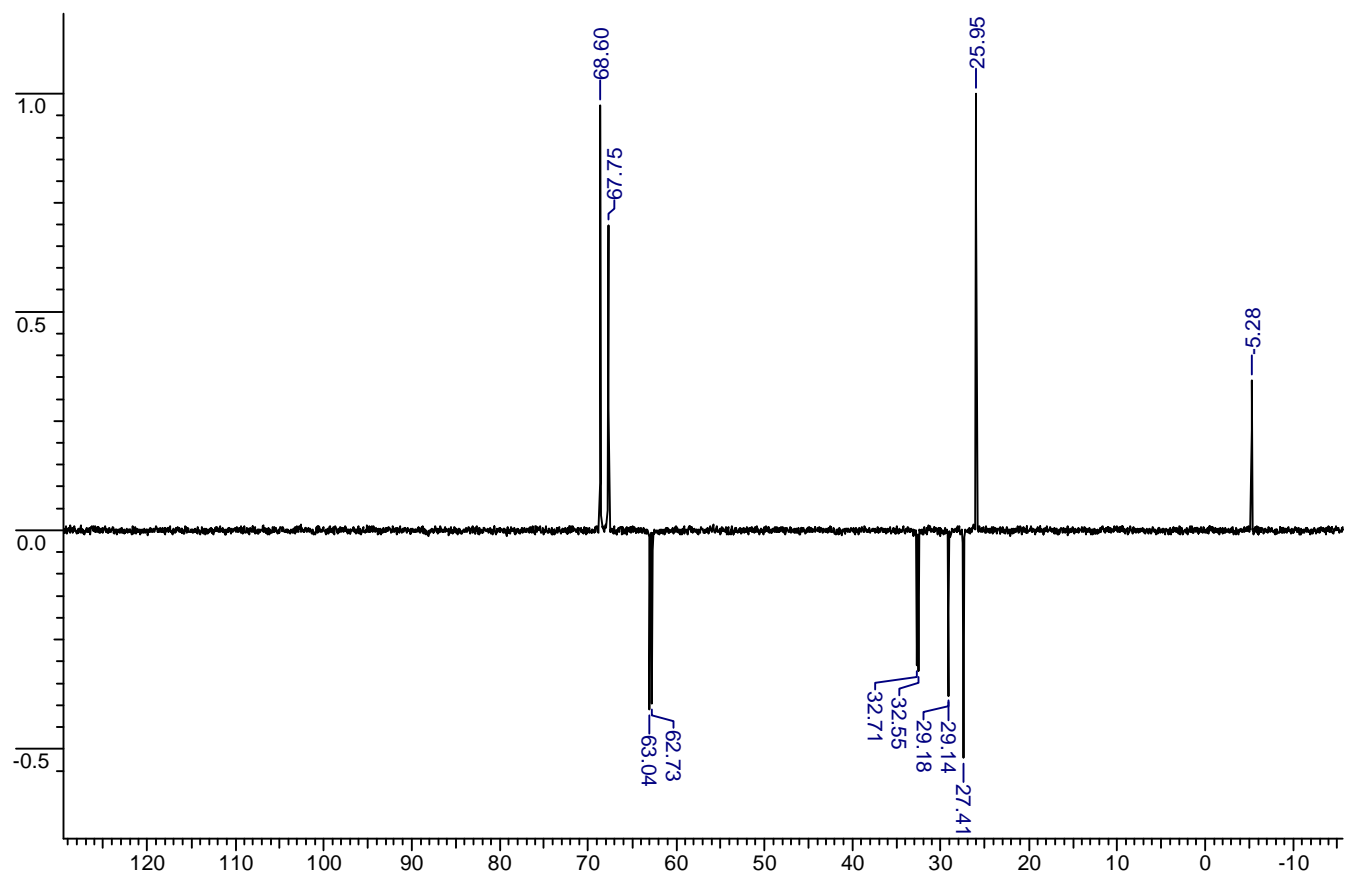

DEPT of 1-(4-Hydroxybutyl)-1'-(4-(tert-butyldimethylsilyloxy)butyl)ferrocene (13) 


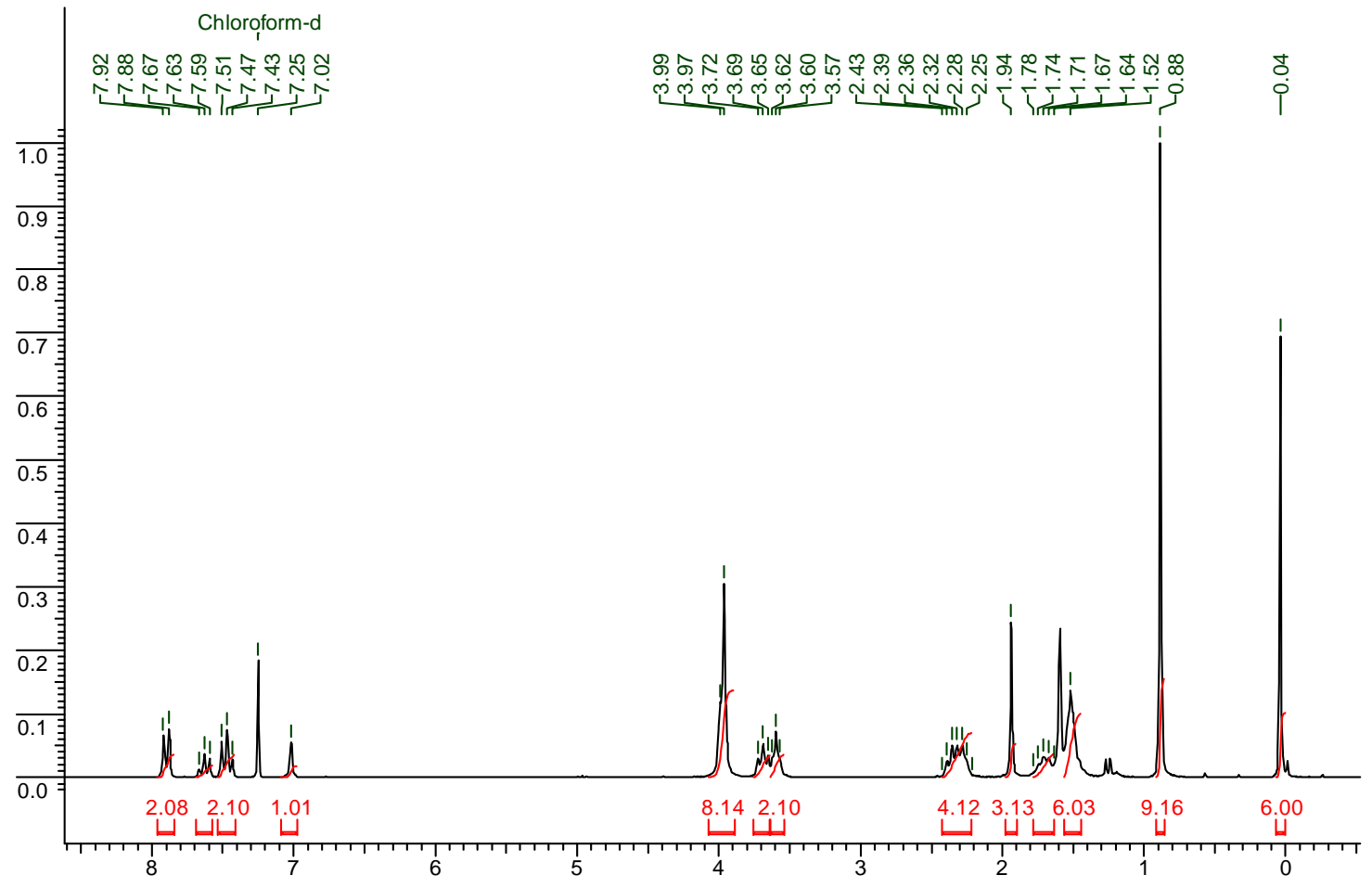

${ }^{1}$ H NMR of 1-(4-(N3-benzoylthyminyl)butyl)-1'-(4(tert-butyldimethylsilyloxy)butyl)ferrocene (14)

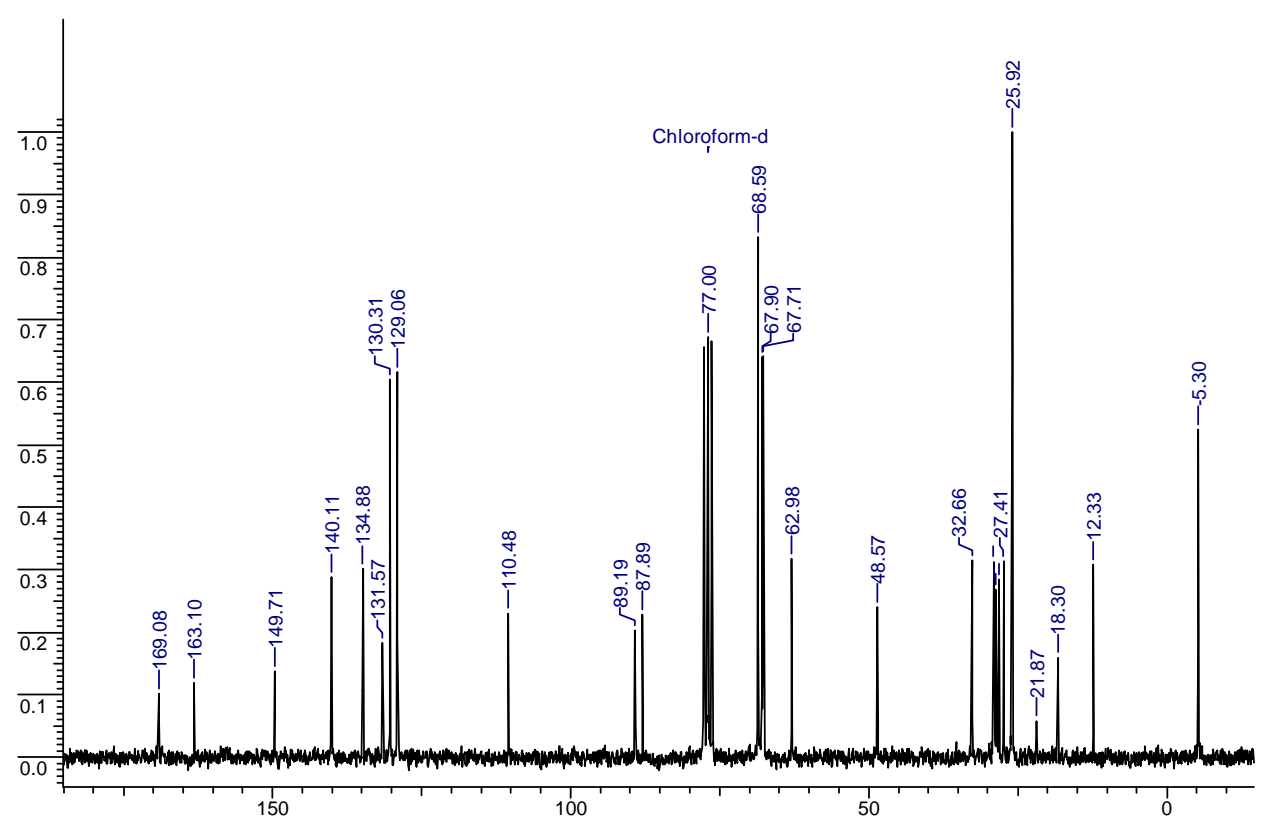

${ }^{13}$ C NMR of 1-(4-(N3-benzoylthyminyl)butyl)-1'-(4(tert-butyldimethylsilyloxy)butyl)ferrocene (14) 


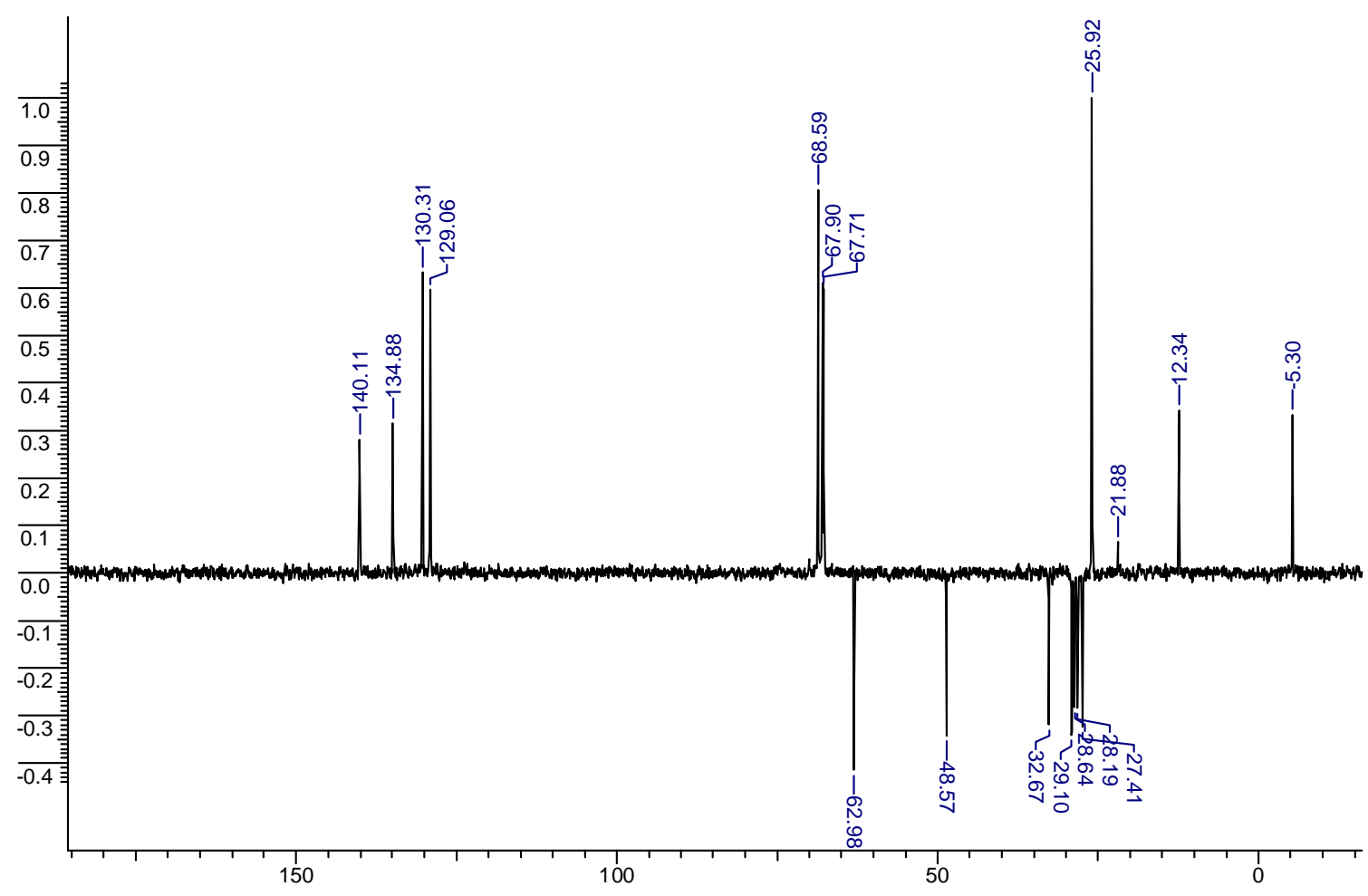

DEPT of 1-(4-(N3-benzoylthyminyl)butyl)-1'-(4-

(tert-butyldimethylsilyloxy)butyl)ferrocene (14) 


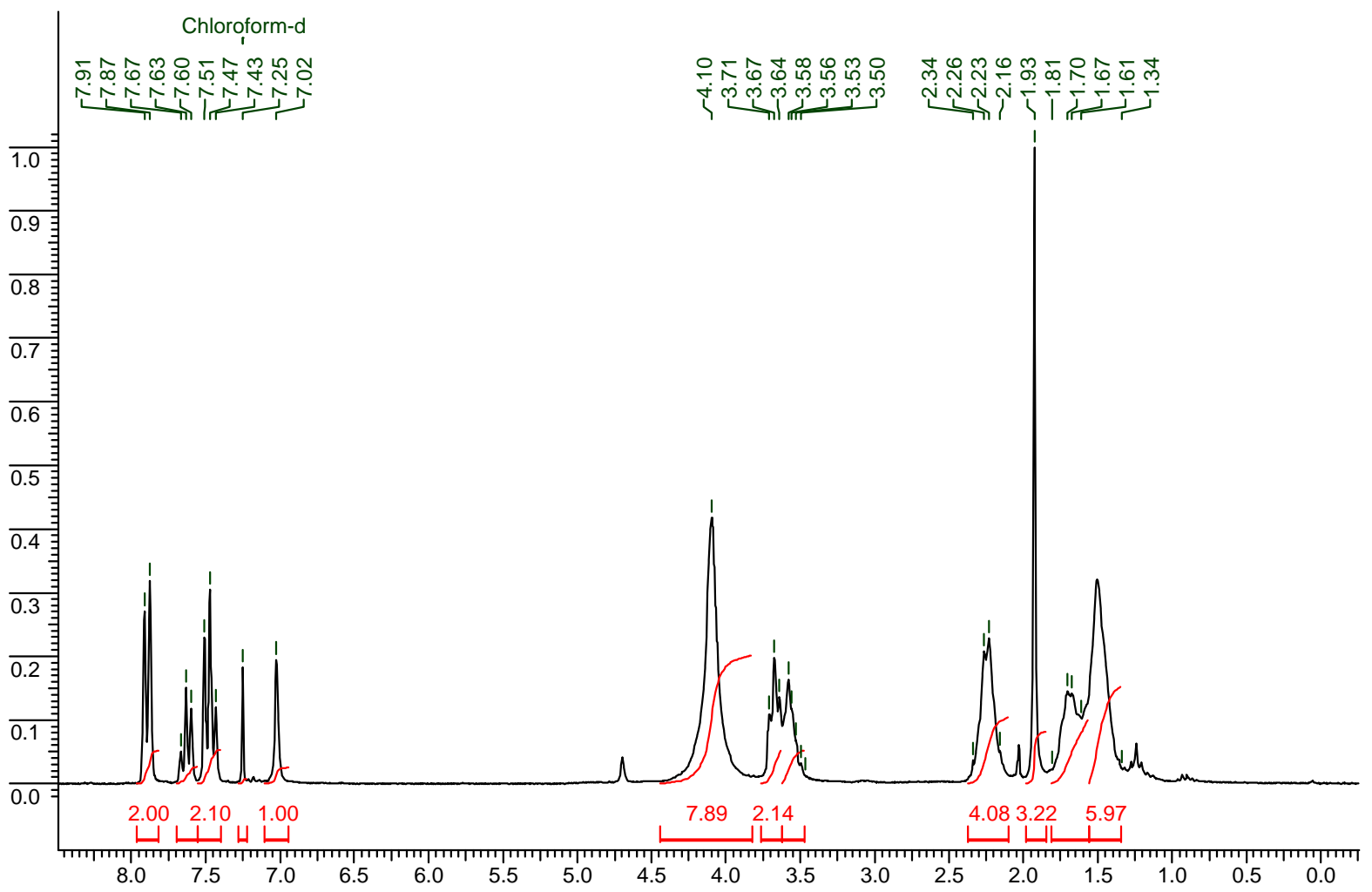

${ }^{1}$ H NMR of 1-(4-(N3-benzoylthyminyl)butyl)-1'-(4-hydroxybutyl)ferrocene (15)

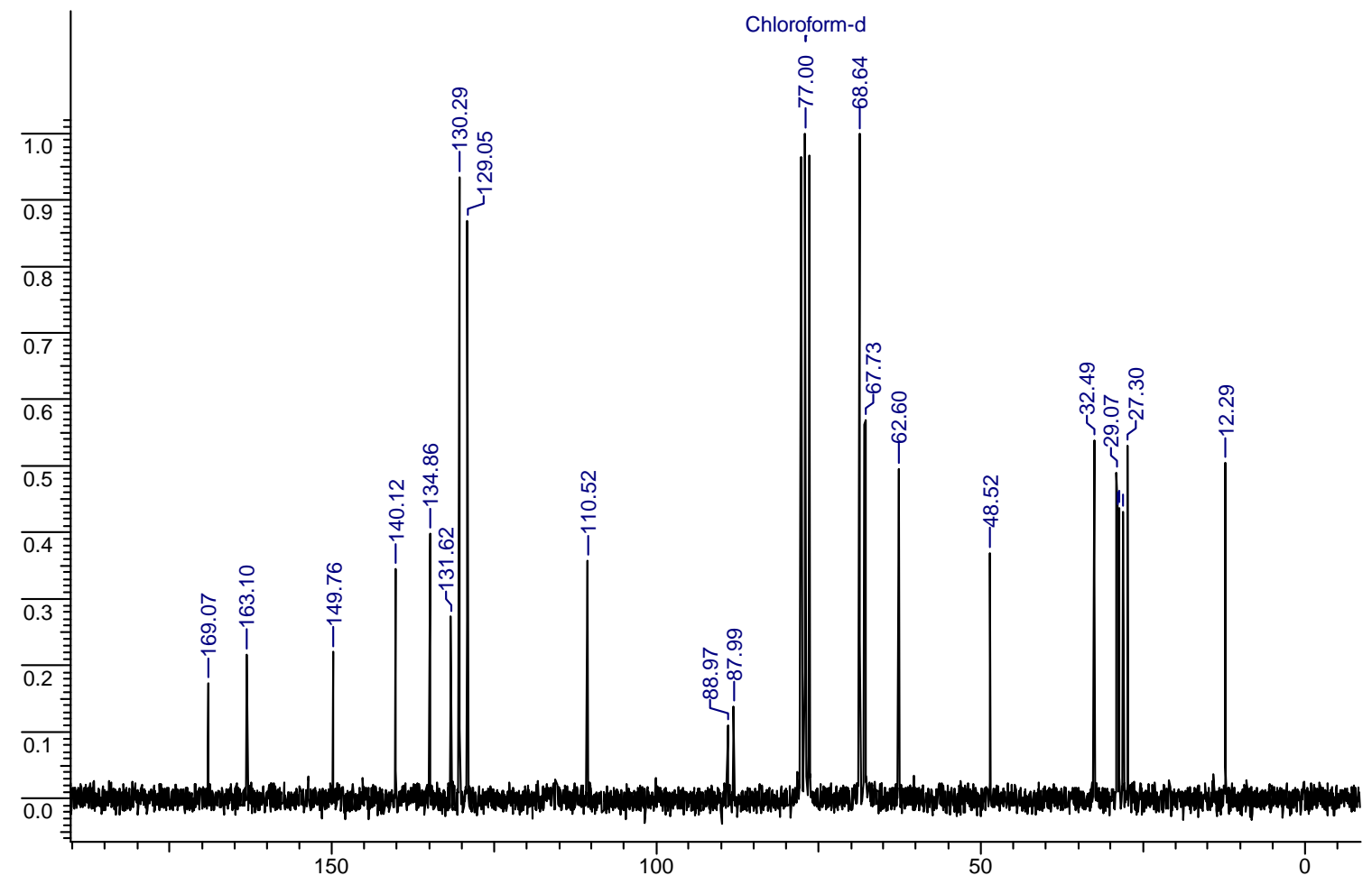

${ }^{13}$ C NMR of 1-(4-(N3-benzoylthyminyl)butyl)-1'-(4-hydroxybutyl)ferrocene (15) 


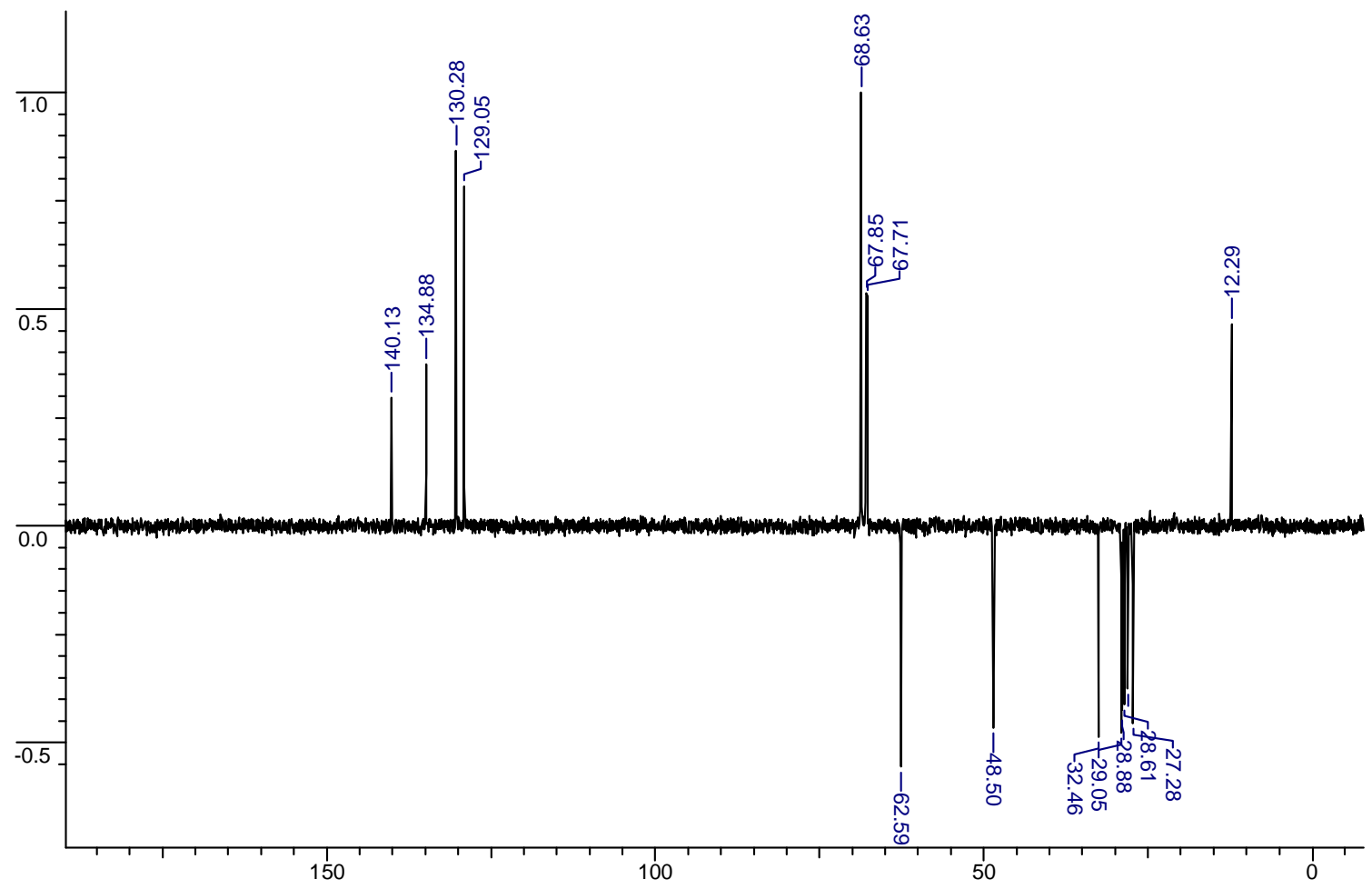

DEPT of 1-(4-(N3-benzoylthyminyl)butyl)-1'-(4-hydroxybutyl)ferrocene (15) 


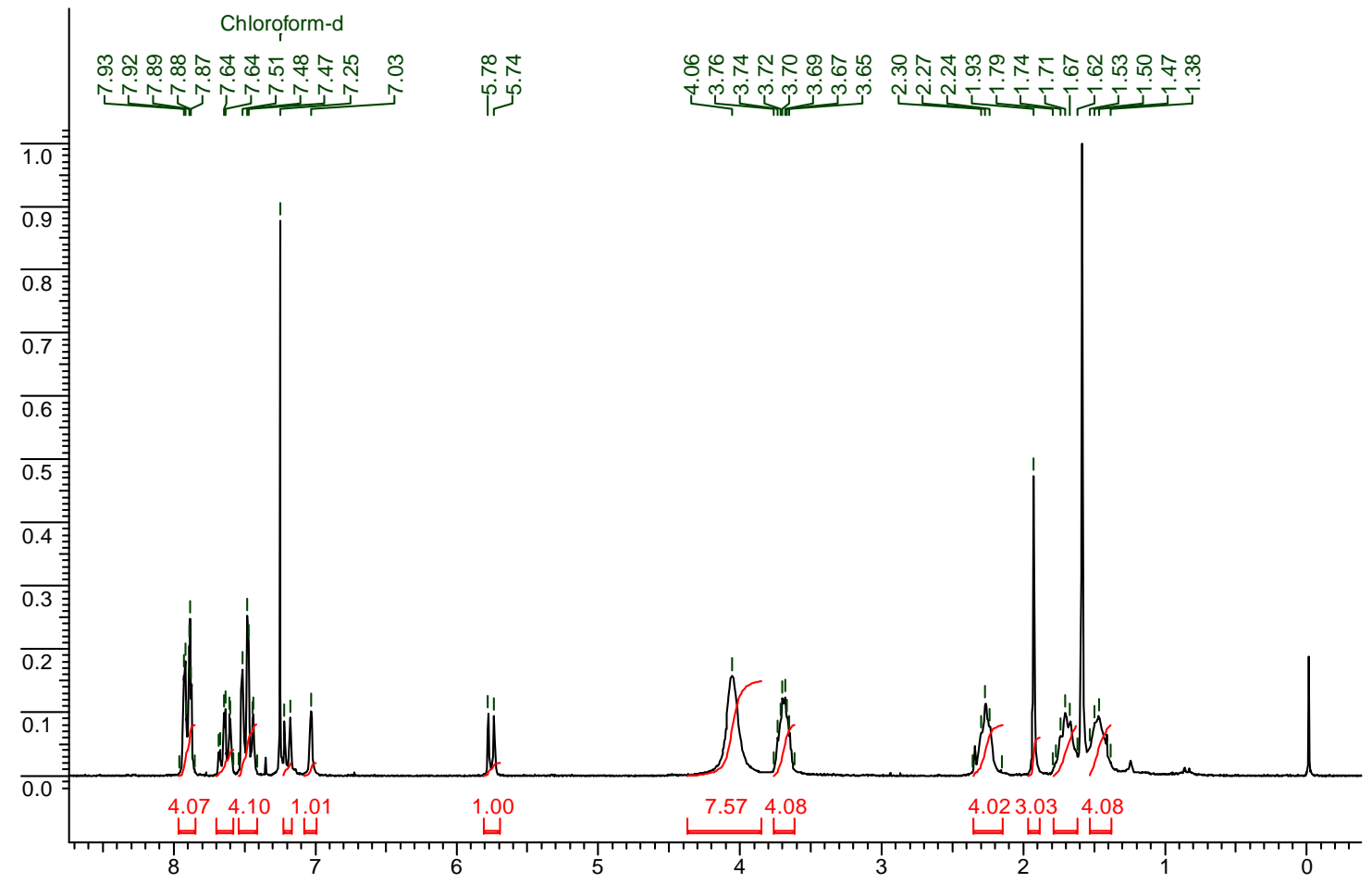

${ }^{1}$ H NMR of 1-(4-(N3-benzoylthyminyl)butyl)-1'-(4-(N3-benzoyluracyl)butyl)ferrocene (16)

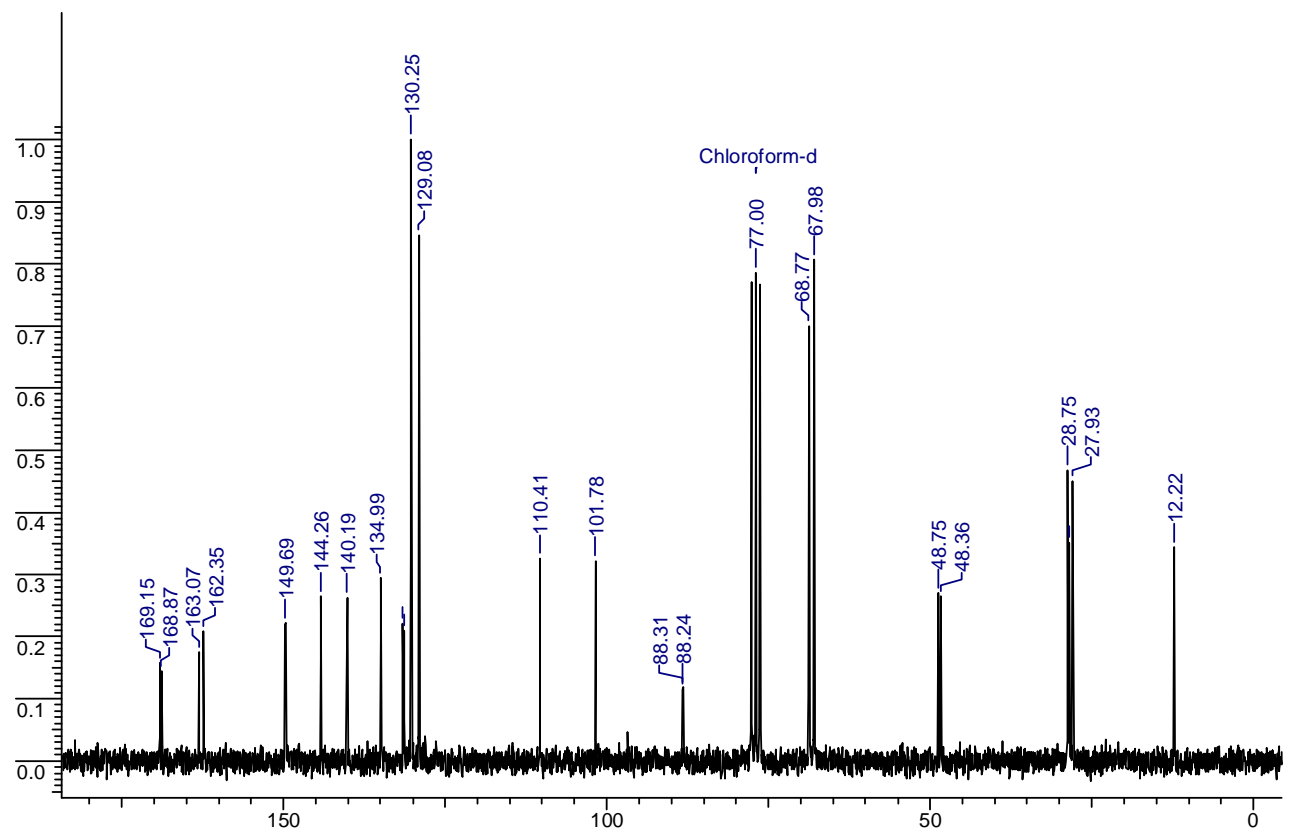

${ }^{13}$ C NMR of 1-(4-(N3-benzoylthyminyl)butyl)-1'-(4-(N3-benzoyluracyl)butyl)ferrocene (16) 


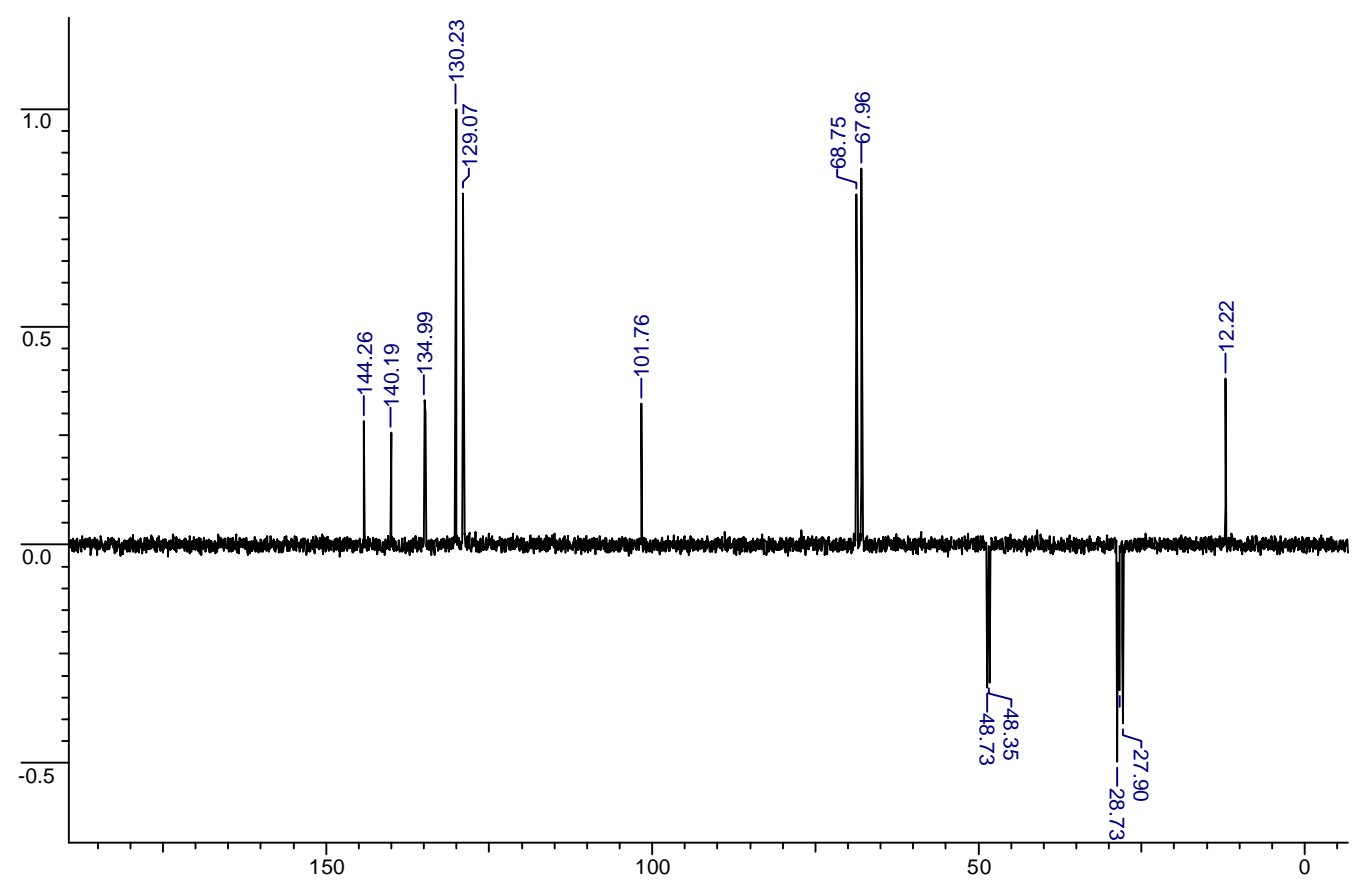

DEPT of 1-(4-(N3-benzoylthyminyl)butyl)-1'-(4-(N3-benzoyluracyl) butyl)ferrocene (16) 


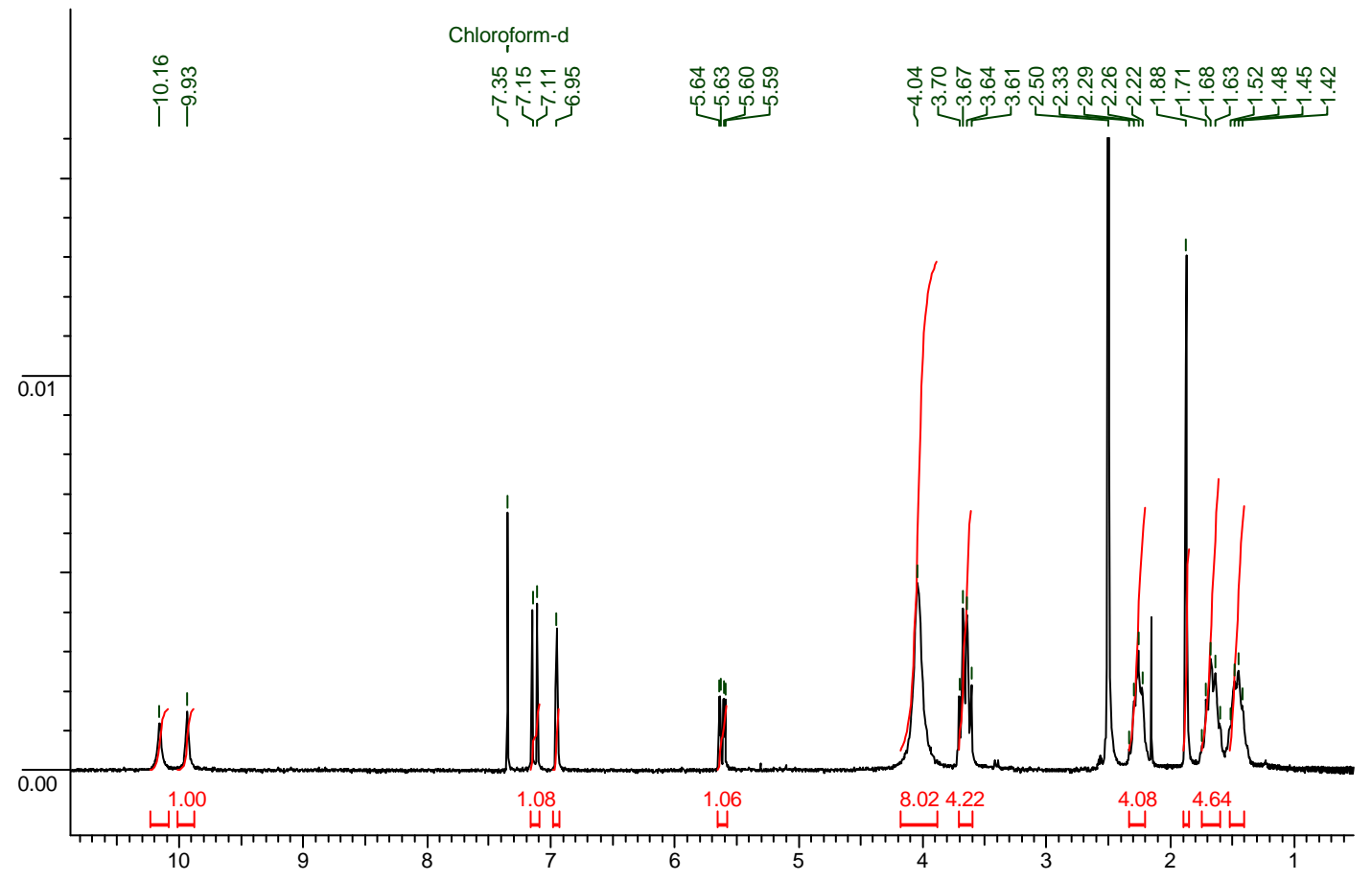

${ }^{1}$ H NMR of 1-(4-(Thyminyl)butyl)-1'-(4-( uracyl)butyl)ferrocene (1d)

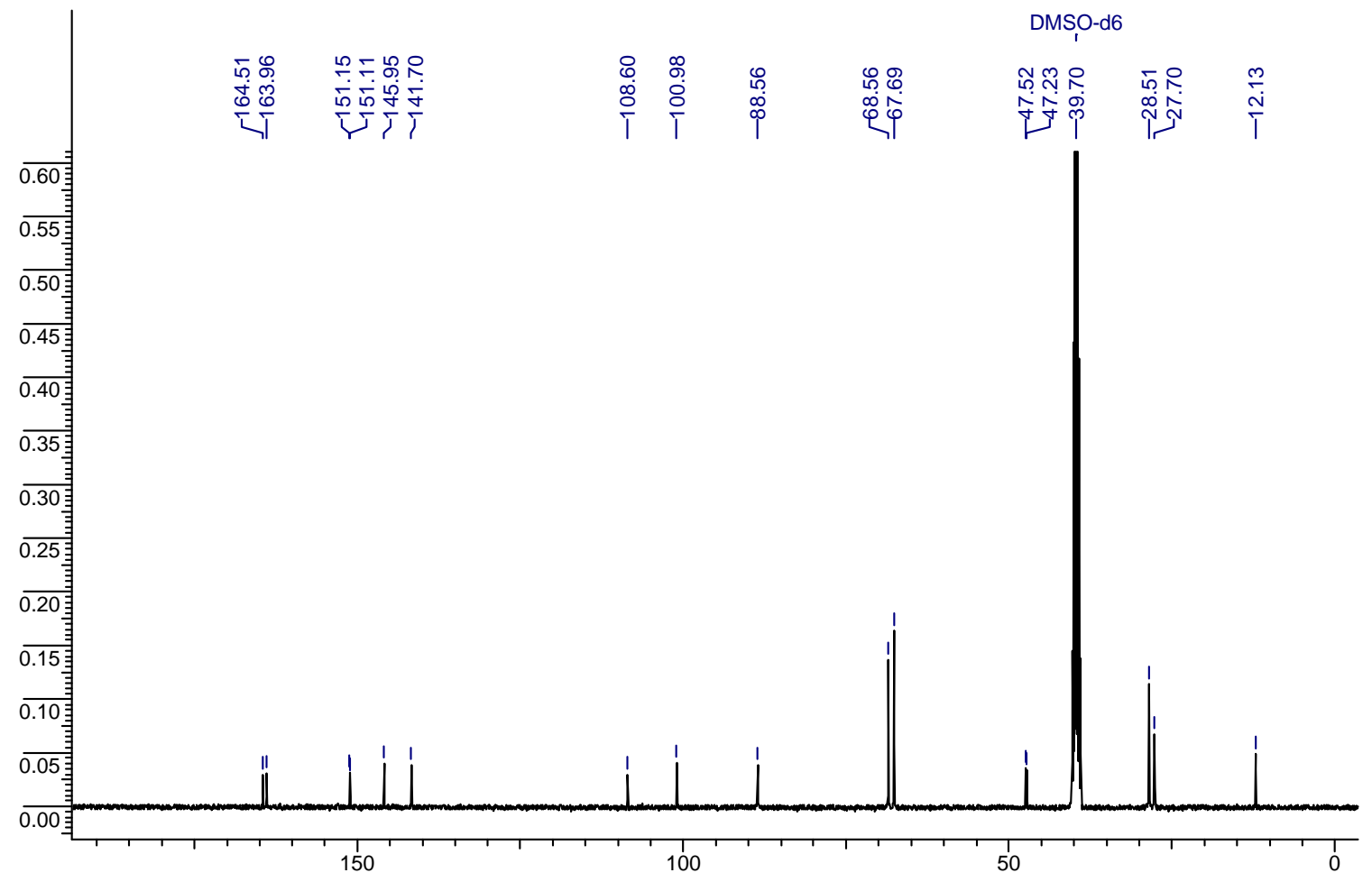

${ }^{13}$ C NMR of 1-(4-(Thyminyl)butyl)-1'-(4-( uracyl)butyl)ferrocene (1d) 


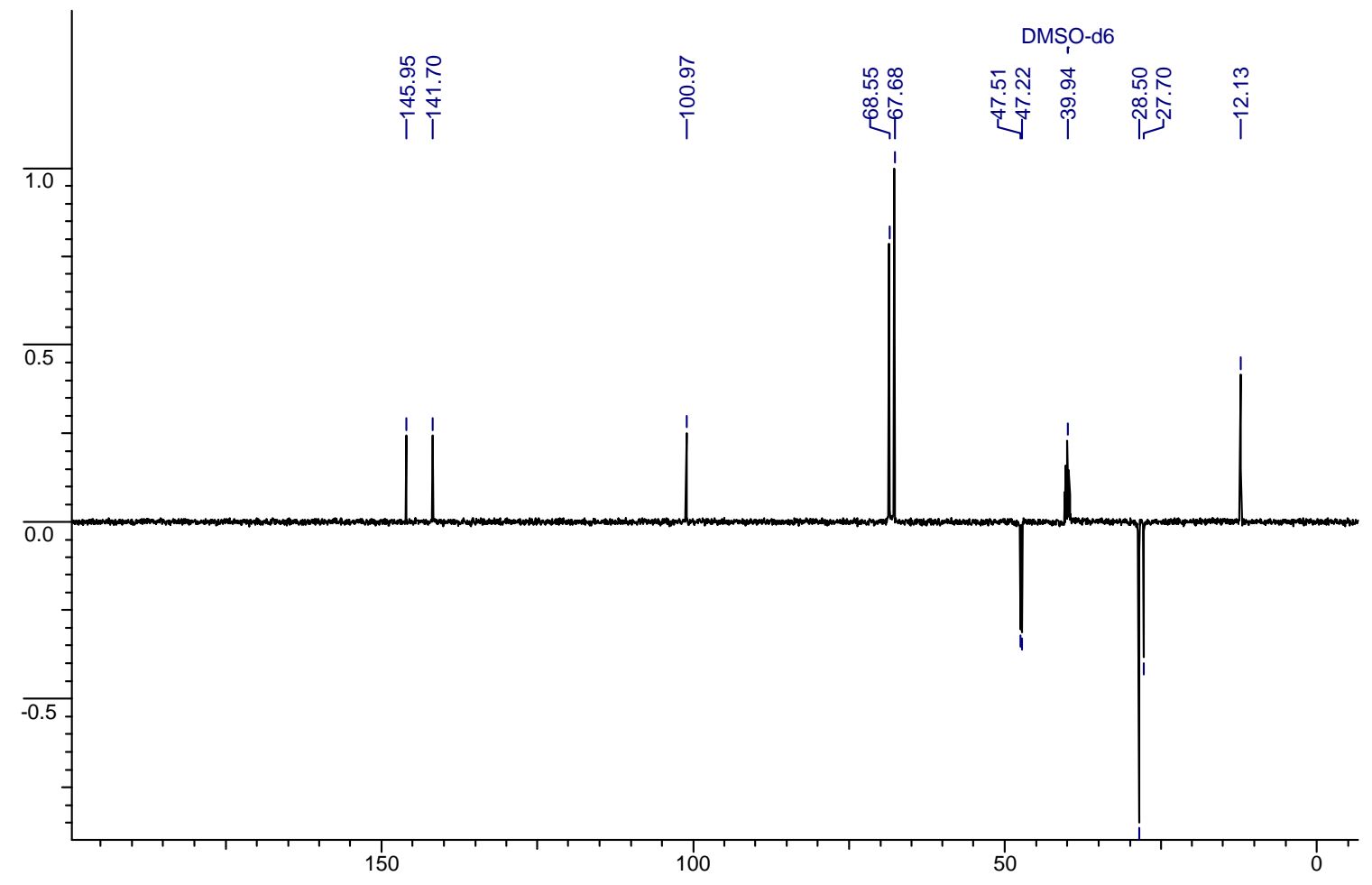

DEPT of 1-(4-(Thyminyl)butyl)-1'-(4-( uracyl)butyl)ferrocene (1d) 


\section{X-ray Crystallography Data}

1a: $\mathrm{C}_{28} \mathrm{H}_{34} \mathrm{FeN}_{4} \mathrm{O}_{4} \mathrm{M}=546.44$, crystal dimensions $0.74 \times 0.13 \times 0.11 \mathrm{~mm}$, Orthorhombic, space group Pccn, $\mathrm{a}=14.074(5), \mathrm{b}=14.676(5), \mathrm{c}=13.252(5) \AA, \mathrm{V}=$ $2737.1(17) \AA^{3}, Z=4, D c=1.326 \mathrm{gcm}^{i 3}, \mu\left(M o-K_{\alpha}\right)=0.591 \mathrm{~mm}^{i ̈ 1}, 2 \theta_{\max }=50.0^{\circ}, \mathrm{F}(000)$ $=1152,12686$ reflections collected, 2400 unique, 1790 observed $(\mathrm{I}>2 \sigma(\mathrm{I}))$ reflections, 173 refined parameters, $\mathrm{R}$ value 0.0412 , $\mathrm{wR} 2=0.1011$ (all data $\mathrm{R}=0.0598$, $w R 2=0.1111), S=1.034$. Data for $1 \mathbf{b}: \mathrm{C}_{26} \mathrm{H}_{30} \mathrm{FeN}_{4} \mathrm{O}_{4} \mathrm{M}=518.39$, crystal dimensions $0.71 \times 0.12 \times 0.11 \mathrm{~mm}$, Triclinic, space group $\mathrm{P}-1, \mathrm{a}=8.403(3), \mathrm{b}=9.705(4), \mathrm{c}=$ 16.496(6) $\AA, \alpha=98.201(7), \beta=92.759(7), \gamma=111.989(7)^{\circ}, \mathrm{V}=1227.1(8) \AA^{3}, \mathrm{Z}=2$, Dc $=1.403 \mathrm{gcm}^{i 3}, \mu\left(\mathrm{Mo}-\mathrm{K}_{\alpha}\right)=0.655 \mathrm{~mm}^{i 1}, 2 \theta_{\max }=50.0^{\circ}, \mathrm{F}(000)=544,14903$ reflections collected, 4308 unique, 2971 observed (I > $2 \sigma(\mathrm{I})$ ) reflections, 324 refined parameters, $R$ value $0.0486, w R 2=0.0958$ (all data $R=0.0844, w R 2=0.1070), S=1.003$. Data for $1 \mathrm{c}$ : $\mathrm{C}_{26} \mathrm{H}_{28} \mathrm{Br}_{2} \mathrm{FeN}_{4} \mathrm{O}_{4} M=676.19$, crystal dimensions 0.61 × 0.13 × $0.08 \mathrm{~mm}$, Orthorhombic, space group Pccn, $a=14.408(4), b=14.455(4), c=13.137(4) \AA, V=2736.1(14) \AA^{3}, Z=$ 4, $D c=1.642 \mathrm{gcm}^{i 3}, \mu\left(\mathrm{Mo}-\mathrm{K}_{\alpha}\right)=3.511 \mathrm{~mm}^{і 1}, 2 \theta_{\max }=50.0^{\circ}, F(000)=1360,12682$ reflections collected, 2406 unique, 1747 observed $(I>2 \sigma(I))$ reflections, 224 refined parameters, $R$ value $0.0420, w R 2=0.0964$ (all data $R=0.0642, w R 2=0.1056$ ), $\mathrm{S}=$ 1.017. Data for 1d: $\mathrm{C}_{27} \mathrm{H}_{32} \mathrm{FeN}_{4} \mathrm{O}_{4} \mathrm{M}=531.41$, crystal dimensions $0.89 \times 0.45 \times 0.05$ mm, Orthorhombic, space group Pccn, $a=13.675(3), b=14.687(3), c=13.361(3) \AA, V=$ 2683.6(9) $\AA^{3}, Z=4, D c=1.315 \mathrm{gcm}^{i 3}, \mu\left(\mathrm{Mo}-\mathrm{K}_{\alpha}\right)=3.511 \mathrm{~mm}^{i 1}, 2 \theta_{\max }=50.0^{\circ}, \mathrm{F}(000)=$

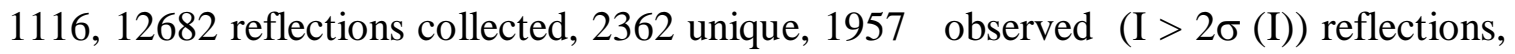


225 refined parameters, $\mathrm{R}$ value $0.0472, \mathrm{wR} 2=0.1068$ (all data $\mathrm{R}=0.0603, \mathrm{wR} 2=$ 0.1122), $\mathrm{S}=1.199$. Data for $2 \mathrm{a}: \mathrm{C}_{19} \mathrm{H}_{22} \mathrm{FeN}_{2} \mathrm{O}_{2} \mathrm{M}=366.24$, crystal dimensions $0.32 \mathrm{x}$ $0.23 \times 0.05 \mathrm{~mm}$, Triclinic, space group P $-1, \mathrm{a}=7.588(3), \mathrm{b}=9.813(5), \mathrm{c}=12.300(6) \AA$, $\alpha=67.192(7), \beta=89.527(8), \gamma=86.364(8)^{\circ}, V=842.4(7) \AA^{3}, Z=2, D c=1.444 \mathrm{gcm}^{i 3}$, $\mu\left(\right.$ Mo- $\left.\mathrm{K}_{\alpha}\right)=0.908 \mathrm{~mm}^{i 1}, 2 \theta_{\max }=50.0^{\circ}, \mathrm{F}(000)=384,8042$ reflections collected, 2937 unique, 2667 observed (I > $2 \sigma(\mathrm{I})$ ) reflections, 294 refined parameters, $\mathrm{R}$ value 0.0363, $\mathrm{wR} 2=0.0877$ (all data $\mathrm{R}=0.0414$, $w \mathrm{R} 2=0.0903$ ), $\mathrm{S}=1.087$. Data for $\mathbf{2 b}$ : $\mathrm{C}_{18} \mathrm{H}_{20} \mathrm{FeN}_{2} \mathrm{O}_{2} \mathrm{M}=352.21$, crystal dimensions $0.32 \times 0.11 \times 0.04 \mathrm{~mm}$, Triclinic, space group P -1, a = 7.376(2), b = 9.785(3), c = 11.757(3) $\AA$, $\alpha=108.301(5), \beta=94.061(6), \gamma$ $=91.481(6)^{\circ}, \mathrm{V}=802.6(4) \AA^{3}, \mathrm{Z}=2, \mathrm{Dc}=1.457 \mathrm{gcm}^{i 3}, \mu\left(\mathrm{Mo}-\mathrm{K}_{\alpha}\right)=0.950 \mathrm{~mm}^{\mathrm{i} 1}, 2 \theta_{\max }$ $=50.0^{\circ}, \mathrm{F}(000)=368,7510$ reflections collected, 2799 unique, 2226 observed $(\mathrm{I}>2 \sigma$ (I)) reflections, 208 refined parameters, $\mathrm{R}$ value $0.0587, \mathrm{wR} 2=0.1163$ (all data $\mathrm{R}=$ 0.0786, $\mathrm{wR} 2=0.1256), \mathrm{S}=1.124 . \mathrm{X}$-ray intensities were measured on a Bruker SMART APEX CCD diffractometer, graphite-monochromatized (Mo $\mathrm{K}_{\alpha}=0.71073 \AA$ ) radiation at room temperature. Intensities were corrected for Lorentzian, polarisation and absorption effects using Brukerô SAINT and SADABS programs. SHELX-97 (G. M. Sheldrick, SHELX-97, University of Göttingen, Germany, 1997) were used for structure solution and full matrix least squares refinement on $\mathrm{F}^{2} . \mathrm{H}$ atoms were included as per the riding model, except for those on nitrogen atoms for $\mathbf{1 a}$ and $\mathbf{1 b}$ whereas for $\mathbf{1 c}$ and $\mathbf{1 d}$ all the hydrogen atoms were located in the difference map and refined isotropically. CCDC 285351-285353, 299075. See http://dx.doi.org/10.1039/b000000x for crystallographic data in cif or other electronic format. 

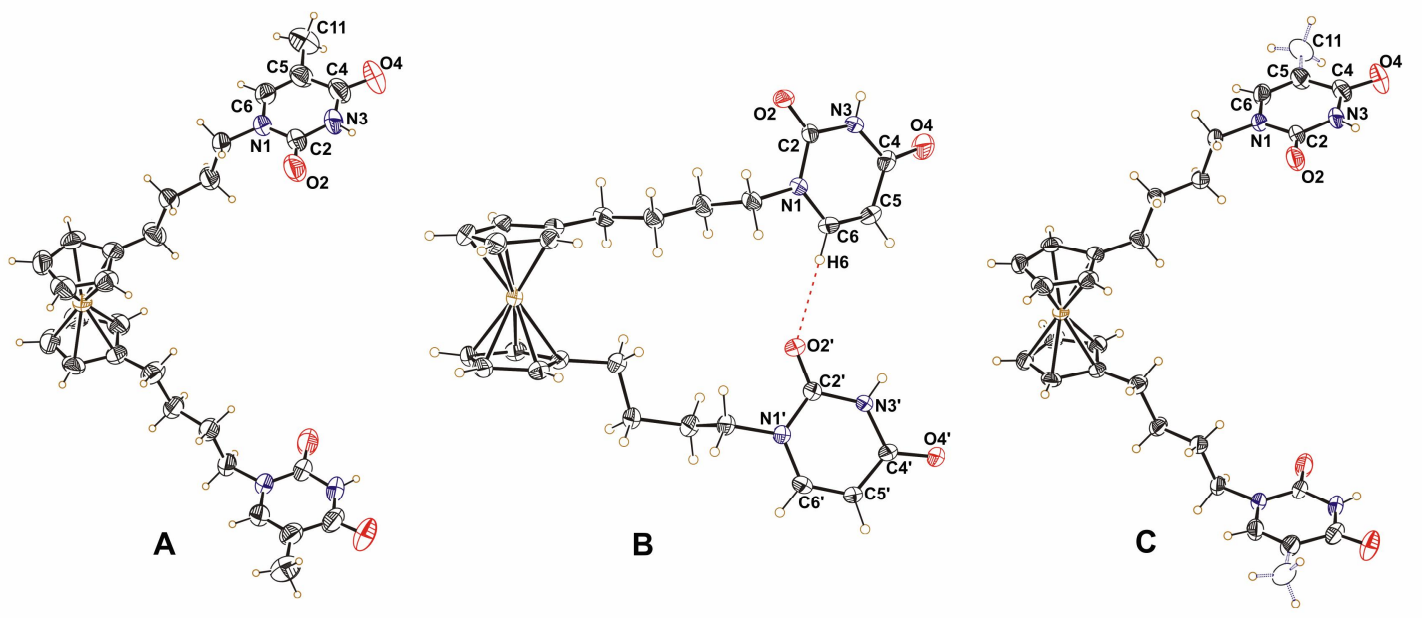

Figure 1. ORTEP views of $1 \mathbf{a}(\mathbf{A}), \mathbf{1 b}(\mathbf{B})$ and $\mathbf{1 d}(\mathbf{C})$. Molecules of 1a (A) and 1d (C) occupy crystallographic 2-fold axis passing through Fe atom. Molecule of 1d acquires 2-fold symmetry by statistical disorder, methyl C11 shown as open boundary ellipsoid has only half occupancy. Molecule of 1b (B) lacking this 2-fold symmetry adapts a different conformation making an intramolecular C6-H6...O2ôcontact. 


\section{Refinement of $1 \mathrm{~d}$}

Unit cell parameters of $\mathbf{1 d}$ were almost identical to that of $\mathbf{1 a}$, suggesting the isostructurality between them; although unit cell volume of 1d was lesser than that of $\mathbf{1 a}$ $\left(V=2737.1(17) \AA^{3}\right.$ for 1a and 2683.6(9) $\AA^{3}$ for 17). Structure refinement carried out with the full occupancy to methyl group carbon C11 atom showed significant increase in the thermal parameters (Uiso 0.18 for full occupancy, which was 0.05 a normally observed value for half occupancy). The chemical analysis also supported the formulation. 


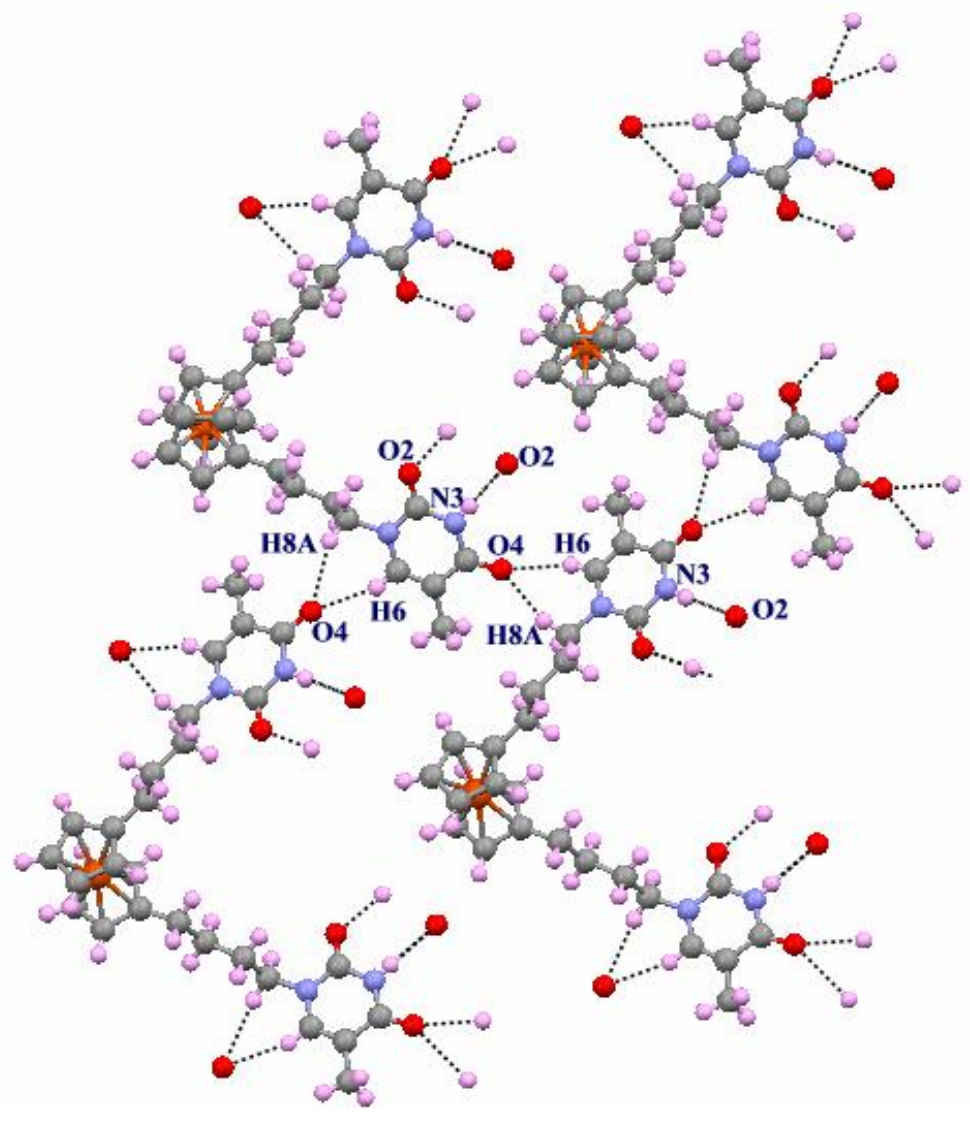

Figure 2. The various C-Hé O interactions in 1a. Other than the base pairing interactions the molecules also make bifurcated C-Hé $\mathrm{O}$ contacts between the perpendiculars sheet. (C6-H6é O4 and C8-H8Aé O4) 


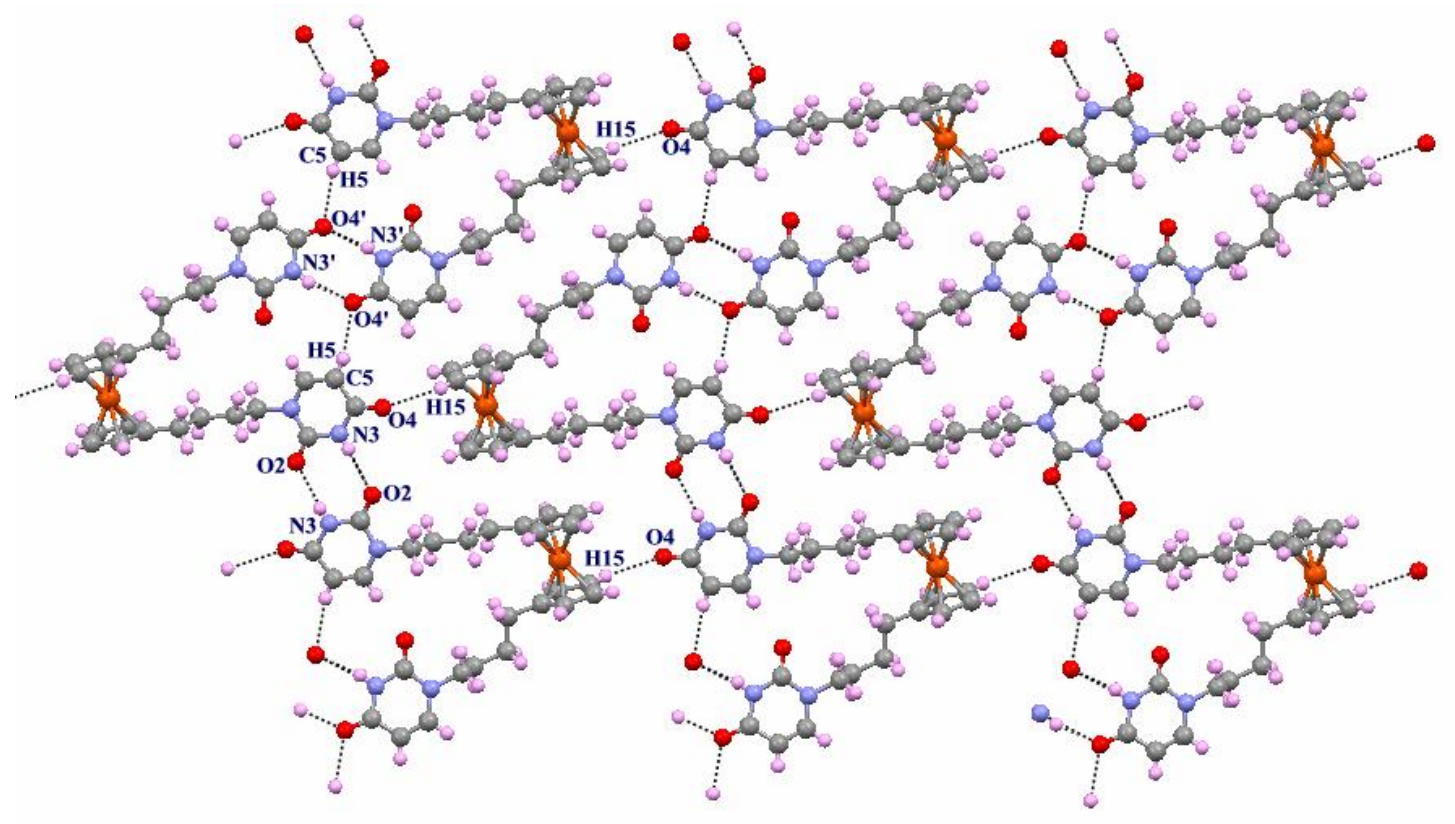

Figure 3. The various $\mathrm{C}-H e$ $\mathrm{O}$ interactions in $\mathbf{1 b}$. The adjacent helices are linked by $\mathrm{C}$-Hé $\mathrm{O}$ contact. The $\mathrm{C} 15$ carbon of the $\mathrm{Cp}$ ring donates its proton to the oxygen atom $\mathrm{O} 4$ of the uracil base. 


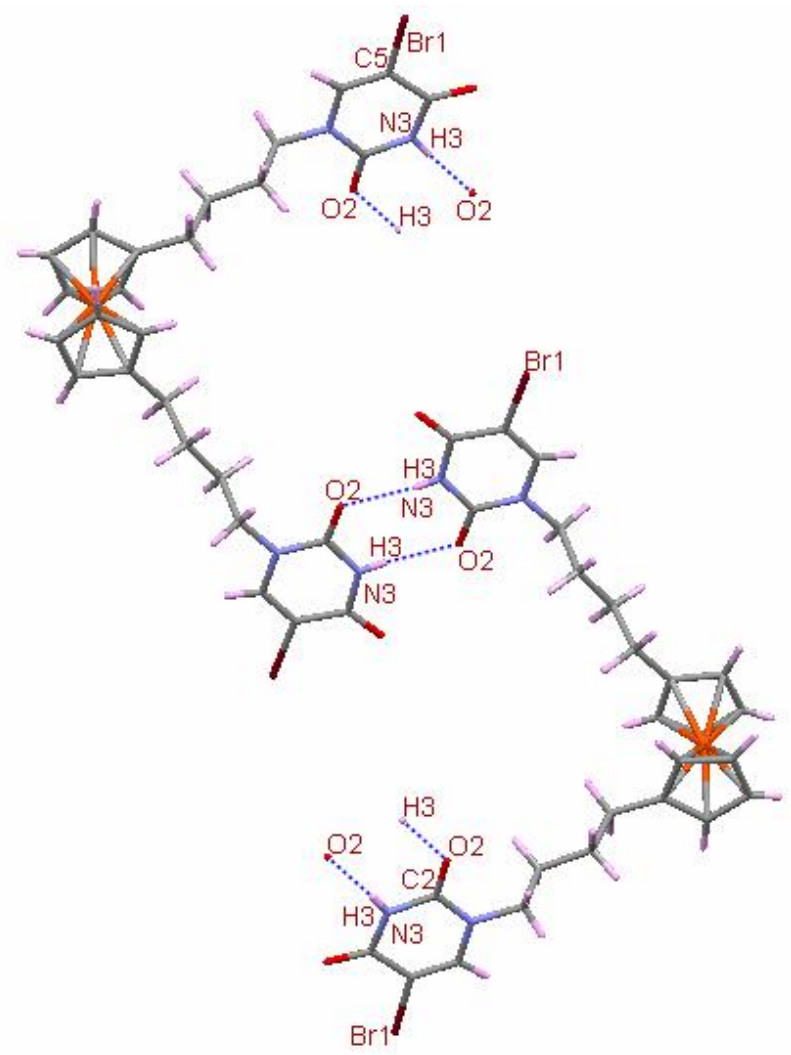

Figure 4. Self Base-Pairing in 1, 1'-Bis[4-(5-bromouracyl)butyl]ferrocene (1c) 


\section{Other Intermolecular C-H...O interactions}

\begin{tabular}{|c|c|c|c|c|c|}
\hline & D-Hé A & D-H $(\AA)$ & Hé A $(\AA)$ & Dé A $(\AA)$ & D-Hé $\mathrm{A}\left({ }^{\circ}\right)$ \\
\hline \multirow[t]{4}{*}{$1 \mathbf{a}$} & N3-H3...O2\#1 & $0.79(3)$ & $2.14(3)$ & $2.913(3)$ & $169(3)$ \\
\hline & C6-H6...O4\#2 & 0.93 & 2.38 & $3.265(4)$ & 160 \\
\hline & C8-H8A...O4\#2 & 0.97 & 2.71 & $3.464(3)$ & 135 \\
\hline & C14-H14é O2\#3 & 0.98 & 2.74 & $3.515(4)$ & 136 \\
\hline \multirow[t]{7}{*}{$1 \mathrm{~b}$} & N3-H3...O2\#4 & $0.75(3)$ & $2.17(3)$ & $2.915(4)$ & $176(3)$ \\
\hline & N3ôH3ô..O4Ĝ\#5 & $0.81(3)$ & $2.05(3)$ & $2.845(4)$ & $169(3)$ \\
\hline & C6-H6é O2ô & 0.93 & 2.29 & $3.209(4)$ & 171 \\
\hline & C5-H5...O4Ĝ\#6 & 0.93 & 2.41 & $3.265(4)$ & 152 \\
\hline & C10-H10B...O2\#7 & 0.97 & 2.72 & $3.527(4)$ & 141 \\
\hline & C15ÔH15âé O4\#7 & 0.93 & 2.56 & $3.368(4)$ & 145 \\
\hline & C16ÔH16œ̂́ O4Ĝ\#6 & 0.93 & 2.70 & $3.565(4)$ & 154 \\
\hline \multirow[t]{6}{*}{ 1c } & N3-H3...O2\#8 & $0.70(4)$ & $2.23(4)$ & $2.919(5)$ & $170(5)$ \\
\hline & C6-H6...O4\#11 & $0.93(4)$ & $2.27(4)$ & $3.189(5)$ & $168(3)$ \\
\hline & C8-H8A...O4\#11 & $0.91(4)$ & $2.72(4)$ & $3.478(5)$ & 141(3) \\
\hline & C14-H14é O2\#12 & $0.94(4)$ & $2.80(4)$ & $3.523(6)$ & 134(3) \\
\hline & C10-H10Aé Br1\#11 & $0.97(3)$ & $3.00(3)$ & $3.786(4)$ & $139(2)$ \\
\hline & C16-H16é Br1\#11 & $0.99(4)$ & $3.02(4)$ & $3.783(4)$ & $135(3)$ \\
\hline \multirow[t]{4}{*}{ 1d } & N3-H3...O2\#8 & $0.76(3)$ & $2.16(3)$ & $2.909(4)$ & $168(3)$ \\
\hline & C6-H6...O4\#9 & $0.86(3)$ & $2.45(3)$ & $3.280(4)$ & $164(2)$ \\
\hline & С8-H8А...О4\#9 & $0.95(3)$ & $2.65(3)$ & $3.367(4)$ & 132(2) \\
\hline & C14-H14é O2\#10 & $0.97(4)$ & $2.75(4)$ & $3.453(5)$ & $130(3)$ \\
\hline
\end{tabular}

Symmetry transformations used to generate equivalent atoms:
$\# 1-x+2,-y+2,-z$
$\# 2-\mathrm{x}+3 / 2, \mathrm{y}, \mathrm{z}+1 / 2$
$\# 3-\mathrm{x}+5 / 2, \mathrm{y}, \mathrm{z}+1 / 2$
\#5 -x+3,-y+3,-z+1 \#6-x+2,-y+2,-z+1 \#7-x+5/2,y,z+1/2
$\# 4-\mathrm{x}+2,-\mathrm{y}+2,-\mathrm{z}$
$\# 9-\mathrm{x}+1 / 2, \mathrm{y}, \mathrm{z}+1 / 2$
\#10 - x-1/2,y,z+1/2 \#11 -x-1/2,y,z-1/2
\#8 -x,-y+1,-z
\#12 $\mathrm{ï}+1 / 2, y, z-1 / 2$

\section{Reference}

(1) Cruickshan, A.; Jiricny, J.; Reese, C. B.; Tetrahedron Lett. 1984, 25, 681. 